\title{
ipen
}

AUTARQUIA ASSOCIADA À UNIVERSIDADE DE SÃO PAULO

\section{PROJETO, CONSTRUÇÃO E CARACTERIZAÇÃO DE SISTEMAS DE REFERÊNCIA PARA FEIXES DE ELÉTRONS DE ACELERADORES CLÍNICOS}

\author{
Fernanda Beatrice Conceição Nonato
}

Tese apresentada como parte dos requisitos para obtenção do Grau de Doutor em Ciências na Área de Tecnologia Nuclear - Aplicações

Orientadora:

Profa. Dra. Linda Viola Ehlin Caldas 
INSTITUTO DE PESQUISAS ENERGÉTICAS E NUCLEARES

Autarquia associada à Universidade de São Paulo

\title{
PROJETO, CONSTRUÇÃO E CARACTERIZAÇÃO DE SISTEMAS DE REFERÊNCIA PARA FEIXES DE ELÉTRONS DE ACELERADORES CLÍNICOS
}

\author{
Fernanda Beatrice Conceição Nonato
}

\author{
Tese apresentada como parte dos \\ requisitos para obtenção do Grau de \\ Doutor em Ciências na Área de Tecnologia \\ Nuclear - Aplicações \\ Orientadora: \\ Profa. Dra. Linda Viola Ehlin Caldas
}

\section{Versão Corrigida}

Versão Original disponível no IPEN

São Paulo

2014 


\section{AGRADECIMENTOS}

À Dra. Linda V. E. Caldas, pela orientação, por ter acreditado em meu potencial, pela dedicação e carinho que prestou a mim e a este trabalho durante todo o meu projeto de doutorado. Muito obrigada.

Meus agradecimentos se estendem:

Ao Dr. Vitor Vivolo, pelo incentivo, prestatividade, comentários e informações que acrescentaram no enriquecimento deste trabalho, e pelas contribuições no Seminário de Área e no Exame de Qualificação.

À Dra. Maria da Penha Albuquerque Potiens, pelo auxílio com os equipamentos do Laboratório de Calibração de Instrumentos do IPEN.

À Dra. Carmem Cecília Bueno, por ter contribuído com valiosas informações em meu Exame de Qualificação e no Seminário de Área.

Aos Srs. Marcos Xavier e Claudinei T. Cescon, pelo auxílio na parte eletrônica da confecção das câmaras de ionização e discussão de ideias.

Ao MSc. Gelson P. dos Santos, por ter me ajudado na compreensão da utilização do irradiador de ${ }^{60} \mathrm{Co}$ e com os padrões de referência do IPEN.

Aos técnicos da Oficina Mecânica do IPEN, em especial ao Sr. José Rodrigues dos Santos, pela confecção das peças constituintes da câmara de ionização à prova d'água.

Ao IPEN, pela infraestrutura oferecida para a realização deste trabalho.

Ao Conselho Nacional de Desenvolvimento Científico e Tecnológico (CNPq) e à Comissão Nacional de Energia Nuclear (CNEN), pelo apoio financeiro.

Aos físicos Roberto Sakuraba e José Carlos Cruz, do Hospital Albert Einstein; Gisela Menegussi, Ângela Habitzreuter, Mary Ângela Teixeira Wiltgen, Ana Cláudia Chiara e Silmara Luci Vernucio, do Instituto do Câncer do Estado de São Paulo; e Camila Sales, do Instituto de Radiologia - Hospital das Clínicas da FMUSP, muito obrigada pela disponibilidade do tempo de Vocês, pela dedicação em me auxiliar no que fosse possível para a realização dos testes das câmaras de ionização nos aceleradores lineares. Sem vocês este trabalho não teria sido possível.

Aos amigos Donata C. O. Zanin, Jonas Oliveira da Silva, Maíra T. Yoshizumi, Cristiane Honda, Daniela P. Groppo, Eduardo Corrêa, Elaine Wirney Martins, Maria Inês Teixeira, Felipe B. Cintra, Nathalia Almeida Costa e Christiane Cavinato, pelos almoços, encontros de aniversários e outros momentos de descontração que fizeram a minha vida mais colorida. 
Aos amigos Patrícia de Lara Antônio, Eric Alexandre Brito, Ana Paula Perini, Lucio Pereira Neves, Tallyson S. Alvarenga, Gustavo B. Villa, Lilian Kuahara e Amanda Bravin, pelos bons momentos de convívio e aprendizado.

Aos amigos queridos, Adélia Kakoi Yuka, Karen Namie Sakata e Raquel Aline Pessoa, pela amizade sincera, pelo apoio e torcida.

Aos amigos da Federação Espírita do Estado de São Paulo, do grupo União Espírita Caminheiros do Bem, qual eu considero parte da minha família, obrigada pelo carinho e pela amizade.

Aos meus pais Darlita Nonato da Conceição e Celso Alves Lemes, pelo amor e paciência em todos os momentos da minha vida. Meu agradecimento se estende a toda família Nonato e a minha tia Olga Di Bella.

Ao meu esposo Roberto Silveira Beneti, a quem tenho muito amor e admiração, obrigada por estar sempre ao meu lado, e à minha sogra Vera Lucia Guimarães Silveira Beneti, por ter me acolhido e por sempre me ouvir.

À Deus, pela oportunidade da vida! 


\section{EPÍGRAFE}

"Embora ninguém possa voltar atrás e fazer um novo começo, qualquer um pode começar agora e fazer um novo fim.” Francisco Cândido Xavier. 


\title{
Projeto, Construção e Caracterização de Sistemas de Referência para Feixes de Elétrons de Aceleradores Clínicos
}

\author{
Fernanda Beatrice Conceição Nonato
}

\begin{abstract}
RESUMO
Os aceleradores lineares vêm substituindo gradativamente os irradiadores de fontes gama nos Serviços de Radioterapia no Brasil. Consequentemente, existe a necessidade de aquisição de câmaras de ionização para uso em dosimetria dos feixes de radiação X e de elétrons dos aceleradores lineares. Entretanto, as câmaras de ionização comerciais para radioterapia apresentam alto custo e todas são importadas. Este trabalho teve como objetivo principal projetar, construir e caracterizar câmaras de ionização de placas paralelas em dosimetria de feixes de elétrons de aceleradores clínicos. Foram desenvolvidas cinco câmaras de ionização utilizando-se acrílico como material principal e tintas de grafite e de prata para a confecção dos eletrodos coletores. Uma das câmaras de ionização é a prova d'água. Todas as câmaras de ionização foram submetidas a feixes de radiação no Laboratório de Calibração de Instrumentos do IPEN e em três Serviços de Radioterapia na cidade de São Paulo onde foram realizados testes, como: tempo de estabilização, repetibilidade da resposta, estabilidade a médio prazo, corrente de fuga, corrente de saturação, eficiência de coleção de íons, linearidade de resposta, variação da resposta com a distância fonte-detector, efeito de polaridade, efeito cabo, simetria das câmaras de ionização, dependência angular. Além disso, as cinco câmaras de ionização foram calibradas em feixes padronizados de radiação gama, para aplicação em aceleradores clínicos de radioterapia. Os resultados foram satisfatórios para todos os testes realizados, mesmo para o efeito de polaridade no qual o resultado não foi menor que 1\%; está de acordo com as câmaras comerciais reportadas na literatura. Assim, as câmaras de ionização desenvolvidas neste trabalho representam a possibilidade de uso em dosimetria de feixes de elétrons de aceleradores lineares em Serviços de Radioterapia.
\end{abstract}




\title{
Design, Construction and Characterization of Reference Systems for Electron Beams of Clinical Accelerators
}

\author{
Fernanda Beatrice Conceição Nonato
}

\begin{abstract}
Linear accelerators are gradually replacing the gamma radiation sources in the Brazilian Radiotherapy Services. Consequently, there is a need for the acquisition of ionization chambers for dosimetry of X-ray and electron beams of linear accelerators. However, the commercial radiotherapy ionization chambers are expensive and they all are imported. The objectives of this work were to design, build and characterize parallel plates ionization chambers to be used in electron beam dosimetry of clinical accelerators. Five ionization chambers were developed using acrylic as main material, and their collecting electrodes were made using graphite and silver paint. One of the ionization chambers is waterproof. All the ionization chambers were tested in the radiation beams of the Calibration Laboratory of Instruments of IPEN, and they were also tested in three Radiotherapy Services of the São Paulo city. The testes performed were: stabilization time, short-term and mediu-term stability tests, leakage current, saturation curve, ion collection efficiency, linearity curve, response in relation to the distance variation, polarity effect, cable effect, symmetry test and angular dependence test. Furthermore, the ionization chambers were calibrated in gamma radiation standard beams, for application in the radiotherapy clinical accelerators. The results of the ionization chambers were satisfactory for all the tests applied, even for the polarity effect test where the response was higher than 1\%; this result agrees with the results of commercial ionization chambers reported in literature. The developed ionization chambers in this work show the possibility of their application in dosimetry of electron beams of linear accelerators of Radiotherapy Services.
\end{abstract}




\section{SUMÁRIO}

1. Introdução ...................................................................................................................................19

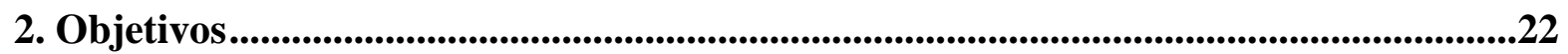

3. Revisão da Literatura.............................................................................................................23

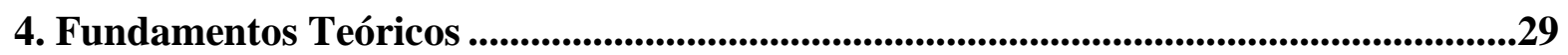

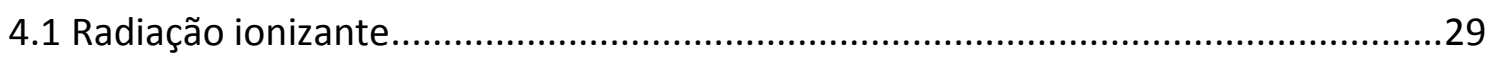

4.1.1 Tipos de radiação ionizante..................................................................29

4.1.2 Formas de decaimento beta ..................................................................30

4.2 Descrição do campo da radiação ionizante..............................................................30

4.3 Grandezas de interação para partículas carregadas ...................................................32

4.3.1 Tipos de colisões...................................................................................33

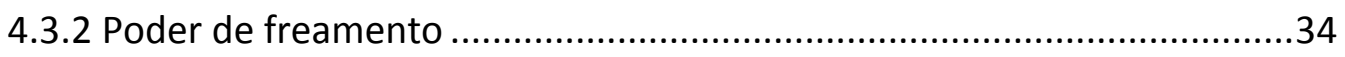

4.3.3 Alcance de partículas carregadas .........................................................35

4.3.4 Transferência linear de energia.............................................................36

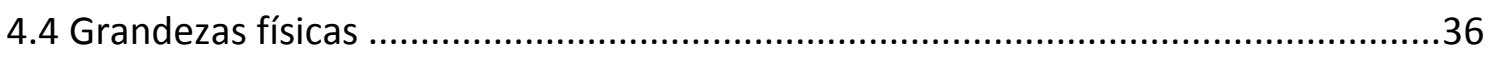

4.4.1 Equilíbrio de partículas carregadas (CPE)..............................................

4.4.2 Equilíbrio transiente de partículas carregadas (TCPE) .............................39

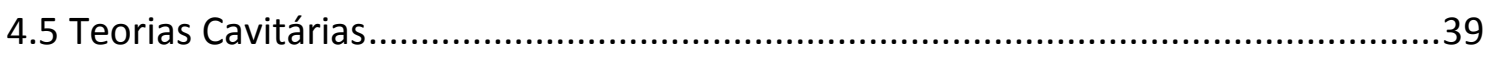

4.5.1 Teoria cavitária de Bragg-Gray ..............................................................39

4.5.2 Teoria cavitária de Spencer-Attix ............................................................41

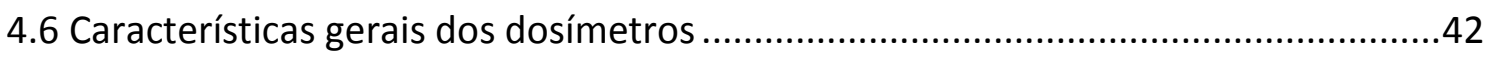

4.6.1 Caráter absoluto ..................................................................................42

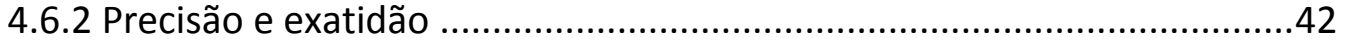

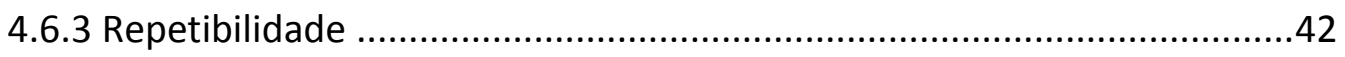

4.6.4 Reprodutibilidade ............................................................................43

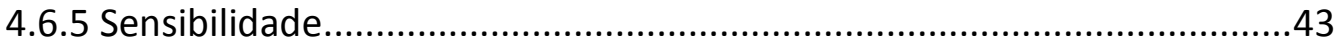

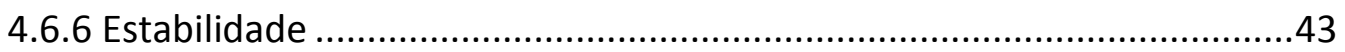

4.6.7 Dependência energética ......................................................................43

4.6.8 Dependência direcional......................................................................44

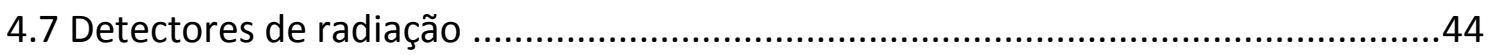

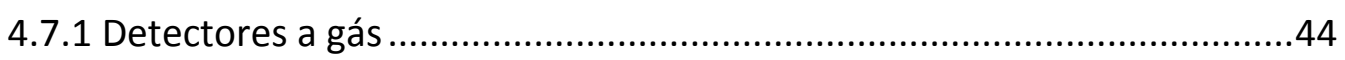




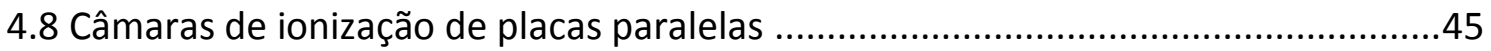

4.9 Distribuição da dose absorvida em profundidade .................................................45

4.10 Calibração de uma câmara de ionização ...............................................................46

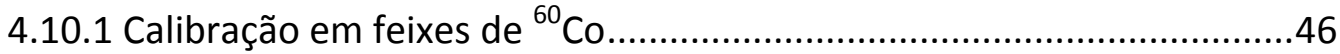

4.10.2 Determinação da dose absorvida na água em feixe de radiação de

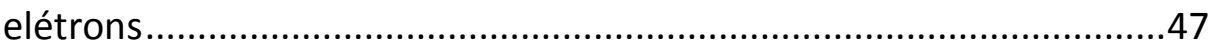

4.10.3 Determinação do fator de correção das qualidades dos feixes $K_{Q, Q_{0}} \ldots 48$

4.11 Objeto simulador

5 Materiais e Métodos .50

5.1 Sistemas de radiação do Laboratório de Calibração de Instrumentos do IPEN .........50

5.2 Sistema de radiação do Departamento de Radioterapia do Hospital Albert Einstein / Sociedade Beneficente Israelita Brasileira

5.3 Sistema de radiação do Departamento de Radioterapia do Instituto do Câncer do Estado de São Paulo (ICESP)

5.4 Sistema de radiação do Departamento de Radioterapia do Instituto de Radiologia do Hospital das Clínicas da Faculdade de Medicina da Universidade de São Paulo - InRad - HCFMUSP.

5.5 Valores do fator de correção, $K_{Q, Q_{0}}$, dos feixes de radiação de elétrons dos aceleradores clínicos utilizados

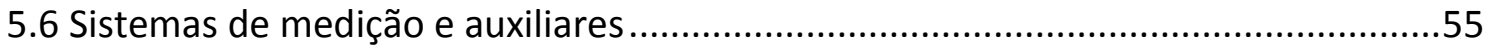

6 Resultados: Desenvolvimento das Câmaras de Ionização

6.1. Materiais utilizados na confecção do eletrodo coletor e do anel de guarda das câmaras de ionização

6.2 Câmara de ionização com eletrodo coletor de grafite: C1 .......................................66

6.3 Câmara de ionização com eletrodo coletor de prata: C2 .....................................66

6.4 Câmara de ionização com eletrodo coletor de grafite: C3 .....................................67

6.5 Câmara de ionização com eletrodo coletor de grafite: C4 ...................................68

6.6 Câmara de ionização à prova d'água, com eletrodo coletor de grafite: C5 ..............69

7 Resultados: Caracterização das Câmaras de Ionização C1 a C5....................................72

7.1 Caracterização das câmaras de ionização C1 a C4 .................................................72

7.1.1 Testes de caracterização realizados no Laboratório de Calibração de Instrumentos do IPEN...................................................................72

7.1.1.1 Tempo de estabilização .................................................................. 72

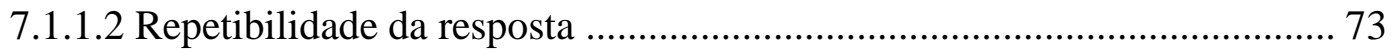




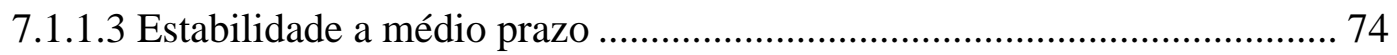

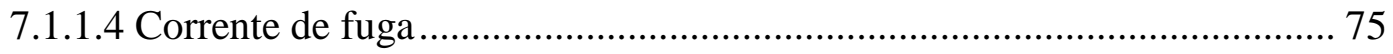

7.1.1.5 Corrente de saturação e eficiência de coleção de íons ............................. 76

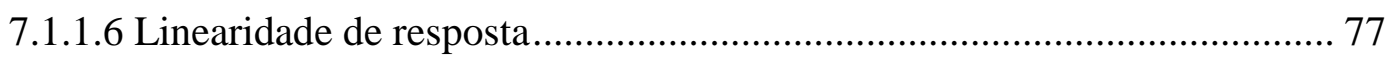

7.1.1.7 Variação da resposta com a distância fonte-detector ............................... 78

7.1.1.8 Calibração das câmaras de ionização em feixes de ${ }^{60} \mathrm{Co}$......................... 80

7.1.2 Testes de caracterização realizados em Serviços de Radioterapia de São Paulo, utilizando feixes de elétrons..............................................81

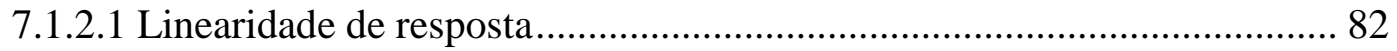

7.1.2.2 Efeito de polaridade em relação ao alcance prático ................................. 83

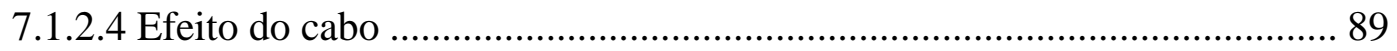

7.1.2.5 Simetria da resposta das câmaras de ionização...................................... 91

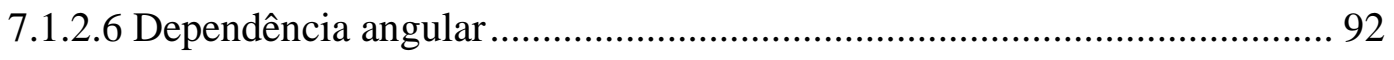

7.2 Caracterização da câmara de ionização C5 ……....................................................95

7.2.1 Testes de caracterização realizados no Laboratório de Calibração do

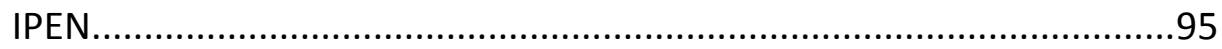

7.2.1.1 Tempo de estabilização ........................................................................... 96

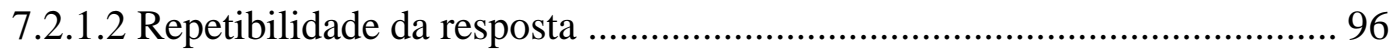

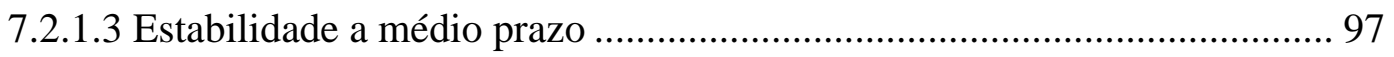

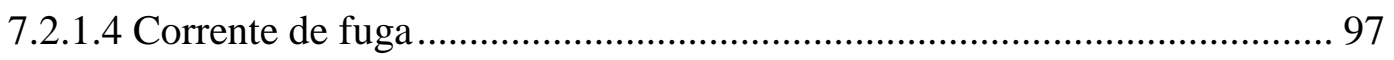

7.2.1.5 Corrente de saturação e eficiência de coleção de íons ............................. 98

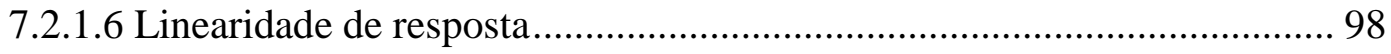

7.2.1.7 Calibração da câmara de ionização em feixe de ${ }^{60} \mathrm{Co}$.............................. 99

7.2.2 Testes de caracterização realizados em Serviços de Radioterapia de São Paulo, utilizando feixes de elétrons...............................................99

7.2.2.1 Linearidade de resposta...................................................................... 101

7.2.2.2 Efeito de polaridade em relação ao alcance prático ............................... 102

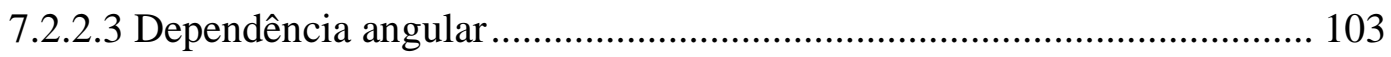

7.2.2.4 Calibração da câmara de ionização C5 em feixes de elétrons do InRad. 104

7.2.2.5 Curva de ionização da câmara de ionização C5 .................................... 105

7.3 Caraterísticas comparativas entre as câmaras de ionização desenvolvidas ............108

Conclusões ................................................................................................................113

Referências Bibliográficas ..................................................................................115

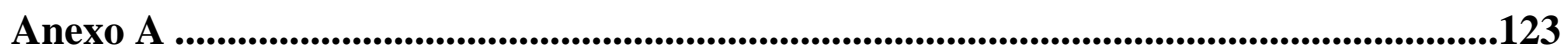


Trabalhos publicados no período do desenvolvimento da tese .123

Artigos completos publicados em periódicos …...........................................123

Trabalho completo submetido a publicação em periódico ............................123

Trabalhos completos publicados em anais de congressos ..........................124

Trabalhos publicados em livros de resumos de congressos .........................124 


\section{Lista de Tabelas}

Tabela 5.1 Valores de $K_{Q, Q_{0}}$ dos feixes de radiação de elétrons dos aceleradores clínicos apresentados neste trabalho

Tabela 7.1 Tempo de estabilização das câmaras de ionização em feixes de radiação gama. Incerteza máxima dos dados: menor que $0,37 \%$.

Tabela 7.2 Estudo da repetibilidade da resposta das câmaras de ionização

Tabela 7.3 Eficiência de coleção de íons (ks) entre $150 \mathrm{~V}$ e $300 \mathrm{~V}$. Todos os resultados apresentam incertezas menores que $0,02 \%$

Tabela 7.4 Coeficientes de calibração das câmaras de ionização

Tabela 7.5 Fator cabo das câmaras de ionização.

Tabela 7.6 Dependência angular da resposta das câmaras de ionização C1, C2, C3

e C4 em feixes de elétrons com energias de $6 \mathrm{MeV}$ e $9 \mathrm{MeV}$ (ICESP)

Tabela 7.7 Comparação entre os parâmetros obtidos pela curva de ionização da câmara de ionização C5 e os parâmetros fornecidos pelo InRad 107

Tabela 7.8 Características das câmaras de ionização desenvolvidas. 110

Tabela 7.9 Resultados comparativos das câmaras de ionização C1, C2, C3 e C4 110

Tabela 7.10 Resultados comparativos da câmara de ionização C5 .

Tabela 7.11 Estimativa do custo da confecção das câmaras de ionização e demais acessórios 


\section{Lista de Figuras}

Figura 4.1 Representação esquemática do campo de radiação ionizante em uma esfera com um círculo de área centralizado em P (ATTIX, 2004)

Figura 4.2 Representação esquemática da fluência de elétrons $\Phi e$ nas interfaces: da cavidade do dosímetro, onde se encontra a dose na cavidade, Dcav; e do meio, onde está apresentada a dose no meio, Dm (TURNER, 2007)

Figura 4.3 Sensibilidade de resposta de um dosímetro representado pela tangente do ângulo $\theta$ (ATTIX, 2004)

Figura 4.4 Curva típica da distribuição terapêutica da dose absorvida em profundidade.

$\mathrm{R}_{100}$ : profundidade de dose máxima;

$\mathrm{R}_{85}$ : profundidade terapêutica, ou seja, profundidade que deve abranger o volume alvo;

$\mathrm{R}_{50}$ : profundidade que corresponde à metade da dose máxima;

$\mathrm{R}_{\mathrm{p}}$ : profundidade de intersecção da tangente através do ponto de maior inclinação (ponto de inflexão) da curva. Esta profundidade é chamada de alcance prático, e é importante do ponto de vista clínico, pois determina o máximo alcance dos elétrons.

Figura 5.1 Sistema de radiação beta: 1-Blindagem das fontes, 2-Sistema do irradiador, 3-Sistema de acionamento das fontes

Figura 5.2 Sistema de radiação gama e posicionamento da câmara de ionização no centro do feixe de radiação, no Laboratório de Calibração de Instrumentos do IPEN.

Figura 5.3 Fonte de controle de ${ }^{90} \mathrm{Sr}+{ }^{90} \mathrm{Y}$ e suporte de acrílico para posicionar a fonte de controle na câmara de ionização, no Laboratório de Calibração de Instrumentos do IPEN

Figura 5.4 Acelerador linear Varian 2100 (LINAC) e sistema de acionamento do feixe de radiação, do Hospital Albert Einstein

Figura 5.5 Acelerador linear Elekta Synergy e sistema de acionamento do feixe de radiação, do ICESP 
Figura 5.6 Acelerador linear 2100 (LINAC) e sistema de acionamento do feixe de radiação, do InRad

Figura 5.7 Eletrômetros utilizados do LCI/IPEN e ICESP (a), do InRad (b) e do Hospital Albert Einstein (c)

Figura 5.8 Materiais em acrílico para auxílio nas medições com a câmara de ionização. 56

Figura 5.9 Suporte de acrílico, câmara de ionização e goniômetro do LCI

Figura 5.10 Objetos simuladores de água sólida, pertencentes ao Hospital Albert Einstein e ao ICESP

Figura 5.11 Objetos simuladores pertencentes ao LCI, com dimensões de $30 \mathrm{~cm}$ x $30 \mathrm{~cm}$; ao ICESP, com posicionador automático, e ao InRad com posicionador manual, ambos com dimensões de $35 \mathrm{~cm} \times 39 \mathrm{~cm}$

Figura 6.1 Esquema de uma câmara de ionização de placas paralelas para uso em feixes de elétrons. Distância entre a janela de entrada e o eletrodo coletor (a); diâmetro do eletrodo coletor (b); largura do anel de guarda (c)

Figura 6.2 Esquema das cinco câmaras de ionização desenvolvidas no IPEN.

Distância entre a janela de entrada e o eletrodo coletor (a); diâmetro do eletrodo coletor (b); largura do anel de guarda (c)

Figura 6.3 Corte transversal detalhado das câmaras de ionização C1, C2, C3 e C4; conjunto de peças de acrílico, enumeradas de 1 a 11

Figura 6.4 Corte transversal detalhado da câmara de ionização C5; conjunto das peças de acrílico, enumeradas de 1 a 11

Figura 6.5 Detalhes das peças 1, 2 e 4 das câmaras de ionização C1 e C2 ....................62

Figura 6.6 Detalhes das peças 1, 2 e 4 das câmaras de ionização C3 e C4

Figura 6.7 Detalhes das peças 3, 5, 6, 7, 8, 9, 10 e 11 das câmaras de ionização $\mathrm{C} 1, \mathrm{C} 2, \mathrm{C} 3$ e $\mathrm{C} 4$

Figura 6.8 Detalhes das 11 peças da câmara de ionização C5

Figura 6.9 Materiais utilizados na confecção do eletrodo coletor e do anel de guarda das câmaras de ionização desenvolvidas

Figura 6.10 Desenvolvimento de uma das câmaras de ionização .65

Figura 6.11 Esquema detalhado da câmara de ionização C1, à esquerda; e o anel de guarda e o eletrodo coletor pintados superficialmente com uma 
mistura de esmalte de unha incolor e grafite em pó, à direita da figura

Figura 6.12 Esquema detalhado da câmara de ionização C2, à esquerda; e o anel de guarda e o eletrodo coletor pintados superficialmente com uma tinta de prata, à direita da figura

Figura 6.13 Esquema detalhado da câmara de ionização C3, à esquerda; e o anel de guarda e o eletrodo coletor pintados superficialmente com uma mistura de esmalte de unha incolor e grafite em pó, à direita da figura

Figura 6.14 Esquema detalhado da câmara de ionização C4, à esquerda; e o anel de guarda e o eletrodo coletor pintados superficialmente com spray de grafite, à direita da figura

Figura 6.15 Primeira tentativa de construção de uma câmara de ionização à prova d'água

Figura 6.16 Esquema detalhado da câmara de ionização C5, à esquerda; e o anel de guarda e o eletrodo coletor pintados superficialmente com uma mistura de esmalte de unha incolor e grafite em pó, à direita da figura

Figura 6.17 Câmara de ionização C1; as câmaras de ionização C2, C3 e C4 são similares externamente

Figura 6.18 Câmara de ionização C5

Figura 7.1 Estabilidade a médio prazo das câmaras de ionização C1, C2, C3 e C4. As incertezas foram menores que $0,03 \%$, não sendo visíveis nos gráficos. As linhas tracejadas representam os limites recomendados pela norma IEC 60731 (2011) (LCI/IPEN)

Figura 7.2 Curvas de saturação das câmaras de ionização C1, C2, C3, C4. As incertezas foram menores que $0,03 \%$, não sendo visíveis nos gráficos (LCI/IPEN)

Figura 7.3 Curvas de linearidade da resposta das câmaras de ionização C1, C2, C3 e C4. As incertezas foram menores que $0,17 \%$, não sendo visíveis nos gráficos (LCI/IPEN)

Figura 7.4 Resposta das câmaras de ionização C1, C2, C3 e C4 em relação à variação da distância fonte-detector, sendo os dados experimentais representados pela legenda Medido e os dados das curvas esperadas 
pela lei do inverso do quadrado da distância representados pela legenda Esperado. A incerteza máxima das partes experimentais foi de $0,31 \%$, não visível no gráfico (LCI/IPEN)

Figura 7.5 Calibração da câmara de ionização $\mathrm{C} 4$ em relação à câmara de ionização Farmer (PTW) em feixes de ${ }^{60} \mathrm{Co}$ do irradiador Gammatron II S 80 (LCI/IPEN)

Figura 7.6 Linearidade de resposta das câmaras de ionização C1, C2, C3 e C4 em feixes de elétrons com energia de $6 \mathrm{MeV}$. As incertezas foram menores que $0,21 \%$, não sendo visíveis nos gráficos (ICESP)

Figura 7.7 Linearidade de resposta das câmaras de ionização C1, C2, C3 e C4 em feixes de elétrons com energia de $9 \mathrm{MeV}$. As incertezas foram menores que $0,22 \%$, não sendo visíveis nos gráficos (ICESP)

Figura 7.8 Materiais utilizados para determinação do efeito de polaridade da resposta das câmaras de ionização (Hospital Albert Einstein)

Figura 7.9 Efeito de polaridade das câmaras de ionização C1, C2, C3 e C4 em feixes de elétrons com energias de $6 \mathrm{MeV}$ e $12 \mathrm{MeV}$. As incertezas foram menores que 0,30\%, não sendo visíveis nos gráficos (Hospital Albert Einstein)

Figura 7.10 Materiais utilizados para o estudo do efeito do retroespalhamento da resposta das câmaras de ionização (ICESP)

Figura 7.11 Efeito de polaridade da câmara de ionização $\mathrm{C} 1$ em feixes de elétrons com energias de $6 \mathrm{MeV}$ e $9 \mathrm{MeV}$, utilizando espessura de água sólida de $1 \mathrm{~cm}$ (a) e de $5 \mathrm{~cm}$ (b) embaixo do suporte de acrílico da câmara de ionização; o terceiro gráfico apresenta os resultados para as duas espessuras com as duas energias (c). As incertezas foram menores que $0,34 \%$, não sendo visíveis nos gráficos (ICESP).

Figura 7.12 Efeito de polaridade em relação ao tamanho do campo de radiação para as câmaras de ionização $\mathrm{C} 1$ e $\mathrm{C} 2$, para as energias de $6 \mathrm{MeV}$ e $9 \mathrm{MeV}$. As incertezas foram menores que 0,35\%, não sendo visíveis nos gráficos (ICESP)

Figura 7.13 Câmara de ionização com o cabo protegido e desprotegido da irradiação dos feixes de elétrons (ICESP).

Figura 7.14 Teste de simetria da resposta das câmaras de ionização, apresentando o gantry angulado em $\pm 30^{\circ}$ (ICESP) 
Figura 7.15 Simetria da resposta das câmaras de ionização C1, C2, C3 e C4 para feixes de elétrons com energias de $6 \mathrm{MeV}$ e $9 \mathrm{MeV}$ em função da rotação do gantry. As incertezas foram menores que $0,26 \%$, não sendo visíveis nos gráficos (ICESP)

Figura 7.16 Sistema de radiação para o estudo da dependência angular da resposta das câmaras de ionização (ICESP)

Figura 7. 17 Sistema de radiação com feixes de ${ }^{60} \mathrm{Co}$ e objeto simulador de água utilizando a câmara de ionização C5 (LCI/IPEN)

Figura 7.18 Estabilidade a médio prazo da resposta da câmara de ionização C5. As incertezas foram menores que $0,06 \%$, não sendo visíveis nos gráficos. As linhas tracejadas representam os limites recomendados pela norma IEC 60731 (2011) (LCI/IPEN)

Figura 7.19 Curva de saturação da câmara de ionização C5. As incertezas foram menores que $0,09 \%$, não sendo visíveis nos gráficos (LCI/IPEN) . .98

Figura 7.20 Curva de linearidade da resposta da câmara de ionização C5 em feixes de ${ }^{60}$ Co. A maior incerteza foi de $0,06 \%$, não sendo visível no gráfico (LCI/IPEN)

Figura 7.21 Esquema de posicionamento da câmara de ionização C5 no objeto simulador de água do ICESP

Figura 7.22 Dispositivo de posicionamento automático da câmara de ionização, que ajusta a profundidade da câmara de ionização em mm (ICESP).......100

Figura 7.23 Visualização da câmara de ionização C5 dentro do objeto simulador de água (a); verificação da câmara de ionização na posição horizontal (b); verificação da distância fonte - detector e alinhamento e centralização da câmara de ionização em relação ao feixe de radiação (c) (ICESP).

Figura 7.24 Linearidade de resposta da câmara de ionização C5 em feixes de elétrons com energias de $12 \mathrm{MeV}$ e $15 \mathrm{MeV}$. As incertezas foram menores que $0,34 \%$, não sendo visíveis nos gráficos (ICESP)

Figura 7.25 Efeito de polaridade da câmara de ionização C5 em feixes de elétrons com energia de $12 \mathrm{MeV}$. As incertezas foram menores que 0,30\%, não sendo visíveis no gráfico (ICESP).

Figura 7.26 Esquema de montagem do goniômetro para a realização do teste da dependência angular (ICESP) 
Figura 7.27 Posicionamento da câmara de ionização C5 e câmara de ionização

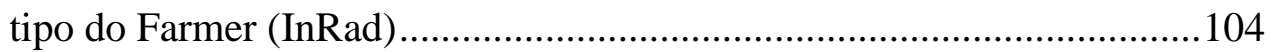

Figura 7.28 Esquema de irradiação da câmara de ionização C5 no acelerador

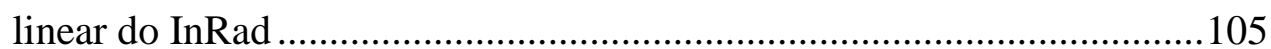

Figura 7.29 Curva de ionização da câmara de ionização C5 (InRad) ...........................106

Figura 7.30 Curva de ionização da câmara de ionização do tipo Farmer. Dados

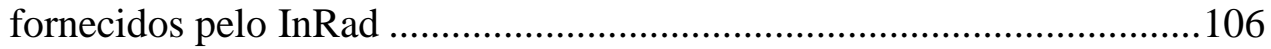




\section{Lista de Siglas}

ABNT

AAPM

DIN

LCI

IAEA

ICESP

ICRU

IEC

INCA

InRad/HCMUSP

IPEN

ISO

PMMA

PTB

PTW

NIST
Associação Brasileira de Normas Técnicas

American Association of Physicists in Medicine

Deutsches Institut für Normung

Laboratório de Calibração de Instrumentos

International Atomic Energy Agency

Instituto do Câncer do Estado de São Paulo

International Commission on Radiation Units and

Measurements

International Electrotechnical Commission

Instituto Nacional do Câncer

Instituto de Radiologia do Hospital das Clínicas da Faculdade de Medicina da Universidade de São Paulo Instituto de Pesquisas Energéticas e Nucleares International Organization for Standardization

Polimetilmetacrilato

Physikalisch-Technische Bundesanstalt

Physikalisch-Technische Werktästten

National Institute of Standards and Technology 


\section{Introdução}

A radioterapia é uma especialidade médica que utiliza a radiação ionizante para tratamento de pacientes com câncer, de forma a liberar uma quantidade de dose de radiação no tecido tumoral. Com o avanço tecnológico da radioterapia, têm sido empregados mais frequentemente os aceleradores lineares com feixes de elétrons a fim de maximizar a dose no volume tumoral com a consequente diminuição das complicações tardias. Em novembro de 2013 foram adquiridos 80 aceleradores lineares que serão distribuídos em 22 estados do Brasil, além do Distrito Federal (INCA, 2014b).

A aplicação dos feixes de elétrons de equipamentos radioterápicos com doses altas de radiação não deve provocar uma variação maior que 5\% (ICRU, 1976) na distribuição da dose absorvida no volume do tumor; são muito importantes os procedimentos dosimétricos por meio da utilização principalmente de câmaras de ionização, como por exemplo, na determinação da dose absorvida numa profundidade de referência. A calibração tanto das câmaras de ionização como dos feixes de radiação de elétrons requer a utilização de diversos fatores de conversão e de correção, devido ao curto alcance das partículas bem como da dependência energética de tais câmaras de ionização. Surgiram, então, recomendações e procedimentos especiais para a calibração de feixes de radiação e de instrumentos detectores de radiação, pelos órgãos internacionais responsáveis (IAEA, 1979; IAEA, 2006; IAEA, 2009). Em 2002, o Laboratório de Calibração de Instrumentos do IPEN (LCI) adotou as recomendações da Norma TRS 398 (IAEA, 2006), o que possibilitou que as câmaras de ionização dos hospitais fossem calibradas também em termos de dose absorvida na água (SIQUEIRA, 2006).

Segundo as recomendações internacionais, a dosimetria de feixes de radiação $\mathrm{X}$, gama e de elétrons pode ser feita utilizando-se câmaras de ionização preenchidas com ar, dosímetros de sulfato ferroso (dosímetro de Fricke) e calorímetros. Entretanto, os dois últimos métodos citados são mais sofisticados e caros, e requerem maiores cuidados na prática dosimétrica, sendo por isso menos viáveis para a rotina em Serviços de Radioterapia. As câmaras de ionização são equipamentos mais simples de utilizar, e são obtidas medições precisas da exposição e da dose absorvida. Por isso, a técnica da ionometria vem sendo a mais utilizada e recomendada pelos órgãos internacionais 
responsáveis (IAEA, 1987). Embora as câmaras cilíndricas possam também ser aplicadas, as câmaras de ionização de placas paralelas são as mais utilizadas para se determinar a dose absorvida na água em feixes de elétrons, pois o efeito de perturbação produzido por estas câmaras de ionização pode ser reduzido, além do fato delas serem ideais para a obtenção de medições em objetos simuladores, de acordo com dados experimentais (ALMOND et al., 1994; ICRU, 1984a; SVENSSON e BRAHME, 2004).

Uma câmara de ionização cilíndrica apresenta um eletrodo central e uma cavidade preenchida por um gás, geralmente ar. Entre o eletrodo central e a parede da câmara é aplicada uma diferença de potencial a fim de estabelecer um campo elétrico apropriado. As cargas, produzidas pela interação da radiação com o gás dentro da cavidade, são coletadas pelos eletrodos centrais que produzem uma corrente elétrica detectada num instrumento de medição denominado eletrômetro. A escolha do tipo de gás e de outros materiais constituintes da câmara de ionização (assim como as suas dimensões) dependerá do tipo de radiação a ser detectada (ATTIX, 2004; KNOLL,1989).

No caso das câmaras de ionização de placas paralelas, existem dois eletrodos (interno e externo) planos e paralelos separados por um pequeno volume de ar. $\mathrm{O}$ eletrodo externo é a janela de entrada da câmara de ionização e deverá estar localizado de frente para o feixe de radiação. O eletrodo interno é um disco circular condutor. A diferença de potencial é aplicada ao eletrodo externo e os íons produzidos pela interação da radiação com o gás (pode ser ar) no volume sensível da câmara de ionização são coletados pelo eletrodo interno (eletrodo coletor). Ao redor do eletrodo coletor existe um terceiro eletrodo chamado anel de guarda, que é responsável por manter uniformes as linhas de campo elétrico entre a janela de entrada e o eletrodo coletor.

Rodrigues e colaboradores (RODRIGUES et al., 2006) utilizaram o protocolo TRS 398 (IAEA, 2006) para estudarem o comportamento de câmaras de placas paralelas em feixes de radiação de elétrons com energias diferentes. Verificaram que a câmara de ionização da Physikalisch-Technische Werktästten (PTW), modelo Markus, apresentava um problema de construção, aparentemente solucionado com o lançamento de um novo modelo de câmara de ionização de placas paralelas, a câmara da PTW, modelo Advanced Markus.

Um ponto importante a se estudar nas câmaras de ionização é a dependência energética de sua resposta, que varia de acordo com sua composição, suas características de construção e com o intervalo de energia de radiação. 
No Instituto de Pesquisas Energéticas e Nucleares, já foram desenvolvidas várias câmaras de ionização de placas paralelas para detecção de radiação $\mathrm{X}$ de energias baixas e de radiação beta (ALBUQUERQUE e CALDAS, 1989; CALDAS e ALBUQUERQUE, 1992), e de radiação de elétrons (SOUZA et al., 1996); uma câmara de extrapolação para radiação $X$ e beta de aplicadores dermatológicos (DIAS e CALDAS, 2001; OLIVEIRA e CALDAS, 2006); uma câmara de ionização de placas paralelas, para feixes de tomografia computadorizada (MAIA e CALDAS, 2006); e duas câmaras de ionização de placas paralelas inseridas em objetos simuladores de corpo humano, formando um sistema Tandem (VIVOLO, 2006).

Vivolo utilizou como modelo básico, para a construção de suas câmaras de ionização, o primeiro protótipo de câmara de ionização de placas paralelas, desenvolvida como sistema padrão secundário, por Ankerhold et al (1999).

Nos últimos anos, o grupo de pesquisa do laboratório de calibração do IPEN construiu novas câmaras de ionização para serem utilizadas em feixes de radiação em radiodiagnóstico, mamografia, radioterapia e tomografia computadorizada (YOSHIZUMI e CALDAS, 2010; SILVA e CALDAS, 2012; NEVES et al., 2012; PERINI et al., 2013). 


\section{Objetivos}

Atualmente as clínicas de radioterapia seguem o protocolo e as diretrizes da publicação TRS 398 (IAEA, 2006), onde os feixes de elétrons são calibrados em termos de dose absorvida na água utilizando câmaras de ionização à prova d'água e objetos simuladores de água; entretanto alguns hospitais ainda utilizam objetos simuladores de acrílico ou de água sólida para realizar os testes rotineiros, chamados de testes diários ou semanais para conferir o coeficiente de calibração ou a qualidade dos feixes de radiação. Neste caso, não há a necessidade da câmara de ionização ser à prova d'água.

Por isso, o primeiro objetivo deste trabalho foi projetar, construir e caracterizar câmaras de ionização de placas paralelas, não necessariamente à prova d'água, para dosimetria de feixes de elétrons de aceleradores clínicos. Primeiramente, houve a necessidade de se testar câmaras de ionização com eletrodos coletores confeccionados com diferentes materiais. Posteriormente, com a experiência na construção de câmaras de ionização para feixes de elétrons, ocorreu a decisão de construção de uma câmara de ionização à prova d'água.

Os objetivos específicos foram:

1. Construção de quatro câmaras de ionização de placas paralelas com eletrodos coletores de materiais diferentes ou com eletrodos coletores com diâmetros diferentes.

2. Construção de uma quinta câmara de ionização à prova d'água.

3. Construção de um simulador de acrílico de placas paralelas para acoplar às quatro primeiras câmaras de ionização.

4. Construção de uma capa de equilíbrio eletrônico de acrílico para ser utilizada com as câmaras de ionização quando expostas em feixes de radiação gama $\left({ }^{60} \mathrm{Co}\right)$.

5. Testes de caracterização e calibração das câmaras de ionização no Laboratório de Calibração de Instrumentos (LCI) do IPEN.

6. Testes de caracterização das câmaras de ionização em aceleradores lineares com feixes de elétrons em três Serviços de Radioterapia da cidade de São Paulo. 


\section{Revisão da Literatura}

A radioterapia é um método capaz de destruir células tumorais utilizando radiações ionizantes que são formadas por partículas carregadas e não carregadas e que transportam energia. Existem várias fontes de energia utilizadas em radioterapia, como por exemplo as radiações $\mathrm{X}$, gama e beta, e os aceleradores lineares que podem oferecer tanto radiação X como radiação de elétrons (INCA, 2014a)

Os aceleradores lineares de fótons e de elétrons estão sendo muito utilizados e substituindo as fontes de cobalto em clínicas. Os resultados da pesquisa a este respeito estão sendo publicados, como forma de controle de qualidade, principalmente para aceleradores lineares que utilizam feixes de elétrons.

Os aceleradores de elétrons são equipamentos resistentes e de grande durabilidade; dependendo da área de aplicação, possuem energias diferentes e sistemas diferentes de manipulação de feixes. Eles são muito utilizados na área médica para tratamento de câncer, em pesquisa e na calibração de instrumentos detectores de radiação; também são aplicados na indústria para melhorar as propriedades físicas e químicas de materiais e reduzir contaminantes indesejáveis como produtos patogênicos ou tóxicos.

$\mathrm{Na}$ área industrial, Chmielewski (2011) reportou que muitos aceleradores de elétrons foram construídos e utilizados na indústria química e em outros processos envolvendo radiação ionizante. Seu trabalho trata sobre as diversas aplicações dos aceleradores lineares de elétrons no controle da poluição ambiental.

$\mathrm{Na}$ área médica existem estudos sobre o controle de qualidade dos aceleradores lineares de elétrons para uso clínico (LINACs); dentre eles está o trabalho de PolaczekGrelik e Karaczyn (2011), que estudaram a geração de radionuclídeos em aceleradores lineares durante a emissão de feixes terapêuticos, em três tipos de LINACs : Primus (15 MV), Clinac 2100 (18 MV) e Clinac 2300 (20 MV). O método utilizado para este fim foi a espectrometria, que é adequado para identificar os radionuclídeos gerados pelos LINACs. A análise deste método permitiu estimar o fluxo de fótons com energia definida e quantificar a dose absorvida nos pontos escolhidos no LINAC. Concluíram que a maior dose foi embaixo do cabeçote do acelerador linear, que se localiza em frente ao sistema de colimação e nos LINACs com maior tensão (POLACZEKGRELIK e KARACZYN, 2011). 
Outro aspecto importante a ser avaliado no LINAC é a dosimetria dos feixes de elétrons, como por exemplo pelo National Bureau of Standards, atual National Institute of Standards and Technology (NIST), que desde 1967 vem oferecendo serviços de dosimetria para feixes de elétrons de 5 a $50 \mathrm{MeV}$, nos Estados Unidos. Naquela época, o dosímetro de referência era o dosímetro Fricke e, de acordo com o trabalho de Ehrlich e Lamperti, verificou-se a necessidade de um sistema de dosimetria mais sensível para realização deste procedimento (EHRLICH e LAMPERTI, 1976).

Hoje existem vários tipos de dosímetros desenvolvidos e aplicados em dosimetria de feixes de radiação gama, beta, $\mathrm{X}$ e de elétrons. Dentre eles estão as câmaras de ionização, instrumentos desenvolvidos para várias aplicações e que existem em diferentes formas de acordo com o tipo de radiação. Por exemplo, as câmaras de ionização de placas paralelas podem ser utilizadas em diferentes tipos de feixes de radiação ionizante.

Mattsson e colaboradores (MATTSSON et al., 1981) desenvolveram uma câmara de ionização de placas paralelas: a câmara NACP, com eletrodo coletor de grafite e isolante de plástico (rexolite), para determinar a dose absorvida em feixes de elétrons. Neste trabalho foi estudado o efeito de polaridade, a corrente de fuga e a estabilidade da resposta da câmara de ionização. De acordo com Mattsson e colaboradores, a estabilidade de uma câmara de ionização com cavidade conectada com o ar atmosférico é influenciada pelo volume sensível da câmara de ionização.

Arbabi e colaboradores (ARBABI et al., 2010) desenvolveram uma câmara de ionização com eletrodo coletor constituído de nanotubos de carbono. Foram investigados o efeito do cabo, a corrente de fuga, a reprodutibilidade de resposta, o efeito de polaridade, e linearidade da resposta da câmara de ionização.

Culberson e colaboradores (CULBERSON et al., 2006) desenvolveram uma câmara de ionização de volume grande com várias aberturas para medições de kerma no ar para fontes de radiação de energias baixas, até $70 \mathrm{keV}$, aplicadas à braquiterapia para tratamento de câncer.

Um grupo de pesquisa do Departamento de Física Médica da Universidade de Wisconsin estudou o comportamento de 10 câmaras de ionização comerciais testadas em feixes de mamografia (DEWERD et al, 2002); Snow e colaboradores (SNOW et al., 2013) investigaram a possibilidade de aplicação de seis microcâmaras de ionização como dosimetros de referência para dosimetria em feixes de radiação $\mathrm{X}$ com energias baixas e médias; e DeWerd e Mackie (DEWERD e MACKIE, 2003) compararam o 
comportamento de câmaras de ionização com volumes diferentes para a determinação de dose absoluta em IMRT.

McNiven e colaboradores (McNIVEN et al., 2006) estudaram a resposta de um protótipo de câmara de ionização de placas paralelas desenvolvida para campos pequenos (menores que $3 \mathrm{~cm} \times 3 \mathrm{~cm}$ ) de raios $\mathrm{X}$. A dosimetria de campos pequenos tem-se tornado importante, porque é muito utilizada em tratamentos modernos de radioterapia como na técnica da radioterapia de intensidade modulada (IMRT) e na radioterapia estereotáxica.

Esses trabalhos mostram a importância do estudo de câmaras de ionização e suas aplicações.

Em 1987, a Agência Internacional de Energia Atômica (IAEA - International Atomic Energy Agency) desenvolveu um Código de Prática Internacional TRS 277 para determinação da dose absorvida para feixes de fótons e elétrons em termos de kerma no ar (IAEA, 1987). Posteriormente, uma segunda edição da norma da TRS 277 foi publicada em 1997, atualizando o método da dosimetria de fótons, principalmente para raios X de energias intermediárias. Apesar da atualização, em 1995, outro código de prática para dosimetria da radioterapia foi publicada, que foi a norma TRS 381 (IAEA, 1995) entitulada: O uso de câmaras de ionização de placas paralelas em feixes de elétrons e fótons de energias altas (IAEA, 1995), como forma de atualizar a norma TRS 277 e complementá-la a respeito do uso das camâras de ionização de placas paralelas. As duas normas TRS 277 e TRS 381 são de grande importância para a dosimetria em feixes de radiação de radioterapia. Nelas, a calibração das câmaras de ionização foi baseada em padrão primário de kerma no ar, mas uma nova tendência foi introduzida na norma TRS 381, que é a calibração das câmaras de ionização diretamente em objetos simuladores de água, em termos de dose absorvida em água (IAEA, 2006).

Segundo Rodrigues e colaboradores, “A dose absorvida na água é a grandeza de interesse principal em radioterapia” (RODRIGUES et al., 2006), pois está relacionada com os efeitos biológicos causados pela radiação ionizante. A grandeza dose absorvida é utilizada desde os padrões primários até os instrumentos de campo e minimiza-se a aplicação de fatores de correção para a obtenção de seu valor e, como consequência, as suas incertezas (RODRIGUES et al., 2006).

De acordo com o documento TRS 398 (IAEA, 2006), um sistema dosimétrico baseado em padrões de dose absorvida na água é possível utilizar praticamente em todos os feixes de radioterapia. Uma forma simples de se determinar a dose absorvida na água 
é dada pelo produto da leitura da câmara de ionização pelo fator de calibração em termos de dose absorvida na água $\left(N_{D, W}\right)$ e pelos fatores de correção. O formalismo na determinação de $N_{D, W}$ para feixes de fótons e de elétrons de energias altas utilizando uma câmara de ionização calibrada em dose absorvida na água em feixe de ${ }^{60} \mathrm{Co}$ é apresentado em detalhes por Hohlfeld (1998). Andreo (1992) e Rogers (1992) também realizaram trabalhos, complementando este tópico. O procedimento para a determinação da dose absorvida foi implantado por recomendações de dosimetria como o Institute of Physical Sciences in Medicine (IPSM, 1990), Deutsches Institut für Normung (DIN, 1997) e American Association of Physicists in Medicine (AAPM, 1999).

De acordo com o trabalho de Rodrigues e colaboradores (2006), a norma TRS 398 determina que uma das alternativas para se determinar a dose absorvida na água seria calibrar as câmaras de ionização de placas paralelas diretamente em feixes de elétrons de energias altas em vários feixes de elétrons com energias diferentes. Como há pouca disponibilidade dessa calibração em laboratórios primários, existe a alternativa de se realizar a calibração cruzada, utilizando uma câmara cilíndrica de referência com seu fator de calibração $N_{D, W}$ conhecido e fornecido por um laboratório padrão e uma câmara de placas paralelas em feixes de elétrons de energias altas.

A dosimetria de feixes de elétrons pode ser realizada por câmaras de ionização cilíndricas para feixes de elétrons acima de $10 \mathrm{MeV}$ e as câmaras de placas paralelas podem ser utilizadas para qualquer faixa de energia, sendo que seu uso é obrigatório para energias menores que $10 \mathrm{MeV}$ (IAEA, 1995; IAEA, 2006). Para se realizar a dosimetria de feixes de elétrons, é imprescindível que se calcule os fatores de correção para a resposta das câmaras de ionização. Muitos trabalhos foram desenvolvidos a este respeito.

Como exemplo, no trabalho de Pearce e colaboradores (2006) foram estudadas e comparadas as respostas de três câmaras de ionização PTW Advanced Markus, modelo 34045. Foram analisados o efeito de polaridade, a recombinação iônica e a perturbação da fluência de elétrons na parede da câmara de ionização. As câmaras foram expostas a feixes clínicos e seus resultados foram comparados com os obtidos pelo National Physical Laboratory (NPL). Neste trabalho, todas as câmaras de ionização apresentaram a mesma resposta para uma determinada energia; entretanto, apresentaram 5\% de efeito de polaridade para uma energia nominal de $4 \mathrm{MeV}$. O desejável seria apresentar um 
efeito de polaridade de até $1 \%$, mas para energias baixas a probabilidade de ocorrer efeito de polaridade maior que $1 \%$ é grande.

No trabalho de Gerbi e Khan (1987), e Havercroft e Klevenhagen (1994), as câmaras de ionização estudadas apresentaram efeito de polaridade maior que $1 \%$ para a maioria das energias utilizadas no trabalho.

Para Pearce e colaboradores (2006), a câmara de ionização PTW Advanced Markus foi desenvolvida em virtude da câmara PTW Markus não atender às expectativas do Institute of Physics and Engineering in Medicine (IPEM, 2003), que recomenda critérios no projeto de câmaras de ionização de placas paralelas utilizadas para se determinar a dose absorvida na água em feixes de elétrons.

A câmara de ionização PTW Markus apresenta uma espessura de anel de guarda fina, o que contribui para um aumento da fluência de elétrons na parede da câmara de ionização. Para este tipo de feixes são utilizadas como referência as câmaras de ionização NACP-02 da Scanditronix e a câmara de ionização Ross, modelo 34001, da Physikalisch-Technische Werkstätten (PTW).

Havercroft e Klevenhagen (1993) analisaram a resposta de uma câmara de ionização de placas paralelas juntamente com uma câmara de ionização dedal em função da recombinação iônica para feixes de fótons e de elétrons. Seu trabalho baseava-se na evolução da recombinação iônica presente nas câmaras de ionização. De acordo com os resultados apresentados, a câmara de ionização de placas paralelas apresenta uma menor recombinação iônica quando comparada com a câmara de ionização dedal, particularmente para radiação pulsada.

Existem outros fatores que têm influência na determinação da dose absorvida na água em feixes de elétrons, além do coeficiente de calibração da câmara de ionização (BULSKI et al., 2007), como o fator de correção para temperatura e umidade. Meger e colaboradores (1987) estudaram o efeito da umidade na resposta das câmaras de ionização, como por exemplo nas câmaras de ionização de grafite, que apresentaram um decréscimo na sua resposta de $2 \%$, quando a câmara absorve água.

Os cálculos de Monte Carlo, um método estatístico utilizado em simulações estocásticas, podem estimar os fatores de correção de uma câmara de ionização. Este método desenvolve uma expressão analítica para descrever o transporte de partículas ionizantes na matéria, utilizando o conhecimento de distribuição de probabilidade que rege as interações dos elétrons e dos fótons. Existem muitas aplicações deste método na área da física médica. Dentre elas estão a braquiterapia, caracterização da câmara de 
ionização, razão entre poderes de freamento, correções de atenuação de parede para padrões primários utilizando a grandeza kerma no ar, modelagem do feixe radioterápico e sistema de planejamento para cálculo de dose em 3-D em feixes radioterápicos de elétrons.

A determinação do fator de correção de espalhamento (YOSHIZUMI et. al., 2010) da parede da câmara de ionização e da correção pela falta de homogeneidade da composição da câmara de ionização (ROGERS, 1992) são exemplos de estudos realizados para caracterizar uma câmara de ionização por meio do método de Monte Carlo, que tem sido amplamente utilizado na área da Física Médica por meio dos códigos BEAM, PENELOPE, EGSnrc e ETRAN/ITS/MCNP.

Desde 2002, Rogers afirmava que o uso do método de Monte Carlo tenderia a crescer (ROGERS, 2002) e até hoje este método vem sendo aplicado em alguns trabalhos, como por exemplo no de Wagner e colaboradores (2013), que simularam câmaras de ionização para serem utilizadas na dosimetria de feixes de radioterapia estereotáxica em campos pequenos, utilizando o código EGSnrc.

Yi e colaboradores (2006) utilizaram o código PENELOPE para estudar a resposta de uma câmara de ionização em feixes de ${ }^{60} \mathrm{Co}$.

Muir e Rogers (2011) publicaram um trabalho recente sobre o cálculo de fatores de conversão da qualidade do feixe de fótons e elétrons, utilizando o método de Monte Carlo, em câmaras de ionização com eletrodo central feito de material com número atômico elevado. 


\section{Fundamentos Teóricos}

\subsection{Radiação ionizante}

A radiação ionizante é caracterizada pela habilidade de excitar e ionizar o meio em que ela incide, arrancando elétrons dos átomos da matéria que atravessa. A energia necessária para arrancar um elétron de um átomo é da ordem de 4 a $25 \mathrm{eV}$. Pode-se classificar a radiação ionizante como radiação diretamente ionizante e indiretamente ionizante (ATTIX, 2004).

A radiação diretamente ionizante ocorre quando as partículas carregadas entregam sua energia diretamente na matéria. Nesse caso, ela pode ser subdividida em partículas carregadas rápidas pesadas e partículas carregadas rápidas leves. Entre as partículas carregadas rápidas leves encontram-se os elétrons e os pósitrons, que colidem com as partículas do meio, perdendo grande parte de sua energia e mudando a direção da trajetória em uma única colisão. O movimento dos elétrons é tratado de forma relativística devido à sua alta velocidade. Com relação ao alcance dos elétrons, ele cresce em relação ao aumento da sua energia e com o decréscimo da densidade do material com que essas partículas interagem. Ao compará-los com as partículas carregadas pesadas, os elétrons possuem maior alcance (ATTIX, 2004; OKUNO e YOSHIMURA, 2010).

\subsubsection{Tipos de radiação ionizante}

Radiação X

A radiação $X$ pode ter duas origens. A primeira ocorre quando um elétron muda de um nível energético (de uma camada mais energética para uma menos energética em um curto período de tempo), liberando energia em forma de raios $\mathrm{X}$ característicos. A segunda forma acontece quando partículas carregadas são freadas formando um espectro contínuo, denominado radiação de freamento (Bremsstrahlung). A fração da energia do elétron convertida em Bremsstrahlung aumenta com a energia do elétron e é maior para materiais de número atômico, $(Z)$, maior (ATTIX, 2004; JOHNS and CUNNINGHAM,1983). 
Radiação gama

É a radiação eletromagnética emitida por um núcleo excitado ou pela aniquilação de pares.

Radiação beta

Ocorre quando um elemento que está com excesso de nêutrons decai para outro elemento. Para que isto ocorra, um nêutron se transforma em um próton e mais um elétron; este elétron é liberado e acompanhado por um antineutrino para equilibrar as forças nucleares. Também pode acontecer do átomo estar com excesso de prótons, então o próton é convertido em um nêutron, emitindo um pósitron e um neutrino (KNOLL, 1989).

\subsubsection{Formas de decaimento beta}

Os elétrons podem ser caracterizados por partículas positivas (pósitrons) e negativas. Um dos processos é a captura eletrônica, que ocorre quando um próton do núcleo atrai um elétron de uma camada eletrônica próxima ao núcleo, como exemplo, um elétron da camada K. Outro tipo de processo é a conversão interna, que ocorre quando um núcleo excitado transfere sua energia para um elétron, que é ejetado do átomo. Também existe a produção de elétrons “Auger”; neste caso, um elétron é ejetado produzindo uma vacância (buraco) na rede, por exemplo, cristalina; com isto, um elétron de um nível mais energético poderá ocupar este buraco liberando energia em forma de fóton. Poderá, ainda, transferir sua energia para um elétron que será ejetado do átomo; este último elétron ejetado é denominado elétron Auger (ATTIX, 2004).

\subsection{Descrição do campo da radiação ionizante}

O campo de radiação ionizante pode ser descrito por grandezas estocásticas e não estocásticas. Para as grandezas estocásticas, seus valores ocorrem aleatoriamente e não podem ser previstos. Os valores são determinados por distribuições de probabilidades. O valor varia descontinuamente no espaço. Alguns desses processos seguem a distribuição de Poisson, como por exemplo o decaimento radioativo. E para as 
grandezas não estocásticas ou determinísticas, os seus valores podem ser previstos por cálculos (ATTIX, 2004).

Ao se imaginar uma esfera, de acordo com a Figura 4.1, de volume $(d v)$, de um círculo com uma área $(d a)$, massa $(d m)$ exposta a uma radiação ionizante durante um determinado tempo $(d t)$, todos infinitesimais, pode-se descrever campos de radiação ionizante e suas interações com a matéria, todas de forma não estocástica. A radiação ionizante caracterizada por $\left(N_{e}\right)$ descreve o valor esperado do número de raios detectados por medição dentro da esfera (ATTIX, 2004).

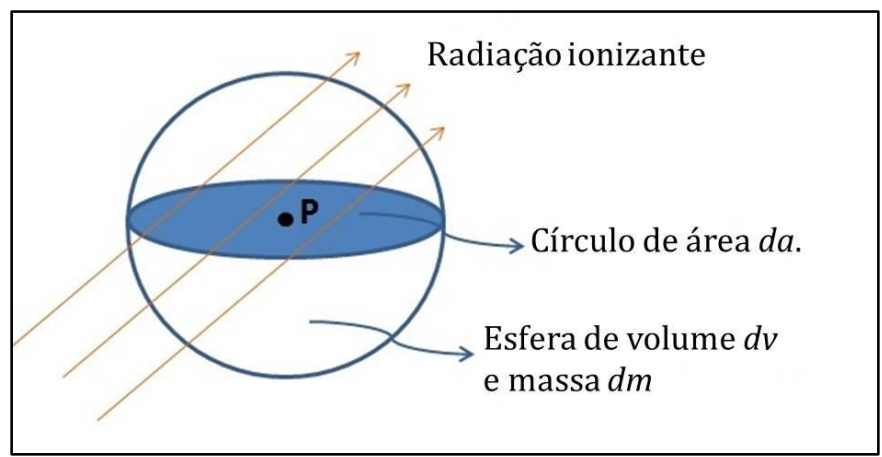

Figura 4.1 Representação esquemática do campo de radiação ionizante em uma esfera com um círculo de área centralizado em P (ATTIX, 2004)

A seguir serão descritos os campos de radiação por grandezas radiométricas.

\section{Fluência $(\Phi)$}

A fluência $(\Phi)$, de acordo com a Figura 4.1, é definida pela razão do número de raios $\left(N_{e}\right)$ que atingem a esfera pela área transversal $(d a)$ em torno do ponto $\mathrm{P}$ :

$$
\Phi=\frac{d N_{e}}{d a}
$$

A unidade da fluência é expressa por $\left(\frac{1}{m^{2}}\right)$. 


\section{Taxa de Fluência ou Densidade de Fluxo $(\dot{\Phi})$}

A taxa de fluência ou a densidade de fluxo $(\Phi)$ é definida pela derivada da fluência no tempo $d t$ :

$$
\dot{\Phi}=\frac{d \Phi}{d t}
$$

A unidade desta grandeza é expressa em $\left(\frac{1}{m^{2} \cdot s}\right)$.

\section{Fluência de Energia $(\Psi)$}

A fluência de energia $(\Psi)$ é definida pela razão da energia radiante que incide na área transversal $d a$ em torno do ponto $\mathrm{P}$ :

$$
\Psi=\frac{d R}{d a}
$$

A unidade da fluência de energia é dada por $\left(\frac{J}{m^{2}}\right)$.

\section{Taxa de Fluência de Energia $(\dot{\Psi})$}

A taxa de fluência de energia $(\dot{\Psi})$ é definida pela derivada da fluência de energia no tempo $d t$ :

$$
\dot{\Psi}=\frac{d \Psi}{d t}
$$

A unidade desta grandeza é expressa em $\left(\frac{J}{m^{2} \cdot s}\right)$.

\subsection{Grandezas de interação para partículas carregadas}

As partículas carregadas interagem muitas vezes com o meio até perderem toda sua energia cinética. É comum um feixe de partículas carregadas, ao atingir um 
material, apresentar uma variação quase nula no número de partículas; entretanto, a sua energia média diminui. As interações que ocorrem com partículas carregadas geralmente acontecem com o átomo como um todo ou com o núcleo (ATTIX, 2004).

\subsubsection{Tipos de colisões}

$>$ Colisão inelástica com o átomo

Esta colisão ocorre entre a partícula e os elétrons das camadas eletrônicas externas do átomo. Nessa ocasião, o átomo geralmente fica excitado e sofre pequena perda de energia e momento. Este evento ocorre com mais frequência em partículas pesadas (OKUNO e YOSHIMURA, 2010).

$>$ Colisão inelástica com elétron fortemente ligado

A partícula, nesse tipo de colisão, perde grande parte de sua energia, pois colide frontalmente com o átomo seguido de ionização dele (ejeção de um elétron do átomo). Quando o elétron adquire muita energia cinética, ele pode seguir outra trajetória, diferente da trajetória da partícula inicial, indo para uma região fora do feixe incidente. Este elétron é chamado de raio delta (OKUNO e YOSHIMURA, 2010).

$>$ Colisão elástica com o núcleo

Uma partícula primária, ao passar próximo do núcleo do átomo, muda sua direção da trajetória transferindo pouca energia para o meio, e o núcleo sofre um recuo para compensar o momento (OKUNO e YOSHIMURA, 2010).

$>$ Colisão inelástica com o núcleo

Este evento geralmente ocorre com partículas com massa de repouso pequena, como no caso dos elétrons e prótons. Nesse caso, a partícula perde sua energia em forma de um fóton, chamada de radiação de freamento (Bremsstrahlung). Quanto mais perto do núcleo a partícula estiver, mais perda de energia vai ocorrer (OKUNO e YOSHIMURA, 2010). 
Aniquilação de pares

Quando um pósitron com velocidade baixa interage com um elétron praticamente em repouso, eles se aniquilam e formam na maioria das vezes dois fótons que se movem em sentidos contrários. Mais difícil, mas que também pode ocorrer é a formação de três fótons (EISBERG e RESNICK, 1983; OKUNO e YOSHIMURA, 2010).

\subsubsection{Poder de freamento}

O poder de freamento $(S)$ é definido como a perda média de energia da partícula $(d T)$, por unidade de caminho percorrido $(d x)$.

$$
S=\frac{d T}{d x}
$$

Também pode ser tratado como poder de freamento mássico, dividindo $(S)$ pela densidade $(\rho)$.

$$
\frac{S}{\rho}=\frac{d T}{\rho d x}
$$

A unidade da grandeza poder de freamento é $\left(\frac{\mathrm{MeV}}{\mathrm{cm}}\right)$ enquanto que o poder de freamento mássico é dado por $\left(\frac{M e V . c m^{2}}{g}\right)$ (ATTIX, 2004; OKUNO e YOSHIMURA, 2010).

O poder de freamento é um conceito estatístico e varia com a energia e ao longo da trajetória de cada partícula. Ele é expresso pela média de um conjunto grande de partículas com suas respectivas trajetórias e histórias. Para as partículas carregadas, considera-se que a perda de energia é contínua em todo o percurso; esta consideração recebe uma sigla em inglês CSDA "Continuous Slowing-Down Approximation" (ATTIX, 2004; OKUNO e YOSHIMURA, 2010).

A perda de energia da partícula carregada pode ser por colisões ou por perdas radiativas; pode-se escrever o poder de freamento como a soma de componentes 
independentes: poder de freamento por colisão $\left(S_{C}\right)+$ poder de freamento por radiação $\left(S_{R}\right)$ (ATTIX, 2004; OKUNO e YOSHIMURA, 2010):

$$
\frac{S}{\rho}=\frac{S_{C}}{\rho}+\frac{S_{R}}{\rho}=\left(\frac{d T}{\rho d x}\right)_{C}+\left(\frac{d T}{\rho d x}\right)_{R}
$$

A unidade da grandeza é expressa por $\left(\frac{M e V \cdot c m^{2}}{g}\right)$.

Poder de freamento por colisão para elétrons.

Os elétrons, ao colidirem com os elétrons do átomo, por possuírem a mesma massa, só podem fornecer para o elétron atômico, no máximo, metade de sua energia. Portanto, o elétron que sai da colisão com energia cinética maior é o elétron incidente e o que estiver com menor energia é o elétron ejetado do átomo. De acordo com dados experimentais e computacionais, o poder de freamento mássico diminui com o aumento do número atômico do meio em que o elétron interage. O poder de freamento por colisão diminui para elétrons com energias intermediárias e cresce para elétrons com energias mais elevadas. (ATTIX, 2004; OKUNO e YOSHIMURA, 2010).

Poder de freamento por radiação para elétrons.

O poder de freamento por radiação trata da quantidade de energia perdida pelo elétron em forma de fótons, mais especificamente por Bremsstrahlung. Quanto maior a energia cinética do elétron, maior será a probabilidade do elétron perder sua energia em forma de Bremsstrahlung, No ar, a emissão de Bremsstrahlung é dominante para elétrons com energia cinética maior que $10 \mathrm{MeV}$ (ATTIX, 2004; OKUNO e YOSHIMURA, 2010).

\subsubsection{Alcance de partículas carregadas}

O alcance de uma partícula carregada depende do tipo da partícula e de sua energia e define-se pelo comprimento de trajetória que a partícula percorre antes de parar. 
Uma grandeza próxima a uma realidade experimental é o alcance $\left(R_{C S D A}\right)$ “Continuous Slowing-Down Approximation”, que representa uma aproximação de perda de energia contínua. Essa grandeza é representada em termos do poder de freamento no qual $\left(T_{0}\right)$ representa a energia inicial da partícula (ATTIX, 2004):

$$
\left(R_{\mathrm{CSDA}}\right)=\int_{0}^{T_{0}}\left(\frac{d T}{\rho d x}\right)^{-1} d T
$$

A unidade desta grandeza é expressa em $\left(\frac{\mathrm{g}}{\mathrm{cm}^{2}}\right)$.

\subsubsection{Transferência linear de energia}

A transferência linear de energia $\left(L_{\Delta}\right.$ ou LET), ou poder de freamento restrito, é a energia depositada por colisões de uma partícula carregada $\left(d E_{c}\right)$ ao percorrer uma distância $(d l)$ menos a soma das energias cinéticas de todos os elétrons $(T)$ com valores de energia maior que $(\Delta)$.

$$
L_{\Delta}=\frac{d T_{\Delta}}{d l}=\frac{d T_{c}-\sum(T>\Delta)}{d l}
$$

A unidade geralmente utilizada é $\frac{J}{m}$.

$\Delta$ indica um valor de restrição e representa os elétrons com energia suficiente para formar seu próprio caminho de ionização: os raios delta. Esses não contribuem para a deposição de energia local (ATTIX, 2004; OKUNO e YOSHIMURA, 2010).

\subsection{Grandezas físicas}

\section{Exposição}

Exposição (X) é uma grandeza não estocástica e é definida como a razão entre o valor absoluto de todas as cargas elétricas dos íons de um mesmo sinal produzidos no ar 
$(d Q)$, quando todos os elétrons liberados por fótons num elemento de volume de ar, representado pela massa $(\mathrm{dm})$, são completamente freados no ar (ICRU, 1998):

$$
X=\frac{d Q}{d m}
$$

A unidade atual é dada por $\left(\frac{C}{k g}\right)$ e a antiga, algumas vezes ainda mencionada, é o Roentgen $(R)$, onde $1 R=2,58 \cdot 10^{-4} \frac{\mathrm{C}}{\mathrm{kg}}$.

\section{Dose absorvida}

A grandeza dose absorvida (D) é importante para todos os tipos de campos de radiação ionizante, seja ela direta ou indiretamente ionizante. Ela representa a energia cedida à matéria, que é descrita pela radiação incidente em um volume, incluindo as partículas carregadas e não carregadas, menos a radiação que sai do volume, tanto as partículas carregadas como as não carregadas; a energia cedida inclui a energia de massa de repouso do núcleo e de partículas elementares. Esta grandeza é dada pela razão da energia média cedida $\left(d \overline{\mathrm{E}_{\mathrm{C}}}\right)$, por unidade de massa $(d m)$ (IAEA, 2000):

$$
D=\frac{d \overline{\mathrm{E}_{\mathrm{C}}}}{d m}
$$

A unidade de dose absorvida é $\left(\frac{J}{k g}\right)$ ou $(G y)$.

\section{Dose absorvida para elétrons}

A dose absorvida para elétrons será o produto do poder de freamento por colisão e a fluência:

$$
D=\frac{S_{C}}{\rho} \cdot \Phi=\left(\frac{d T}{\rho d x}\right)_{C} \cdot \Phi
$$


A unidade de dose absorvida para elétrons é $\left(\frac{M e V}{k g}\right)$ e com as devidas conversões pode-se tratar como unidade em (Gy) (ATTIX, 2004).

\section{Kerma}

Kerma $(K)$ é uma grandeza definida em relação a grandezas estocásticas e que descreve o processo de dissipação de energia de partículas não carregadas, transferida para uma partícula carregada; é a razão da energia transferida, $\left(d E_{T R}\right)$, por unidade de massa, (dm) (ATTIX, 2004; ICRU, 1998):

$$
K=\frac{d E_{T R}}{d m}
$$

A unidade de kerma no ar é dada por $\left(\frac{\mathrm{J}}{\mathrm{kg}}\right)$ ou $G y$.

A grandeza kerma para radição X e gama consiste na energia transferida para as partículas carregadas. Ela pode ser expressa por duas componentes: kerma por interações de colisão $\left(K_{C}\right)$ e kerma por interações radioativas $\left(K_{R}\right)$ (Bremsstrahlung): $\left(K_{C}\right)$ é o valor esperado da energia transferida para a partícula carregada por unidade de massa em um ponto de interesse, menos a energia perdida por radiação e a energia transferida para outra partícula carregada (ATTIX, 2004).

\subsubsection{Equilíbrio de partículas carregadas (CPE)}

O equilíbrio de partículas carregadas ocorre quando cada partícula carregada que deixa o volume $(V)$ é substituída (recolocada) por uma partícula idêntica, de mesma energia, que entra no volume $(V)$.

Para a radiação indiretamente ionizante o equilíbrio de partículas carregadas ocorre sob determinadas condições:

- A composição atômica do meio é homogênea;

- A densidade do meio é homogênea;

- Existe um campo uniforme de radiação indiretamente ionizante;

- Não existem campos elétricos ou magnéticos não homogêneos. 
Sob condições do equilíbrio de partículas carregadas e desprezando-se a radiação de freamento, pode-se afirmar que $(D)$ é igual a $\left(K_{C}\right)$ (ATTIX, 2004).

\subsubsection{Equilíbrio transiente de partículas carregadas (TCPE)}

O equilíbrio transiente de partículas carregadas ocorre em todos os pontos dentro de uma região na qual $(D)$ seja proporcional a $\left(K_{C}\right)$ por meio de uma constante $(c)$.

À medida que vai aumentando a profundidade do meio absorvedor, ocorre um decréscimo contínuo na fluência de fótons, e com isso um decréscimo no kerma. E como há uma perda significativa por parte do $\left(K_{R}\right)$, o kerma deixa de ser igual ao kerma de colisão, $(K) \neq\left(K_{C}\right)$.

Também pode-se notar que a dose absorvida vai aumentando com o aumento de ionizações secundárias causadas pelas partículas ionizantes primárias. A dose absorvida aumenta até a condição de equilíbrio eletrônico que ocorre após a região de build-up. Após o equilíbrio eletrônico, a dose absorvida é proporcional ao kerma de colisão (ATTIX, 2004; IAEA, 2005):

$$
D=K_{C} \cdot c
$$

\subsection{Teorias Cavitárias}

Para se medir a dose absorvida em um meio, é necessário que haja um dosímetro (dispositivo sensível à radiação ionizante) inserido nesse meio. A teoria da cavidade relaciona a dose absorvida no meio sensível do dosímetro (cavidade) com a dose absorvida em torno do meio que contém a cavidade. As teorias cavitárias são definidas de acordo com o alcance e a energia das partículas carregadas secundárias, liberadas pelas interações iniciais. De acordo com as dimensões das cavidades relacionadas com o alcance das partículas, define-se o tamanho da cavidade: pequena, intermediária e grande (IAEA, 2005).

\subsubsection{Teoria cavitária de Bragg-Gray}

A teoria cavitária de Bragg-Gray, de acordo com a Figura 4.2, supõe que a fluência entre as interfaces do meio e do dosímetro é contínua. Esta condição é válida em regiões de equilíbrio eletrônico. Portanto, a dose no meio $\left(D_{m}\right)$ e a dose no volume 
sensível $\left(D_{\text {cav }}\right)$ do dosímetro podem ser escritas como uma razão das doses; de acordo com a equação 4.15, tem-se (ATTIX, 2004, IAEA, 2005):

$$
\frac{D_{m}}{D_{c a v}}=S_{m, c a v}
$$

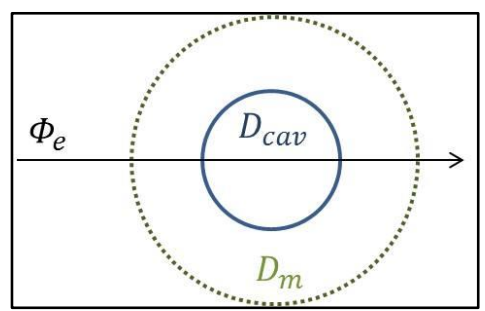

Figura 4.2 Representação esquemática da fluência de elétrons $\Phi_{e}$ nas interfaces: da cavidade do dosímetro, onde se encontra a dose na cavidade, $D_{\text {cav }}$; e do meio, onde está apresentada a dose no meio, $D_{m}$ (TURNER, 2007)

Supondo que a cavidade do dosímetro seja de um material diferente do meio em que ela está inserida, Bragg e Gray criaram a primeira condição da teoria cavitária de Bragg-Gray (ATTIX, 2004):

1. A espessura da cavidade deve ser tão pequena em comparação ao alcance das partículas carregadas que a penetram, de modo que sua presença não interfira no campo de partículas carregadas no meio.

Entretanto, as propriedades de espalhamento do meio e da cavidade devem ser similares, especialmente no caso dos elétrons; mesmo para cavidades pequenas, eles podem sofrer uma perturbação significativa, a não ser que o número atômico do meio e da cavidade sejam próximos (ATTIX, 2004).

Considerando que nenhuma partícula seja formada ou freada dentro da cavidade e que toda a energia depositada é devida às partículas carregadas que atravessam esta cavidade, foi criada a segunda condição de Bragg-Gray (ATTIX, 2004; IAEA, 2005):

2. A dose absorvida na cavidade deve ser causada apenas pelas partículas que a atravessam. 
O cumprimento das duas condições de Bragg-Gray dependerá do tamanho da cavidade, que está baseada no alcance dos elétrons na cavidade do meio.

\subsubsection{Teoria cavitária de Spencer-Attix}

Alguns experimentos realizados em 1950 comprovaram que a teoria de Brag-Gray não previa exatamente as ionizações que acontecem no interior de uma cavidade, especialmente quando o material destas cavidades possui um número atômico alto. Spencer e Attix (1955) sugeriram que a produção de raios delta poderia ser levada em conta na teoria da cavidade e que o tamanho da cavidade também poderia ser alterado.

A teoria de Spencer-Attix leva em consideração as condições de Bragg-Gray e acrescenta a influência dos raios delta. Com isso, a teoria relaciona o tamanho da cavidade com a energia $\Delta$, que é a energia média necessária para os elétrons secundários (raios delta) poderem atravessar a cavidade. Caso os elétrons possuam energia maior que $\Delta$, eles podem transportar energia e podem cruzar a cavidade. Caso eles possuam energia menor que $\Delta$, supõe-se que os elétrons possuem alcance zero (perdem sua energia no ponto de formação) e não entram na cavidade (ATTIX, 2004; IAEA, 2005).

O método de Monte Carlo mostra que existem diferenças entre as teorias de Bragg-Gray e Spencer-Attix; mesmo assim, elas não são significativas (IAEA, 2005), desde que os poderes de freamento para diferentes meios mostrem similaridades em função da energia da partícula. A teoria de Spencer-Attix aproxima-se mais das observações experimentais, por considerar a produção de raios delta; entretanto, ao se tratar cavidades maiores do que o alcance dos elétrons, as duas teorias apresentam falhas (ATTIX, 2004; IAEA, 2005).

O uso das teorias de Bragg-Gray e de Spencer Attix é recomendado em normas internacionais de dosimetria (IAEA, 1995; IAEA, 2000), em cálculos de fatores de correção de câmaras de ionização.

Além da teoria de Bragg-Gray e da teoria de Spencer-Attix existem outras teorias, como a teoria de Burlin, criada para feixes de fótons. Esta teoria não é utilizada na prática, por ser considerada muito simplista. 


\subsection{Características gerais dos dosímetros}

A dosimetria das radiações estuda a relação da dose absorvida com qualquer outra grandeza resultante da interação da radiação com a matéria. Define-se um dosímetro como um dispositivo capaz de fornecer uma leitura $(L)$ correlacionada à dose absorvida $(D)$, em um determinado volume $(V)$. Para um dosímetro ideal, $(L)$ seria proporcional a $(D)$. Entretanto, na realidade, a maioria dos dosímetros apresenta uma falta de linearidade em algum ponto da curva correspondente a um intervalo de dose (ATTIX, 2004; IAEA, 2005). Algumas características são importantes para que os detectores de radiação sejam considerados dosímetros; dentre elas estão o carácter absoluto, precisão, exatidão, repetibilidade, reprodutibilidade, sensibilidade, dependência energética e dependência direcional.

\subsubsection{Caráter absoluto}

Um dosímetro absoluto é um instrumento que obtém o valor de dose no seu próprio volume sensível, sem a necessidade de calibrá-lo num feixe de radiação com características conhecidas. Como exemplo, tem-se o calorímetro, que é um dosímetro que mede diretamente o calor produzido pela dose absorvida sem a necessidade de coeficientes de conversão (ATTIX, 2004; IAEA, 2005).

\subsubsection{Precisão e exatidão}

A precisão de resposta de um dosímetro especifica a reprodutibilidade das medições em condições semelhantes. Uma precisão alta está associada a um desvio padrão pequeno dos resultados de medição. A exatidão de um dosímetro representa o quão próximo está o valor medido com relação ao valor de referência (IAEA, 2005).

\subsubsection{Repetibilidade}

A repetibilidade de resposta de um detector de radiação representa o quão próximos estão os resultados obtidos por medições sucessivas, mantendo-se as mesmas condições experimentais para um mesmo dosímetro. Representa também a estabilidade a curto prazo da resposta do detector (IAEA, 2005). 


\subsubsection{Reprodutibilidade}

A reprodutibilidade de resposta de um detector de radiação representa o quão próximos estão os resultados obtidos por medições sucessivas, ao longo do tempo, sob condições experimentais reprodutíveis, para um mesmo dosímetro. Representa também a estabilidade a longo prazo da resposta do detector (IAEA, 2005).

\subsubsection{Sensibilidade}

A sensibilidade de resposta de um dosímetro corresponde ao intervalo no qual a leitura do dosímetro é proporcional à dose. Entretanto, os dosímetros podem apresentar regiões de supralienaridade ou uma região de saturação, como no caso da Figura 4.3. A curva apresenta linearidade até $D_{2}$ e a sensibilidade é o resultado da tangente do ângulo $\theta$ (ATTIX, 2004; IAEA, 2005).

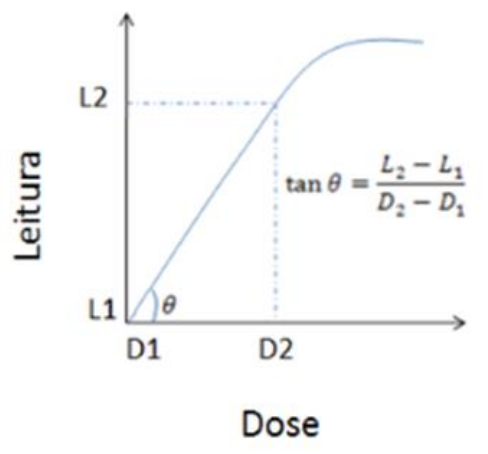

Figura 4.3 Sensibilidade de resposta de um dosímetro representado pela tangente do ângulo $\theta$ (ATTIX, 2004)

\subsubsection{Estabilidade}

A estabilidade de um dosímetro está na sua capacidade de não desvanecer com as condições ambientais, como temperatura, pressão e umidade, ou ainda com outros fatores externos como luz (IAEA, 2005).

\subsubsection{Dependência energética}

A resposta do dosímetro pode ser analisada em função do valor de energia do feixe de radiação ao qual ele é submetido. Cada dosímetro possui um comportamento 
com relação à dependência energética. Geralmente as normas internacionais limitam um valor para a dependência energética: quanto menor for este valor, melhor. $\mathrm{O}$ dosímetro deve ser calibrado em toda faixa de energia no qual ele será utilizado (IAEA, 2005).

\subsubsection{Dependência direcional}

A variação da resposta de um dosímetro em função do ângulo de incidência da radiação caracteriza a sua dependência direcional ou angular. O ideal é que o dosímetro não possua dependência direcional; entretanto, isto vai depender da geometria e do material do dosímetro e do tipo de radiação ao qual ele está sendo submetido (IAEA, 2005).

\subsection{Detectores de radiação}

Os detectores de radiação são dispositivos sensíveis à radiação ionizante e têm como função determinar a quantidade de radiação presente em um determinado meio. Existe uma série de detectores de radiação. Dentre eles estão os detectores a gás: câmaras de ionização, contadores proporcionais, detectores do tipo Geiger-Müller; semicondutores: diodos, MOSFET; dosímetros químicos como Fricke-gel; filmes; dosímetros termoluminescentes; dosímetros luminescentes opticamente estimulados; cintiladores, etc (ATTIX, 2004; IAEA, 2005).

\subsubsection{Detectores a gás}

Os detectores a gás são qualificados de acordo com a tensão de operação, ou seja, a tensão aplicada entre os seus eletrodos. O princípio de funcionamento dos detectores está baseado na produção de íons pela interação da radiação ionizante com o volume de gás.

As câmaras de ionização, sob um feixe de radiação, coletam todas as cargas criadas pela ionização direta do gás por meio da aplicação de um campo elétrico. Apesar da maioria das câmaras de ionização serem utilizadas no modo corrente, com dispositivo dc, elas também podem ser operadas no modo pulsado, o que as diferencia dos detectores Geiger-Müller e detectores proporcionais, que são sempre utilizados no modo pulsado (KNOLL, 1989). 


\subsection{Câmaras de ionização de placas paralelas}

As câmaras de ionização de placas paralelas são utilizadas em feixes de fótons e de elétrons de energias altas. Elas são altamente recomendadas para todas as faixas de energia para feixes de elétrons e seu uso é obrigatório para energias menores que $10 \mathrm{MeV}$. Para fótons, elas são adequadas para dosimetria de referência somente quando a calibração em termos de dose absorvida na água estiver disponível para a qualidade de radiação desejável. Também são adequadas para dosimetria de referência para prótons e íons pesados. As câmaras de ionização de placas paralelas devem, preferencialmente, ser à prova d'água, homogêneas e de material equivalente à água. As câmaras de ionização construídas para utilização em objetos simuladores sólidos devem ser construídas de material semelhante ao do simulador. Uma das principais vantagens de se utilizar uma câmara de ionização de placas paralelas em feixes de elétrons é minimizar os efeitos de perturbação devido ao espalhamento. Elas podem ser projetadas de forma a provar que a contribuição dos elétrons que entram pelas paredes laterais da câmara é insignificante. Como o ponto efetivo de medida deste tipo de instrumento é no centro da superfície interna da janela de entrada, as correções quanto ao efeito de atenuação do feixe não necessitam ser realizadas (IAEA, 1995; IAEA, 2006).

\subsection{Distribuição da dose absorvida em profundidade}

A distribuição da dose absorvida em profundidade pode ser determinada utilizando uma câmara de ionização.

A curva da distribuição da dose absorvida em profundidade possui alguns parâmetros apresentados na Figura 4.4. 


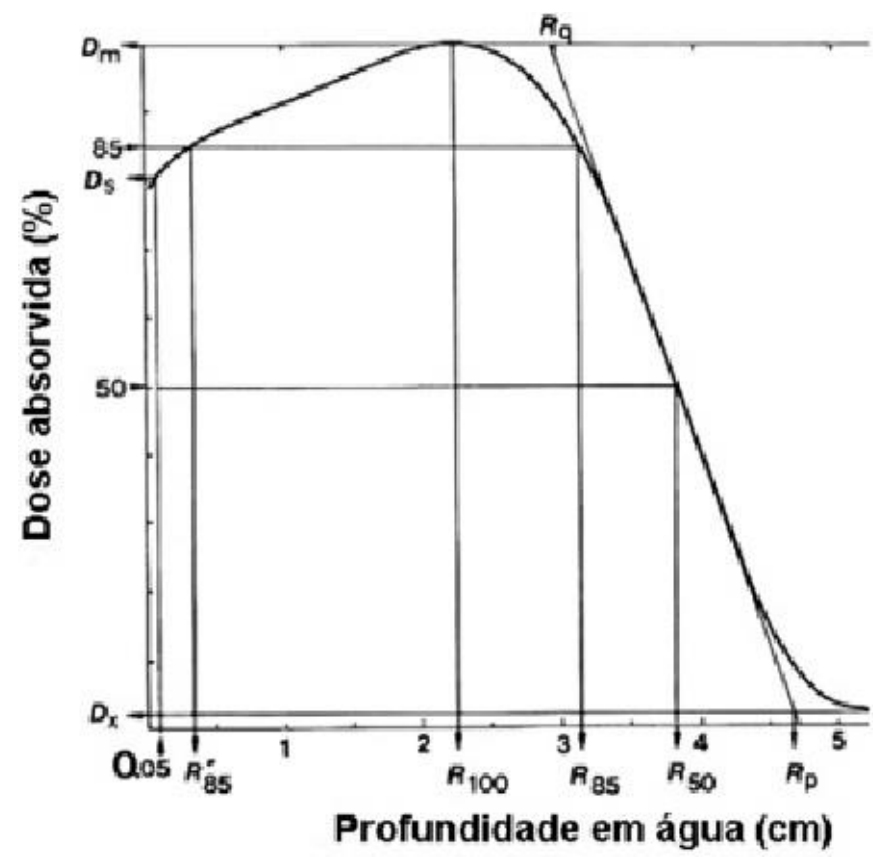

\section{Figura 4.4 Curva típica da distribuição terapêutica da dose absorvida em profundidade}

$\mathrm{R}_{100}$ : profundidade de dose máxima;

$\mathrm{R}_{85}$ : profundidade terapêutica, ou seja, profundidade que deve abranger o volume alvo;

$\mathrm{R}_{50}$ : profundidade que corresponde à metade da dose máxima;

$\mathrm{R}_{\mathrm{p}}$ : profundidade de intersecção da tangente através do ponto de maior inclinação (ponto de inflexão) da curva. Esta profundidade é chamada de alcance prático, e é importante do ponto de vista clínico, pois determina o máximo alcance dos elétrons.

\subsection{Calibração de uma câmara de ionização}

A câmara de ionização de referência deve ser calibrada em um laboratório padrão, para uma qualidade $\left(Q_{0}\right)$ a cada dois ou três anos ou sempre que houver a suspeita de que a câmara tenha sido danificada e após seu concerto. De acordo com a norma TRS 398, a qualidade $\left(Q_{0}\right)$ define o feixe de radiação gama de ${ }^{60}$ Co (IAEA, 1995; IAEA, 2006).

\subsubsection{Calibração em feixes de ${ }^{60} \mathrm{Co}$}

Em um laboratório primário ou secundário, utiliza-se a câmara de referência para determinar a dose absorvida na água. Supõe-se que a dose absorvida na água, $\left(D_{W}\right)$, é conhecida a uma profundidade de $5 \mathrm{~g} \cdot \mathrm{cm}^{-2}$ em um objeto simulador de água para feixes de radiação gama, ${ }^{60} \mathrm{Co}$. A câmara de ionização a ser calibrada é posicionada 
nessa profundidade dentro do objeto simulador de água e o coeficiente de calibração, $\left(N_{D, W}\right)$, é determinado de acordo com a equação (IAEA, 1995; IAEA, 2006):

$$
N_{D, W}=\frac{D_{w}}{M}
$$

onde

$(M)$ é a leitura, da câmara sob calibração, corrigida por grandezas influentes para corresponder às condições de referência.

Para se determinar o coeficiente de calibração $\left(N_{D, W, Q_{0}}^{C i}\right)$ de uma câmara de ionização desconhecida é necessário calibrá-la em relação a uma câmara de ionização de referência que possui um coeficiente de calibração $\left(N_{D, W, Q_{0}}^{R e f}\right)$. Neste caso,

$$
N_{D, W, Q_{0}}^{C i}=\frac{M^{R e f}}{M^{C i}} N_{D, W, Q_{0}}^{R e f}
$$

onde

( $M^{R e f}$ ) é a medição obtida com a câmara de referência;

$\left(M^{C i}\right)$ é a medição obtida com a câmara de ionização a partir da qual se pretende obter o coeficiente de calibração.

\subsubsection{Determinação da dose absorvida na água em feixe de radiação de elétrons}

Quando o usuário da câmara de ionização possuir um coeficiente de calibração $\left(N_{D, W, Q_{0}}\right)$ em termos de dose absorvida na água para uma qualidade de referência $\left(Q_{0}\right)$, pode-se determinar a dose absorvida na água $\left(D_{w, Q}\right)$ em feixes de elétrons posicionando a câmara de ionização na posição de referência e por meio da equação (IAEA, 1995; IAEA, 2006):

$$
D_{w, Q}=M_{Q} N_{D, W, Q_{0}} K_{Q, Q_{0}}
$$

onde

$\left(M_{Q}\right)$ é a leitura da câmara com os fatores de correções $\left(\prod K_{i}\right)$ incorporados para as grandezas influentes; 
$\left(K_{Q, Q_{0}}\right)$ é o fator de correção para as diferenças entre a qualidade do feixe $\left(Q_{0}\right)$ e o feixe atual utilizado $(Q)$.

Esta equação é válida para feixes de radiação de elétrons e para todos os outros campos de radiação em que o código de prática TRS 398 (IAEA, 2006) se aplica (feixes externos para radioterapia).

\subsubsection{Determinação do fator de correção das qualidades dos feixes $K_{Q, Q_{0}}$}

Para obter a dose absorvida na água, $\left(D_{w, Q}\right)$, em feixes de radiação de elétrons é necessário obter os fatores de correção para as energias de feixes de elétrons $\left(K_{Q, Q_{0}}\right)$ da câmara de ionização.

De acordo com a TRS 398, uma expressão geral de $\left(K_{Q, Q_{0}}\right)$ pode ser dada por:

$$
K_{Q, Q_{0}} \approx \frac{S_{\text {água, } a r_{Q}}}{S_{\text {água, } a r_{Q_{0}}}} \frac{P_{Q}}{P_{Q_{0}}}
$$

onde

$\left(S_{\text {água,ar }} Q_{0}\right)$ é o poder de freamento obtido em feixes de radiação gama ${ }^{60}$ Co e de acordo com a TRS 398 tem um valor de 1,133;

É necessário também calcular o fator de perturbação $\left(P_{Q_{0}}\right)$ para o feixe de radiação de ${ }^{60} \mathrm{Co}$, e é obtido calculando-se os fatores de correção:

- $\quad P_{c a v}$ : fator de correção da cavidade da câmara de ionização, que no caso para câmaras de ionização de placas paralelas é igual a 1;

- $P_{\text {parede }}$ : fator de correção da parede da câmara de ionização, aplicada somente para câmaras de ionização cilíndricas;

- $\quad P_{\text {dist }}$ fator de correção da distância do ponto efetivo da câmara de ionização, é apenas aplicado para câmaras de ionização cilíndricas.

$S_{\text {água,ar }}$ é poder de freamento obtido em feixes de elétrons e é dado por:

$$
S_{\text {água, } a r_{Q}}=1,253-0,1487\left(R_{50}^{0,214}\right)
$$

onde 
$R_{50}$ é a profundidade onde a dose absorvida atinge $50 \%$ do seu valor;

$P_{Q}$ é o fator de perturbação para feixes de elétrons, e é obtido calculando-se os fatores de correção da câmara de ionização:

- $\quad P_{c a v}$ : fator de correção da cavidade da câmara de ionização para feixes de elétrons; a câmara de ionização que possuir uma largura de anel de guarda igual ou maior que 1,5 vezes a altura da cavidade da câmara de ionização, o fator de correção da cavidade é igual a 1 ;

- $P_{\text {parede: }}$ fator de correção da parede da câmara de ionização de placas paralelas em feixes de elétrons é considerado igual a 1;

- $\quad P_{\text {dist }}$ f fator de correção da distância do ponto efetivo da câmara de ionização, de placas paralelas em feixes de elétrons, possui uma incerteza menor que $0,2 \%$ (IAEA, 2006).

\subsection{Objeto simulador}

O objeto simulador de água é recomendado pelo código de prática TRS 277 (IAEA, 1987) como um meio de referência para se determinar dose absorvida tanto para feixes de fótons como para elétrons.

Objetos simuladores sólidos como PMMA também podem ser utilizados para feixes de elétrons com energias abaixo de $10 \mathrm{MeV}$. Entretanto, a determinação da dose deve ser sempre referida à água. Para feixes de elétrons, o simulador sólido deve ser similar à água, ou seja, os poderes de freamento por colisão e por radiação do material do objeto simulador devem ser muito próximos aos da água. Em materiais plásticos com alto teor de carbono, o numero atômico efetivo é mais baixo com relação ao da água; esta diferença pode ser reduzida acrescentando um material de um número atômico maior para o simulador. Quando são utilizados objetos simuladores de material isolante, o usuário, ao calibrar a câmara de ionização de placas paralelas em feixes de elétrons, deve estar atento ao problema de armazenamento de carga, que gera um campo elétrico ao redor da câmara de ionização, influenciando diretamente a fluência de elétrons e, portanto afetando a leitura da câmara de ionização. A fim de minimizar este efeito, a espessura das placas deve ser a menor possível e pode ser de até no máximo $2 \mathrm{~cm}$ cada (IAEA, 1995; IAEA, 2006). 


\section{Materiais e Métodos}

Neste capítulo serão apresentados os métodos utilizados para o desenvolvimento deste trabalho. Primeiramente serão apresentados os sistemas de radiação do Laboratório de Calibração de Instrumentos (LCI) do IPEN, em seguida os sistemas de radiação dos hospitais utilizados neste trabalho. Os materiais utilizados também estão apresentados neste capítulo.

\subsection{Sistemas de radiação do Laboratório de Calibração de Instrumentos do IPEN}

Para a realização de alguns testes de caracterização das câmaras de ionização desenvolvidas neste trabalho, foram utilizadas algumas fontes de radiação do LCI. As fontes de radiação são descritas a seguir.

Uma das fontes de radiação beta do sistema padrão secundário, marca Buchler, modelo BSS1, apresentada na Figura 5.1, foi utilizada. Esta fonte é a de ${ }^{90} \mathrm{Sr}+{ }^{90} \mathrm{Y}$ com atividade nominal de $1,85 \mathrm{GBq}(50 \mathrm{mCi}, 1981)$, com certificado de calibração do laboratório padrão primário alemão Physikalisch-Technische Bundesanstalt (PTB).

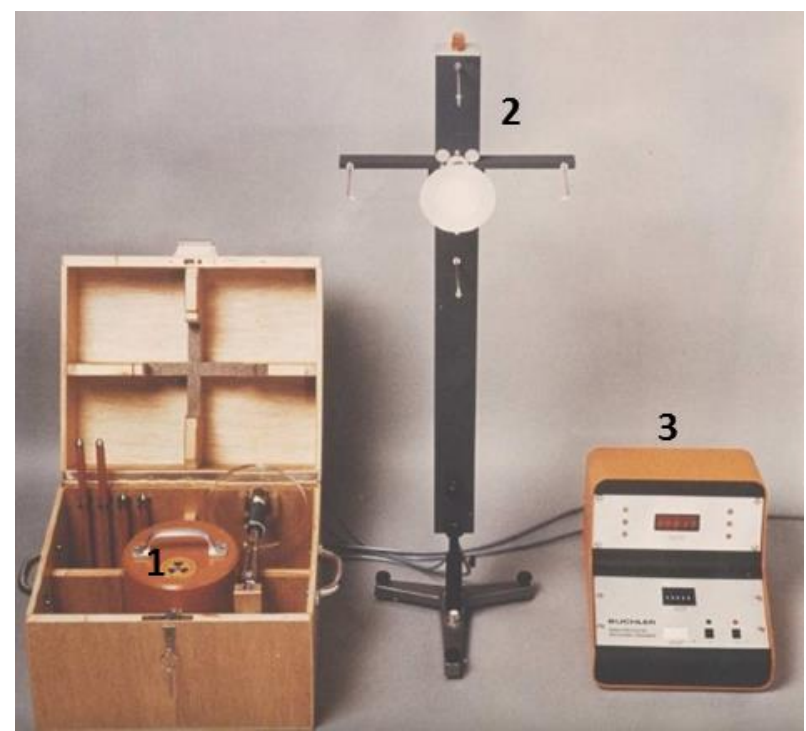

Figura 5.1 Sistema de radiação beta: 1-Blindagem das fontes, 2-Sistema do irradiador, 3-Sistema de acionamento das fontes 
Um sistema de radiação gama da Siemens / Gammatron II S80, utilizado para calibração de dosímetros clínicos no Laboratório de Calibração de Instrumentos do IPEN está apresentado na Figura 5.2. O equipamento Gammatron possui uma taxa de kerma no ar de $(0,487 \pm 0,009) \mathrm{mGy} / \mathrm{s}(16 / 09 / 2014)$. A fonte de ${ }^{60} \mathrm{Co}$ foi utilizada para a realização de alguns testes.

Uma câmara de ionização do tipo Farmer da PTW, modelo TN 30013, é utilizada no LCI para dosimetria dos feixes de radiação gama deste sistema e foi aplicada neste trabalho para calibrar as câmaras de ionização desenvolvidas.

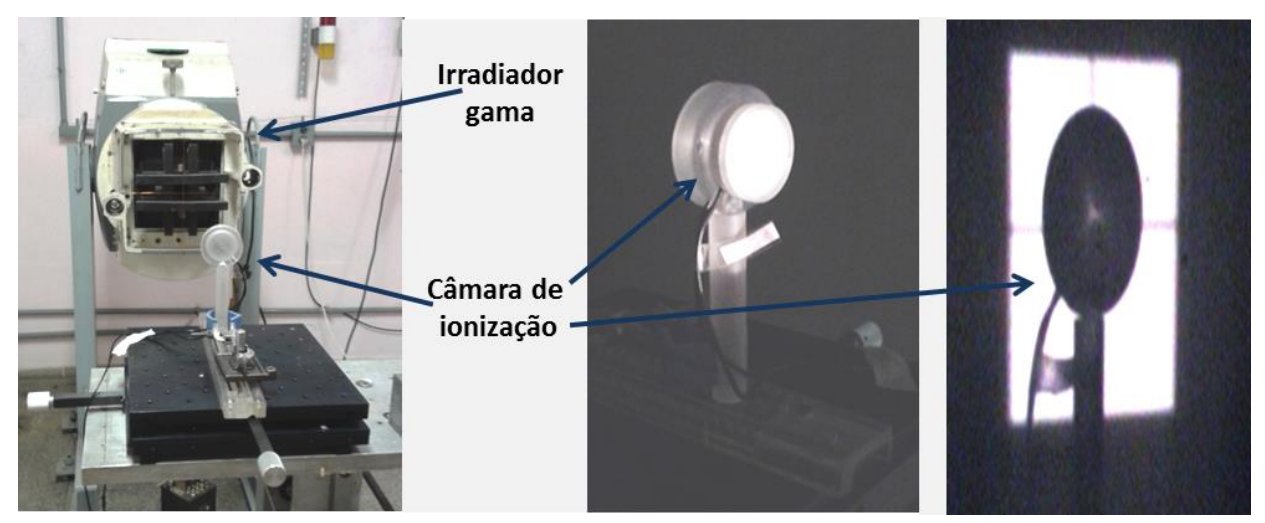

Figura 5.2 Sistema de radiação gama e posicionamento da câmara de ionização no centro do feixe de radiação, no Laboratório de Calibração de Instrumentos do IPEN

Uma fonte de controle de ${ }^{90} \mathrm{Sr}+{ }^{90} \mathrm{Y}$, Physikalisch-Technische Werkstätten (PTW), modelo 8921, com atividade nominal de $33 \mathrm{MBq}$ (1994) foi utilizada em alguns testes de caracterização das câmaras de ionização e está apresentada na Figura 5.3.

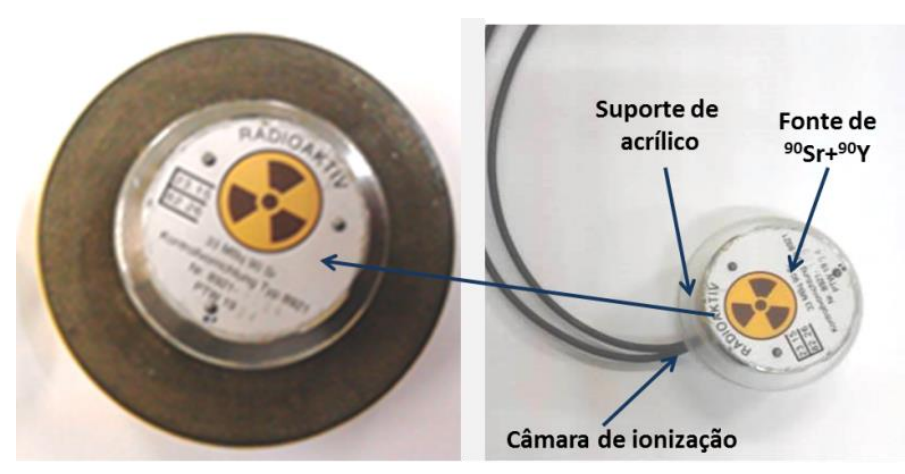

Figura 5.3 Fonte de controle de ${ }^{90} \mathrm{Sr}+{ }^{90} \mathrm{Y}$ e suporte de acrílico para posicionar a fonte de controle na câmara de ionização, no Laboratório de Calibração de Instrumentos do IPEN 


\subsection{Sistema de radiação do Departamento de Radioterapia do Hospital}

\section{Albert Einstein / Sociedade Beneficente Israelita Brasileira}

O Hospital Albert Einstein disponibilizou um acelerador linear Varian, modelo 2100 (LINAC), que pode ser observado na Figura 5.4. Este acelerador possui feixes de elétrons com energias de 6, 9, 12 e $16 \mathrm{MeV}$.

A câmara de ionização utilizada para calibração dos feixes é a do tipo Farmer, marca PTW, modelo 30013, que possui certificado de calibração do Laboratório de Calibração de Instrumentos do IPEN. As energias utilizadas neste trabalho foram $6 \mathrm{MeV}$ e $12 \mathrm{MeV}$, sendo que uma unidade monitora (1 UM) equivale a $10 \mathrm{mGy}$ (1 cGy) de dose absorvida, para todas as energias do feixe de radiação de elétrons, à distância de referência de $100 \mathrm{~cm}$.

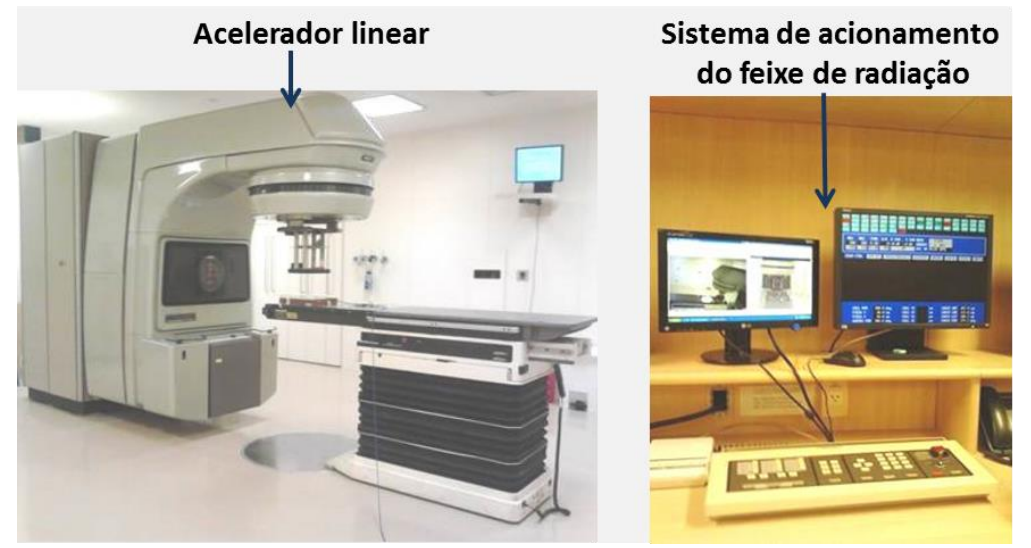

Figura 5.4 Acelerador linear Varian 2100 (LINAC) e sistema de acionamento do feixe de radiação, do Hospital Albert Einstein

\subsection{Sistema de radiação do Departamento de Radioterapia do Instituto do Câncer do Estado de São Paulo (ICESP)}

Na Figura 5.5 está apresentado o acelerador linear Elekta Synergy, disponibilizado pelo Hospital ICESP, e que possui feixes de elétrons com energias de 4, 6, 9, 12, $15 \mathrm{MeV}$ do ICESP.

A câmara de ionização utilizada para calibração dos feixes é do tipo Farmer, marca PTW, modelo 30013, que possui certificado de calibração do Laboratório de Calibração de Instrumentos do IPEN. As energias utilizadas neste trabalho foram 6, 9, 12 e 
$15 \mathrm{MeV}$, sendo que a relação da unidade monitora com a dose absorvida é de: $1 \mathrm{UM}$ equivale a 8,03 mGy (0,803 cGy) para a energia de $6 \mathrm{MeV} ; 1 \mathrm{UM}$ equivale a 8,15 mGy (0,815 cGy) para a energia de $9 \mathrm{MeV} ; 1 \mathrm{UM}$ equivale a 9,08 mGy $(0,908 \mathrm{cGy})$ para a energia de $12 \mathrm{MeV}$ e 1 UM equivale a 8,96 mGy (0,896 cGy) para a energia de $15 \mathrm{MeV}$, à distância de referência de $100 \mathrm{~cm}$.

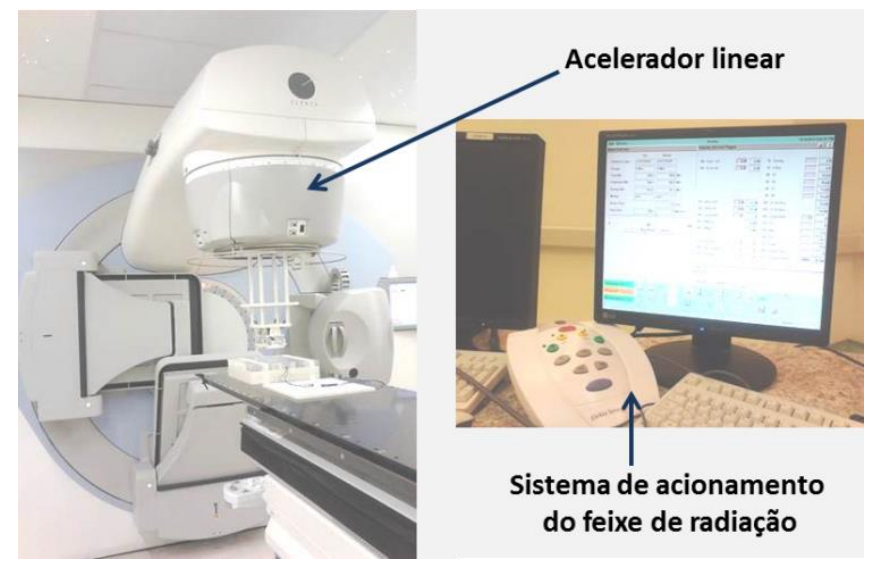

Figura 5.5 Acelerador linear Elekta Synergy e sistema de acionamento do feixe de radiação, do ICESP

\subsection{Sistema de radiação do Departamento de Radioterapia do Instituto de Radiologia do Hospital das Clínicas da Faculdade de Medicina da Universidade de São Paulo - InRad - HCFMUSP}

O acelerador linear Varian, modelo 2100 (LINAC), apresentado na Figura 5.6, foi utilizado neste trabalho. Este acelerador linear pertence ao InRad e possui feixes de elétrons com energias de 4, 9, 12 e $15 \mathrm{MeV}$.

A câmara de ionização utilizada para calibração dos feixes é do tipo Scanditronix FC-65P, com certificado de calibração do Laboratório de Calibração de Instrumentos do IPEN. A energia utilizada neste trabalho foi de $15 \mathrm{MeV}$, sendo que uma unidade monitora 1 UM equivale a $10 \mathrm{mGy}$ ( $1 \mathrm{cGy}$ ) da dose absorvida, para a energia de $15 \mathrm{MeV}$ à distância de referência de $100 \mathrm{~cm}$. 


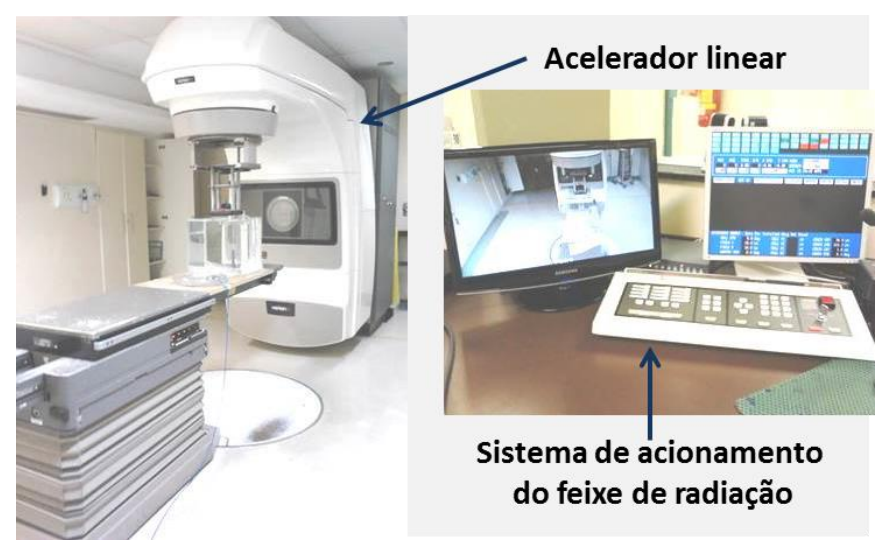

Figura 5.6 Acelerador linear 2100 (LINAC) e sistema de acionamento do feixe de radiação, do InRad

\subsection{Valores do fator de correção, $K_{Q, Q_{0}}$, dos feixes de radiação de elétrons dos aceleradores clínicos utilizados}

Com o objetivo de se determinar a dose absorvida na água em feixes de radiação de elétrons de aceleradores clínicos, as câmaras de ionização foram calibradas em feixes de ${ }^{60}$ Co. De acordo com a norma da TRS 398 (IAEA, 2006), para utilizar as câmaras de ionização em feixes de elétrons, além do coeficiente de calibração, é necessário conhecer o fator de correção de qualidade $K_{Q, Q_{0}}$, da Equação 4.18. Isto possibilita corrigir a diferença do tipo e da energia entre feixes de radiação de ${ }^{60} \mathrm{Co}$ em relação às energias de feixes de radiação de elétrons que o acelerador clínico disponibiliza.

Portanto, é necessário calcular o poder de freamento tanto dos feixes de radiação de ${ }^{60} \mathrm{Co}$, disponibilizado na publicação TRS 398 (IAEA, 2006), quanto o poder de freamento dos feixes de radiação de elétrons calculados de acordo com a Equações 4.19 e 4.20. Para isto é necessário obter o valor $\left(\mathrm{em} \mathrm{cm}\right.$ ) da profundidade $\mathrm{R}_{50}$ de cada feixe utilizado neste trabalho. Na Tabela 5.1 estão apresentados os valores de $K_{Q, Q_{0}}$ calculados para cada feixe de radiação de elétrons dos aceleradores clínicos utilizados neste trabalho. 
Tabela 5.1 Valores de $K_{Q, Q_{0}}$ dos feixes de radiação de elétrons dos aceleradores clínicos apresentados neste trabalho

\begin{tabular}{|c|c|c|}
\hline \multicolumn{3}{|c|}{$\begin{array}{l}\text { Hospital Albert Einstein } \\
\text { Acelerador linear } \\
\text { Varian } 2100 \text { (LINAC) } \\
\end{array}$} \\
\hline $\begin{array}{c}\text { Energia } \\
(\mathrm{MeV})\end{array}$ & $\mathrm{R}_{50}(\mathrm{~cm})$ & $K_{Q, Q_{0}}$ \\
\hline 6 & 2,45 & 0,95 \\
\hline 9 & 3,62 & 0,93 \\
\hline 12 & 5,08 & 0,92 \\
\hline 16 & 8,10 & 0,90 \\
\hline \multicolumn{3}{|c|}{$\begin{array}{l}\text { Estado de São Paulo } \\
\text { Acelerador linear Elekta Synergy }\end{array}$} \\
\hline 4 & 1,75 & 0,96 \\
\hline 6 & 2,55 & 0,95 \\
\hline 9 & 3,57 & 0,93 \\
\hline 12 & 4,84 & 0,92 \\
\hline 15 & 6,11 & 0,91 \\
\hline \multicolumn{3}{|c|}{$\begin{array}{l}\text { Instituto de Radiologia } \\
\text { do Hospital das Clínicas } \\
\text { Acelerador linear } \\
\text { Varian } 2100 \text { (LINAC) }\end{array}$} \\
\hline 6 & 2,11 & 0,95 \\
\hline 9 & 3,32 & 0,94 \\
\hline 12 & 4,80 & 0,92 \\
\hline 15 & 6,23 & 0,91 \\
\hline
\end{tabular}

\subsection{Sistemas de medição e auxiliares}

Foram utilizados os eletrômetros da PTW, modelo UNIDOS E, pertencentes ao IPEN e ao ICESP; o eletrômetro da Keithley, modelo 35617EBS, pertencente ao Hospital Albert Einstein; e o eletrômetro da Scanditronix, modelo Dose 1, pertencente ao InRad. Os eletrômetros podem ser observados na Figura 5.7. 


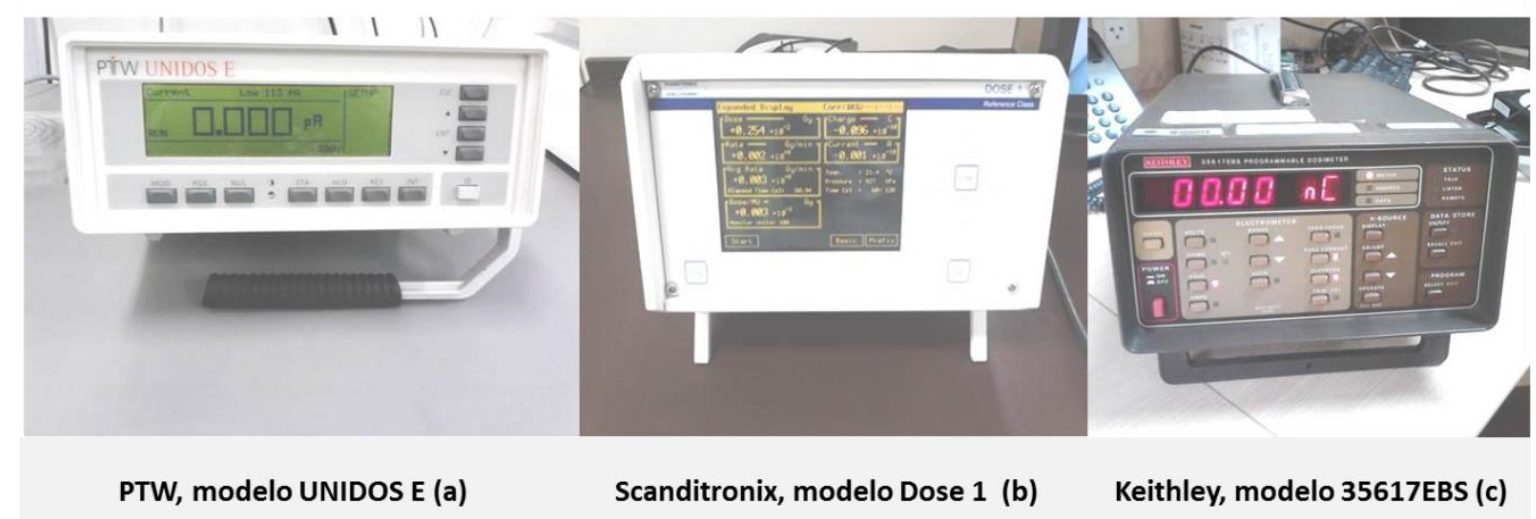

Figura 5.7 Eletrômetros utilizados do LCI/IPEN e ICESP (a), do InRad (b) e do Hospital Albert Einstein (c)

Foi ainda utilizado um suporte para a fonte de controle, uma mesa pequena para se posicionar a câmara de ionização para realização das medições e um suporte para a câmara de ionização utilizada nos irradiadores beta e gama. Esses materiais foram confeccionados neste trabalho e estão apresentados na Figura 5.8.

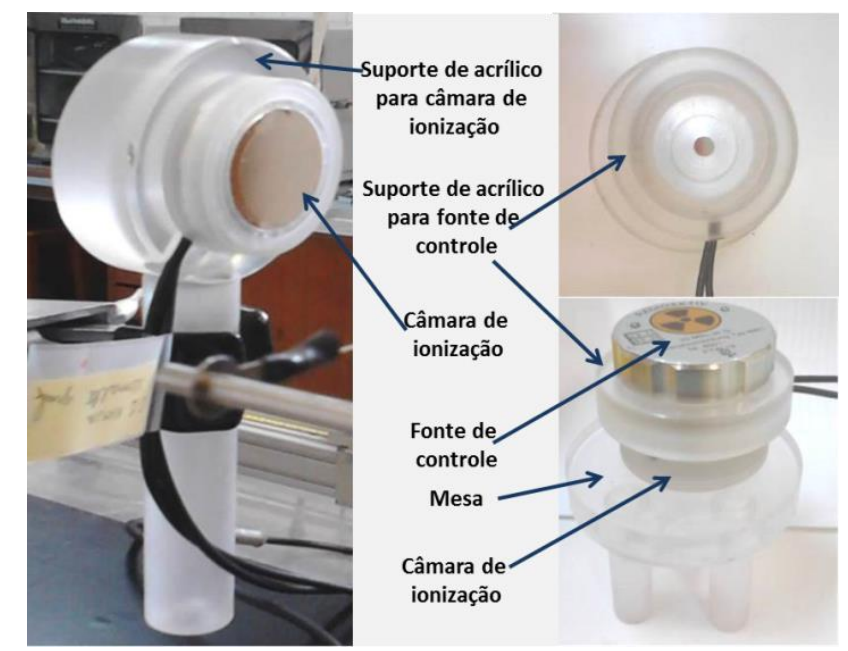

Figura 5.8 Materiais em acrílico para auxílio nas medições com a câmara de ionização

Foi confeccionado um suporte de placas de acrílico para as câmaras de ionização utilizadas em feixes de elétrons dos aceleradores lineares, com área de $30 \times 30 \mathrm{~cm}^{2}$. Foi utilizado um goniômetro de acrílico do Laboratório de Calibração de Instrumentos do IPEN. Este goniômetro é constituído de duas peças de acrílico, de forma que a peça 
circular gire sobre a peça retangular, em ângulos de $45^{\circ}$, do $0^{0}$ ao $360^{\circ}$. O suporte de placas de acrílico e o goniômetro estão apresentados na Figura 5.9.

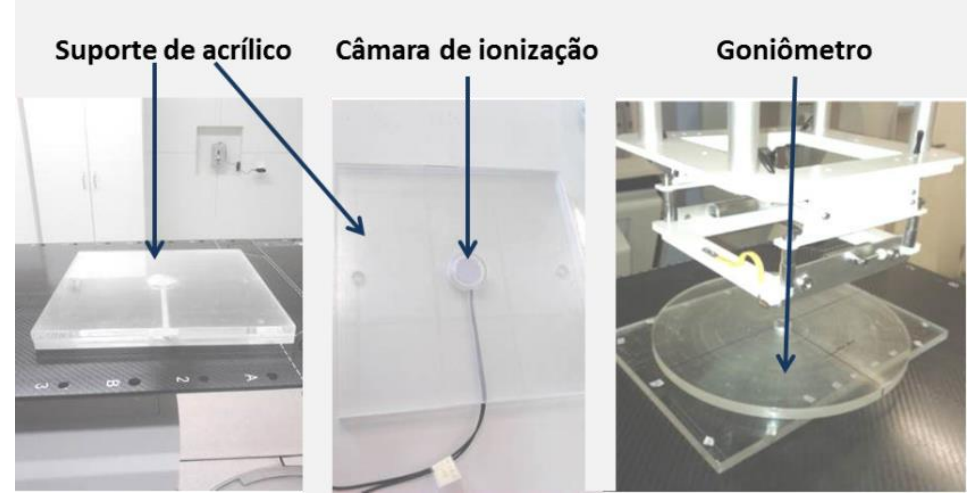

Figura 5.9 Suporte de acrílico, câmara de ionização e goniômetro do LCI

Os objetos simuladores de placas de água sólida com área de $30 \times 30 \mathrm{~cm}^{2}$ do Hospital Albert Einstein e ICESP estão apresentados na Figura 5.10.

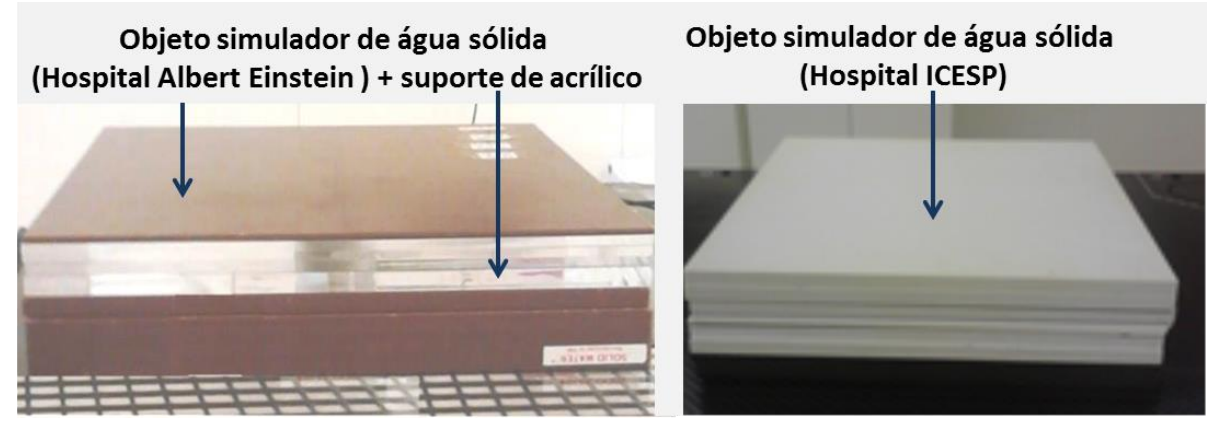

Figura 5.10 Objetos simuladores de água sólida, pertencentes ao Hospital Albert Einstein e ao ICESP

Os objetos simuladores de água sólida foram utilizados nas medições com as câmaras de ionização dentro da água e podem ser observados na Figura 5.11. 


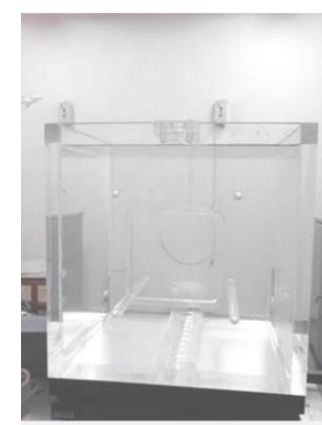

LCI/IPEN

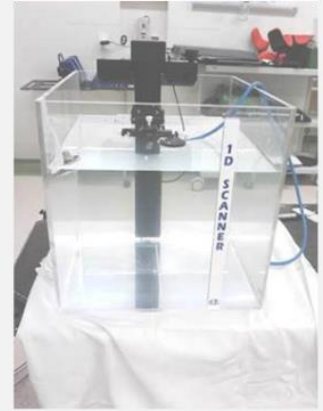

ICESP

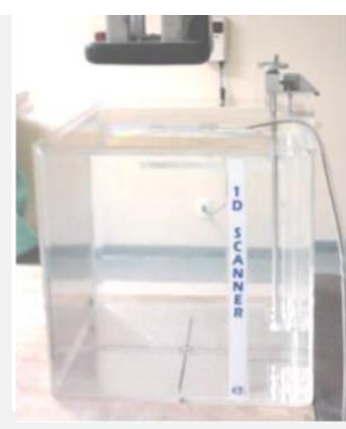

InRad

Figura 5.11 Objetos simuladores pertencentes ao LCI, com dimensões de $30 \mathrm{~cm} \times 30 \mathrm{~cm}$; ao ICESP, com posicionador automático, e ao InRad com posicionador manual, ambos com dimensões de $35 \mathrm{~cm} \times 39 \mathrm{~cm}$

Foi confeccionada uma capa de equilíbrio eletrônico de PMMA com espessura de $4 \mathrm{~mm}$ para ser utilizada no irradiador gama; além disso, foram utilizados desumificadores, climatizadores, barômetros, termômetros e higrômetros como auxilio na obtenção das medições neste trabalho. 


\section{Resultados: Desenvolvimento das Câmaras de Ionização}

Neste capitulo serão apresentadas as câmaras de ionização desenvolvidas neste trabalho de acordo com as diretrizes estabelecidas por normas internacionais que tratam da dosimetria de feixes de elétrons em aceleradores clínicos utilizando câmaras de ionização de placas paralelas.

De acordo com as normas internacionais (IAEA, 1995; IAEA, 2006), as câmaras de ionização de placas paralelas devem ter os seguintes parâmetros para uso em feixes de elétrons:

- O volume sensível deve variar de $0,05 \mathrm{~cm}^{3}$ a $0,5 \mathrm{~cm}^{3}$;

- A espessura da janela de entrada deve ser igual ou menor que $1 \mathrm{~mm}$;

- A distância entre a janela de entrada e o eletrodo coletor deve ser igual ou menor que $2 \mathrm{~mm}$;

- O diâmetro do eletrodo coletor deve ser igual ou menor que $20 \mathrm{~mm}$;

- A razão entre a largura do anel de guarda e a altura da cavidade da câmara deve ser igual ou menor que 1,5 .

Um esquema de uma câmara de ionização de placas paralelas típica está apresentado na Figura 6.1.

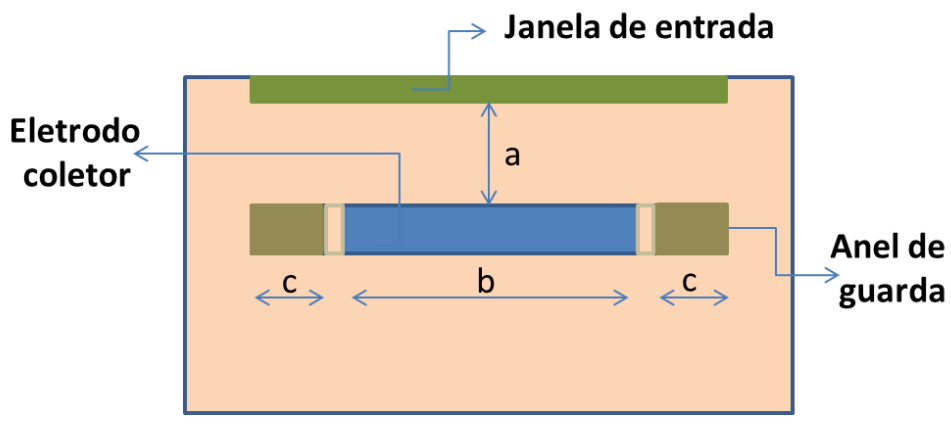

Figura 6.1 Esquema de uma câmara de ionização de placas paralelas para uso em feixes de elétrons. Distância entre a janela de entrada e o eletrodo coletor (a); diâmetro do eletrodo coletor (b); largura do anel de guarda (c) 
Cinco câmaras de ionização foram projetadas e desenvolvidas, para serem testadas em feixes de elétrons de aceleradores lineares.

Todas as câmaras de ionização desenvolvidas neste trabalho apresentam estruturas muito semelhantes. As especificações técnicas estão apresentadas na Figura 6.2. Todas apresentam o corpo constituído de acrílico (Polimetil-metacrilato, PMMA), com variações quanto às superfícies dos eletrodos coletores e dos anéis de guarda, que foram pintados com materiais diferentes, e o diâmetro dos eletrodos coletores, além do material da janela de entrada de uma das câmaras de ionização. Os parâmetros das câmaras de ionização desenvolvidas neste trabalho estão representados por a, b e c na Figura 6.2.

Foram projetadas 11 peças para cada câmara de ionização, que se encaixam uma na outra e estão enumeradas de 1 a 11 e apresentadas na Figura 6.3, representando as quatro primeiras câmaras de ionização desenvolvidas: C1, C2, C3 e C4, e na Figura 6.4 está representada a câmara de ionização C5.

As câmaras de ionização C1 e C2 possuem dimensões iguais e o mesmo ocorre para as câmaras de ionização C3 e C4. Por este motivo foi feito uma divisão, onde a Figura 6.5 apresenta as medições das câmaras de ionização C1 e C2, diferentes das medições das câmaras de ionização $\mathrm{C} 3$ e C4, que estão apresentadas na Figura 6.6. As Figuras 6.5 e 6.6 identificam as peças 1, 2 e 4 apresentadas na Figura 6.3. O restante das outras peças é igual para as quatro câmaras de ionização e estão apresentadas na Figura 6.7.

Os detalhes das peças confeccionadas para a câmara de ionização C5 estão apresentados na Figura 6.8.

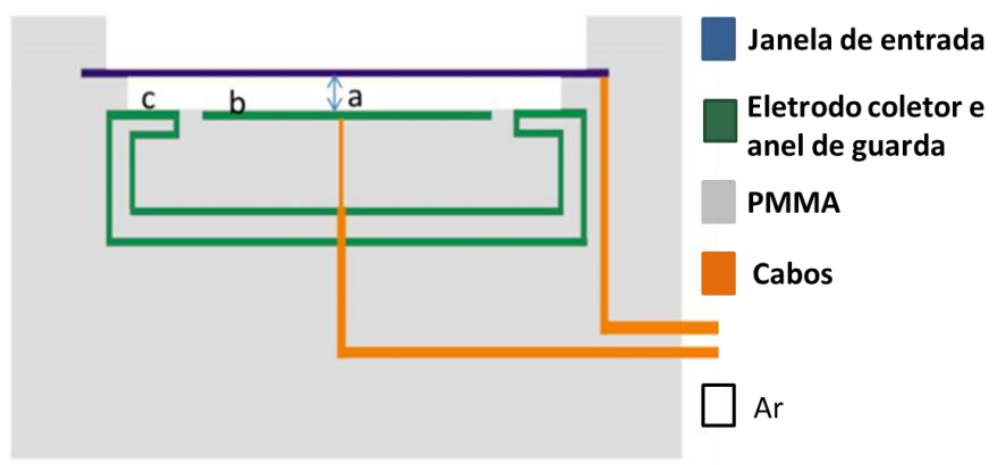

Figura 6.2 Esquema das cinco câmaras de ionização desenvolvidas no IPEN. Distância entre a janela de entrada e o eletrodo coletor (a); diâmetro do eletrodo coletor (b); largura do anel de guarda (c) 


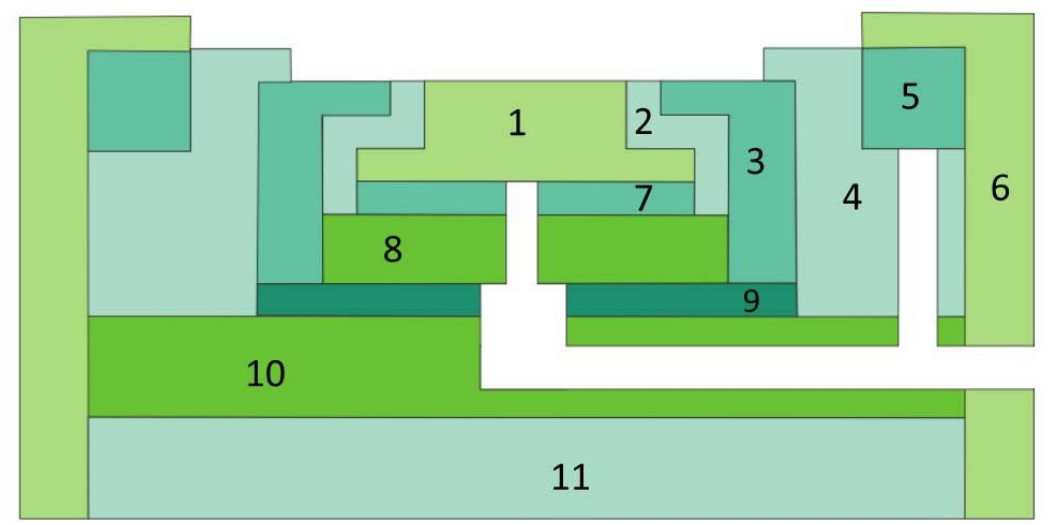

Figura 6.3 Corte transversal detalhado das câmaras de ionização C1, C2, C3 e C4; conjunto de peças de acrílico, enumeradas de 1 a 11 . $O$ detalhamento das peças está nas Figuras 6.5, 6.6 e 6.7

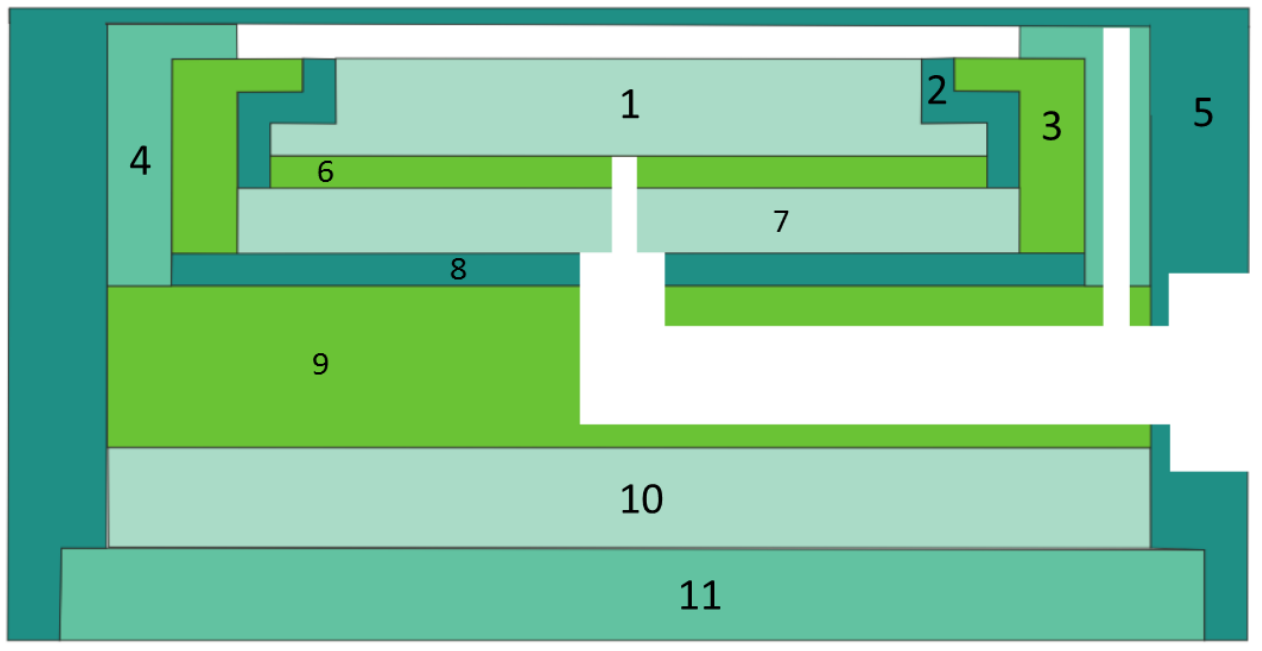

Figura 6.4 Corte transversal detalhado da câmara de ionização C5; conjunto das peças de acrílico, enumeradas de 1 a 11. . O detalhamento das peças está na Figura 6.8 

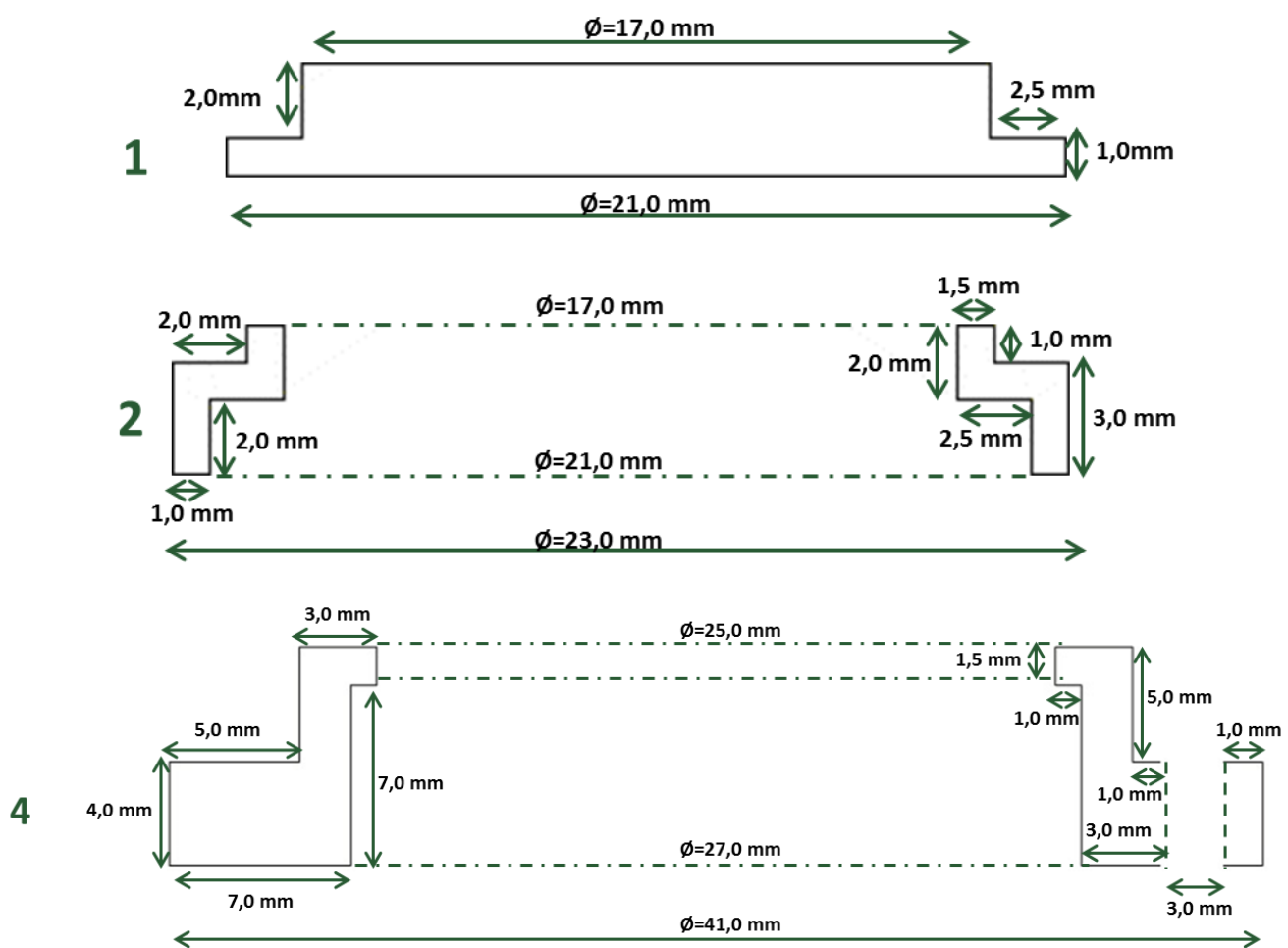

Figura 6.5 Detalhes das peças 1, 2 e 4 das câmaras de ionização C1 e C2
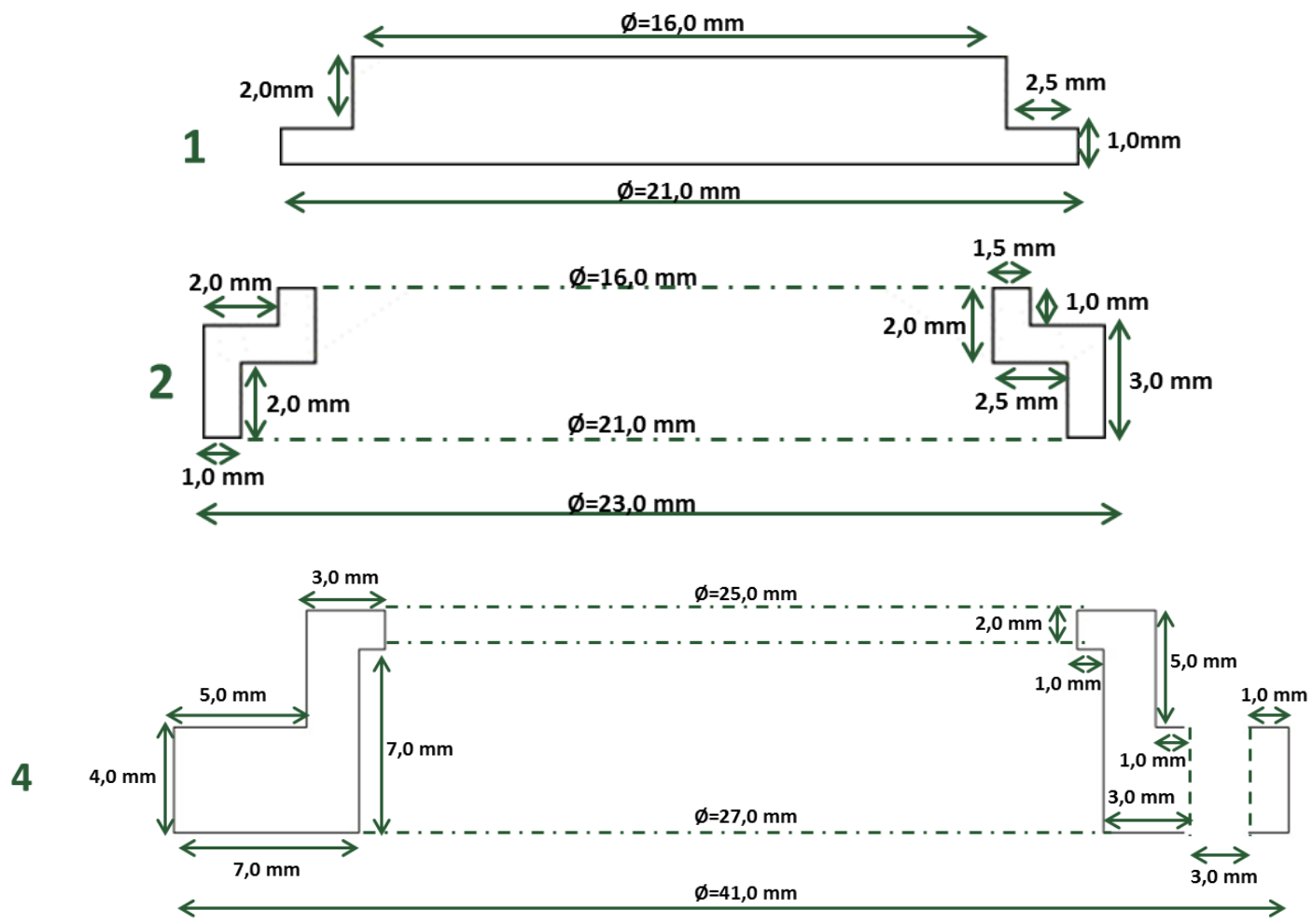

Figura 6.6 Detalhes das peças 1, 2 e 4 das câmaras de ionização C3 e C4 


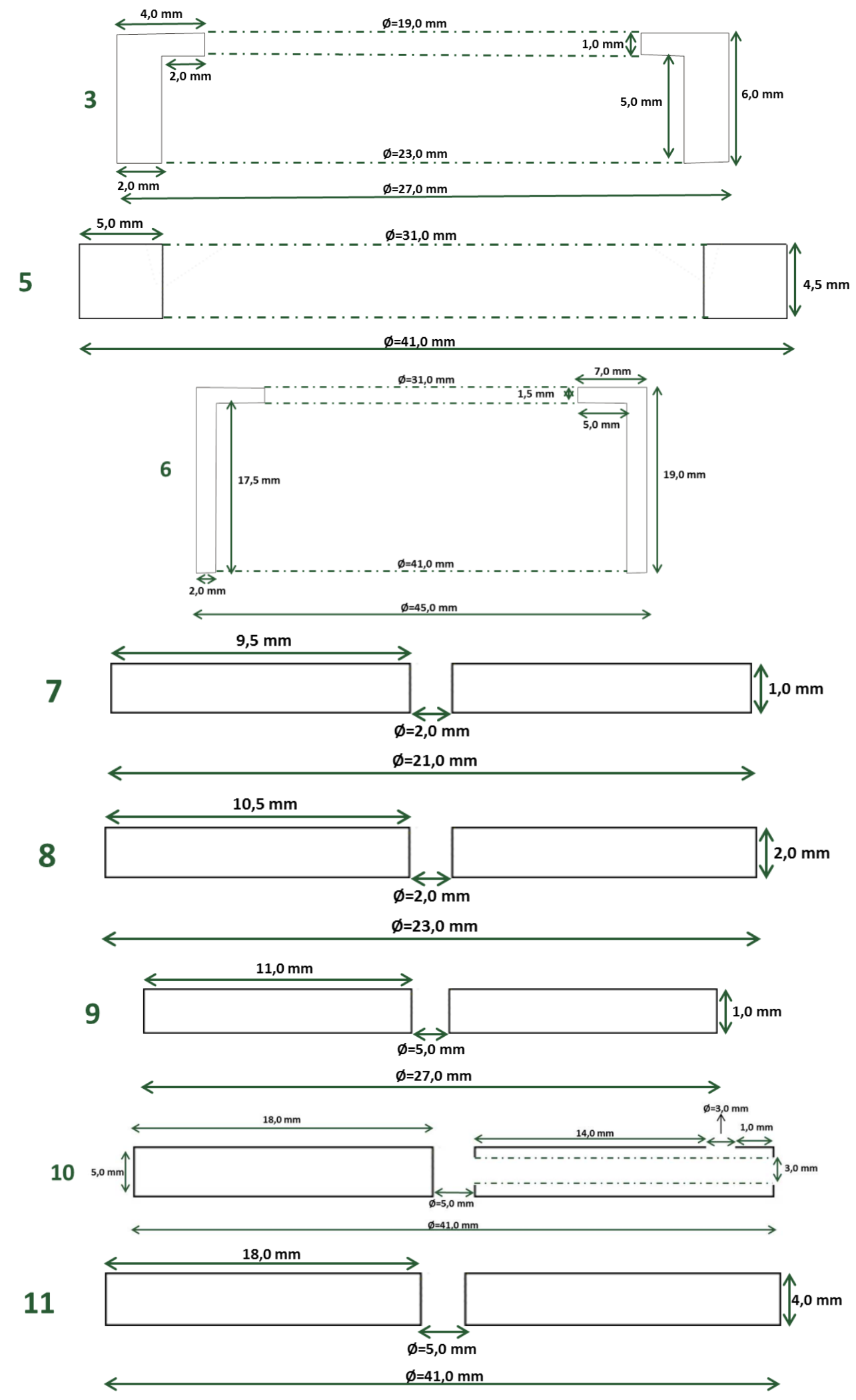

Figura 6.7 Detalhes das peças 3, 5, 6, 7, 8, 9, 10 e 11 das câmaras de ionização $\mathrm{C} 1$, $\mathrm{C2}, \mathrm{C} 3$ e C4 


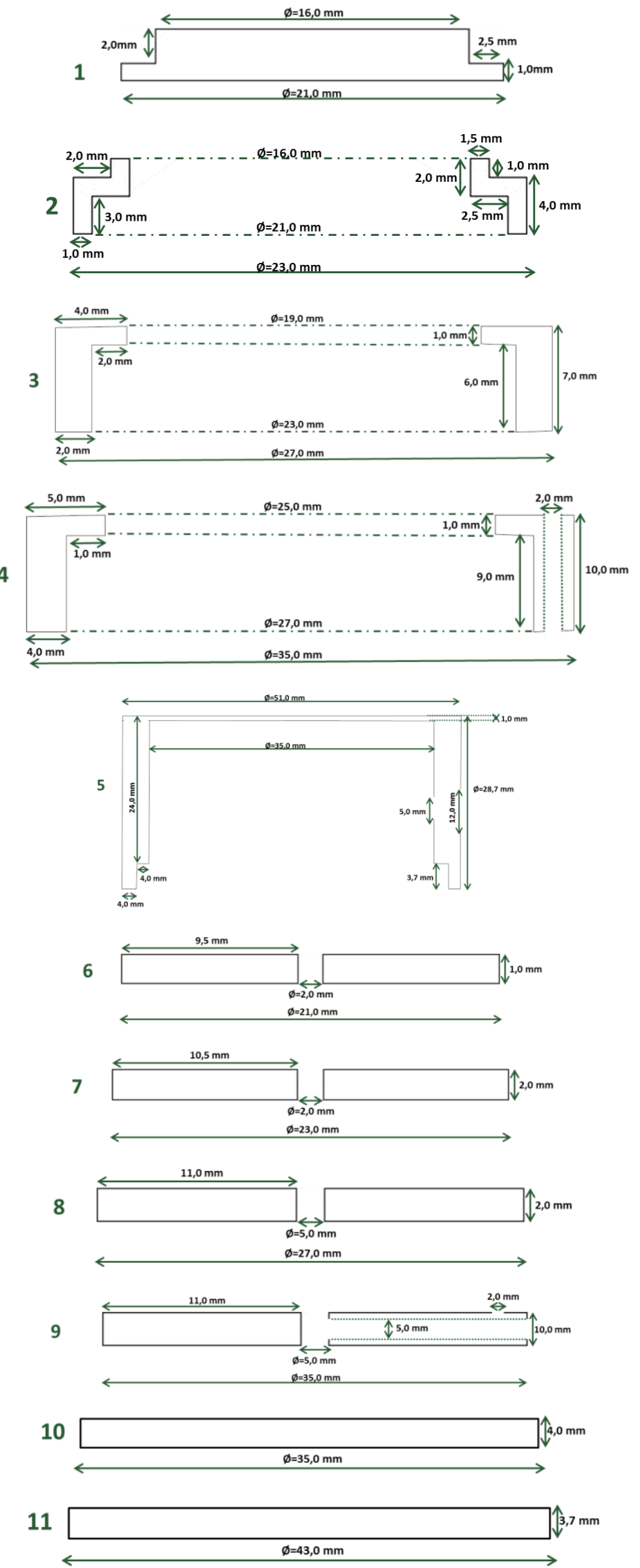

Figura 6.8 Detalhes das 11 peças da câmara de ionização C5 


\subsection{Materiais utilizados na confecção do eletrodo coletor e do anel de guarda das câmaras de ionização}

Os materiais utilizados na confecção do eletrodo coletor e do anel de guarda foram grafite em pó misturado com esmalte de unha (marca Colorama), spray de grafite e tinta de prata; podem ser observados na Figura 6.9. Esses materiais foram aplicados superficialmente no acrílico, de forma cuidadosa para deixar a superfície a mais homogênea possível. A montagem de uma das câmaras de ionização na qual foi utilizada grafite em pó misturado com esmalte de unha na confecção do eletrodo coletor e do anel de guarda pode ser observada na Figura 6.10.

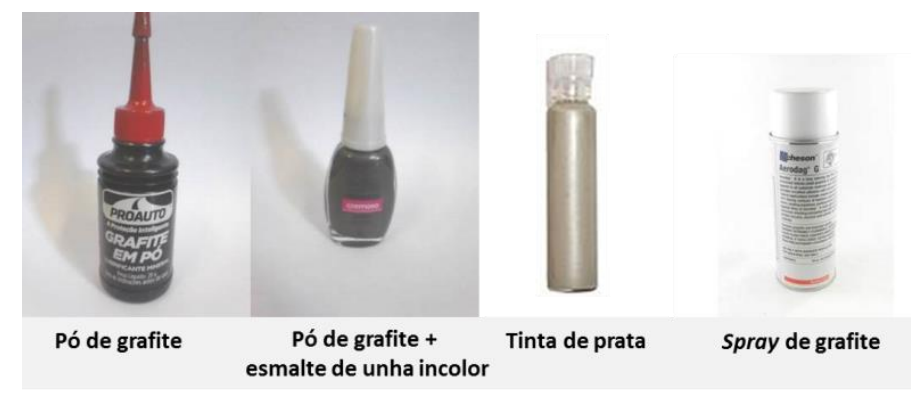

Figura 6.9 Materiais utilizados na confecção do eletrodo coletor e do anel de guarda das câmaras de ionização desenvolvidas

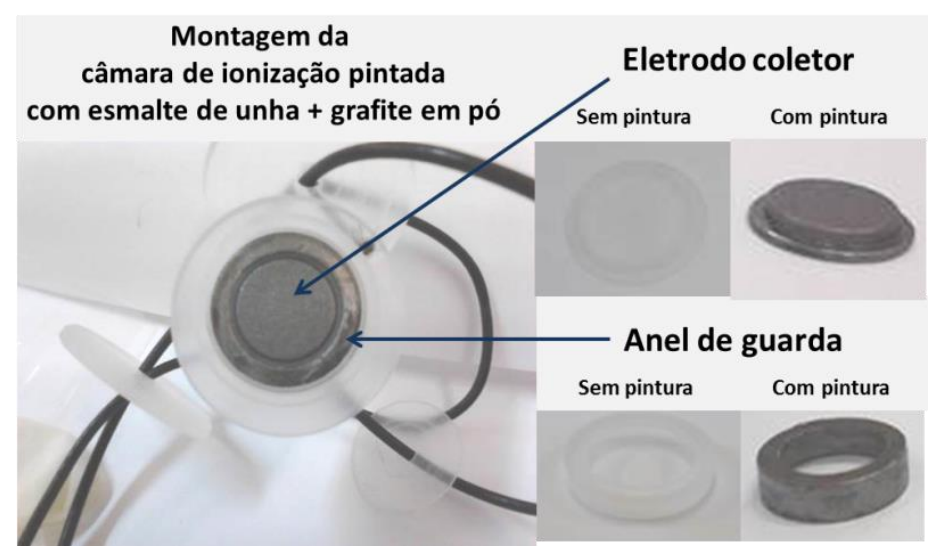

Figura 6.10 Desenvolvimento de uma das câmaras de ionização 


\subsection{Câmara de ionização com eletrodo coletor de grafite: C1}

A primeira câmara de ionização desenvolvida possui eletrodo coletor e anel de guarda pintados superficialmente com uma mistura de esmalte de unha incolor e grafite em pó; sua janela de entrada é de poliéster e alumínio (Mylar) com 1,87 mg.cm ${ }^{-2}$ de densidade superficial. A câmara de ionização C1 apresenta um volume sensível de aproximadamente $0,34 \mathrm{~cm}^{3}$ e possui eletrodo coletor com $17 \mathrm{~mm}$ de diâmetro, anel de guarda com $3 \mathrm{~mm}$ de largura e a distância entre o eletrodo coletor, e janela de entrada de 1,5 mm. O ponto efetivo de medição da câmara de ionização situa-se na janela de entrada de Mylar. A câmara de ionização C1, o eletrodo coletor e o anel de guarda estão apresentados na Figura 6.11.
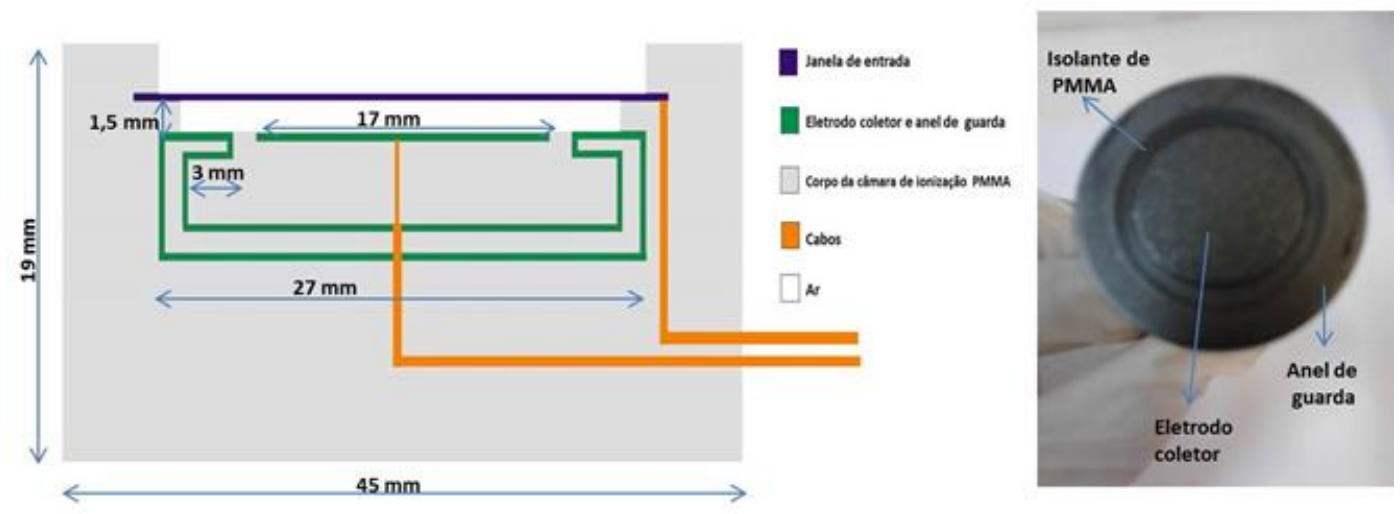

Figura 6.11 Esquema detalhado da câmara de ionização C1, à esquerda; e o anel de guarda e o eletrodo coletor pintados superficialmente com uma mistura de esmalte de unha incolor e grafite em pó, à direita da figura

\subsection{Câmara de ionização com eletrodo coletor de prata: C2}

Para estudar o comportamento da resposta de uma câmara de ionização com eletrodo coletor de material diferente em relação à câmara de ionização $\mathrm{C} 1$, foi projetada e desenvolvida a segunda câmara de ionização C2. Esta câmara de ionização possui eletrodo coletor e anel de guarda pintados superficialmente com uma tinta de prata. O ponto efetivo de medição da câmara de ionização situa-se na janela de entrada, que é de poliéster e alumínio (Mylar) com 1,87 mg. $\mathrm{cm}^{-2}$ de densidade superficial. A câmara de ionização C2 apresenta um volume sensível de aproximadamente $0,34 \mathrm{~cm}^{3} \mathrm{e}$ 
possui eletrodo coletor com $17 \mathrm{~mm}$ de diâmetro, anel de guarda com $3 \mathrm{~mm}$ de largura, e distância entre o eletrodo coletor e a janela de entrada de $1,5 \mathrm{~mm}$. A câmara de ionização C2, o eletrodo coletor e o anel de guarda estão apresentados na Figura 6.12.

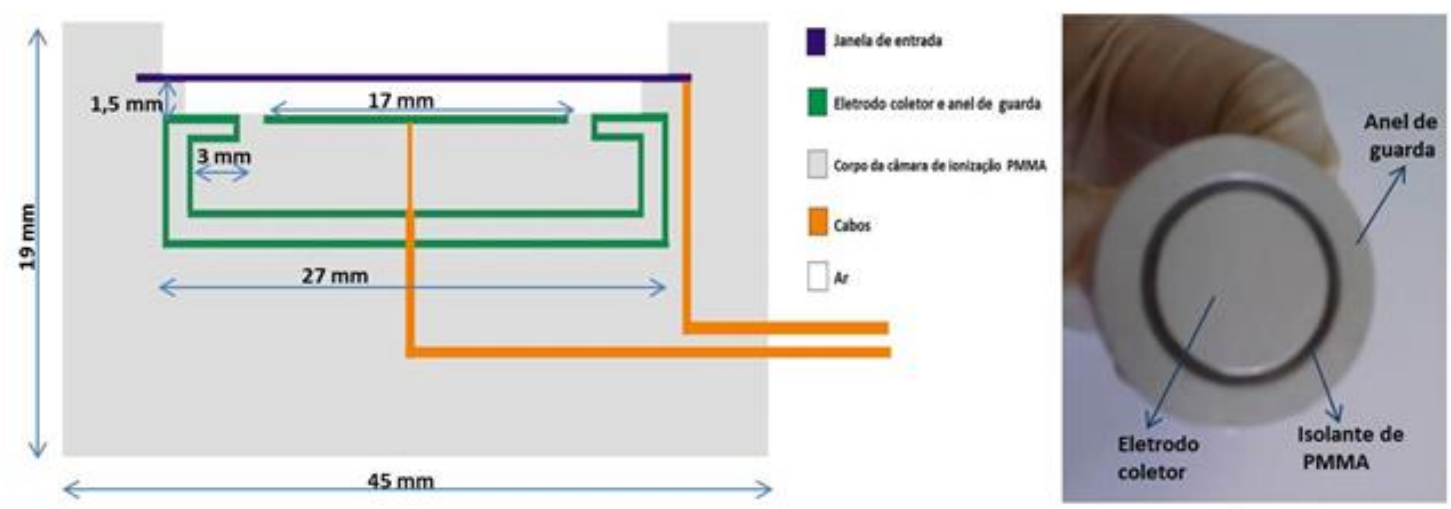

Figura 6.12 Esquema detalhado da câmara de ionização C2, à esquerda; e o anel de guarda e o eletrodo coletor pintados superficialmente com uma tinta de prata, à direita da figura

\subsection{Câmara de ionização com eletrodo coletor de grafite: C3}

Com o objetivo de estudar o comportamento da resposta da câmara de ionização com relação à coleção de cargas, foi construída a seguir uma câmara de ionização com a distância entre a janela de entrada e o eletrodo coletor, e o diâmetro do eletrodo coletor de tamanhos diferentes em relação às câmaras de ionização já construídas C1 e C2. Esta diferença foi mínima, para que o volume sensível da câmara de ionização C3 fosse próxima ao volume sensível das câmaras de ionização já construídas; esta diferença foi de apenas $0,06 \mathrm{~cm}^{3}$. O ponto efetivo de medição da câmara de ionização situa-se na janela de entrada de Mylar. A terceira câmara de ionização C3 possui eletrodo coletor e anel de guarda pintados superficialmente com uma mistura de esmalte incolor de unha e grafite em pó; e sua janela de entrada é de poliéster com alumínio (Mylar) com $1,87 \mathrm{mg} . \mathrm{cm}^{-2}$ de densidade superficial. A câmara de ionização C3 apresenta um volume sensível de aproximadamente $0,40 \mathrm{~cm}^{3}$ e possui eletrodo coletor com $16 \mathrm{~mm}$ de diâmetro, anel de guarda com $3 \mathrm{~mm}$ de largura e a distância entre o eletrodo coletor e a janela de entrada de $2 \mathrm{~mm}$. A câmara de ionização C3, o eletrodo coletor e o anel de guarda estão apresentados na Figura 6.13. 

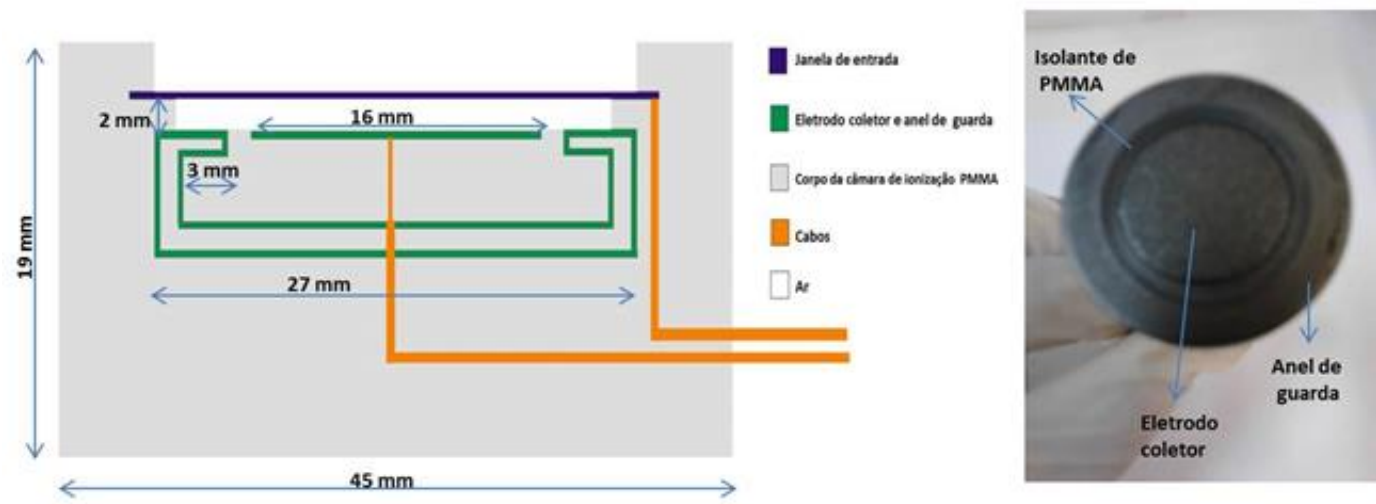

Figura 6.13 Esquema detalhado da câmara de ionização C3, à esquerda; e o anel de guarda e o eletrodo coletor pintados superficialmente com uma mistura de esmalte de unha incolor e grafite em pó, à direita da figura

\subsection{Câmara de ionização com eletrodo coletor de grafite: C4}

Foi projetada e desenvolvida uma câmara de ionização com eletrodo coletor e anel de guarda pintados com spray de grafite para comparar sua resposta com relação ao novo material aplicado nas câmaras de ionização C1 e C3. O spray de grafite é um material já muito utilizado em câmaras de ionização desenvolvidas pelo grupo do IPEN. A quarta câmara de ionização C4 possui eletrodo coletor e anel de guarda pintados superficialmente com spray de grafite, da marca Acheson; sua janela de entrada é de poliéster e alumínio (Mylar) com 1,87 mg. $\mathrm{cm}^{-2}$ de densidade superficial. A câmara de ionização C4 apresenta um volume sensível aproximadamente de $0,40 \mathrm{~cm}^{3}$ e possui eletrodo coletor com $16 \mathrm{~mm}$ de diâmetro, anel de guarda com $3 \mathrm{~mm}$ de largura e a distância entre o eletrodo coletor e a janela de entrada de $2 \mathrm{~mm}$. O ponto efetivo de medição da câmara de ionização situa-se na janela de entrada de Mylar. A câmara de ionização C4, o eletrodo coletor e o anel de guarda estão apresentados na Figura 6.14. 


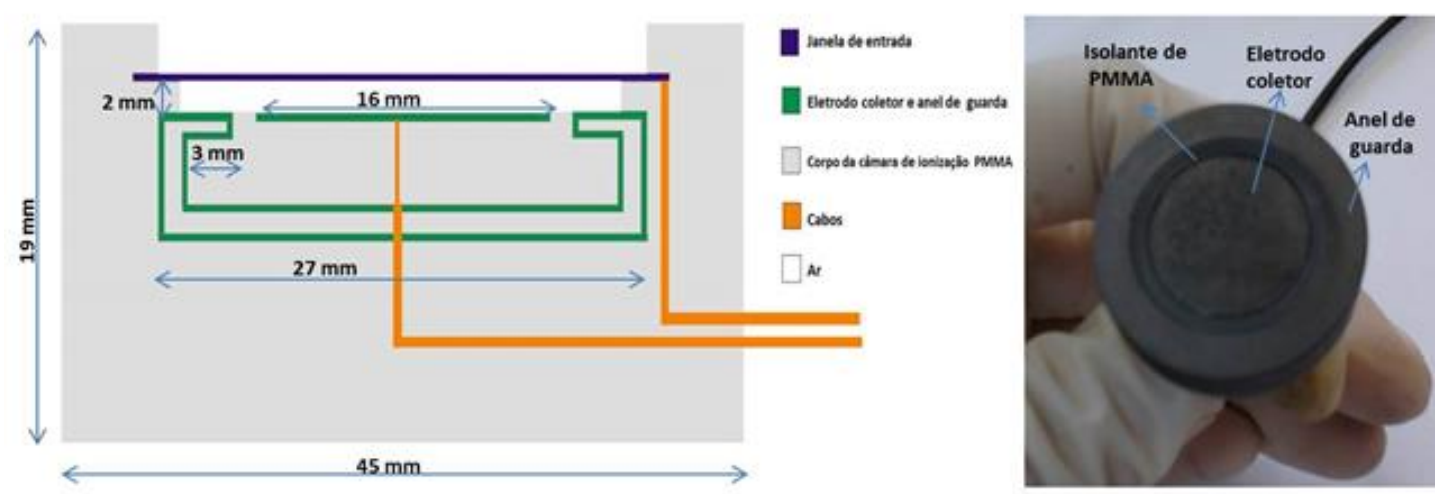

Figura 6.14 Esquema detalhado da câmara de ionização C4, à esquerda; e o anel de guarda e o eletrodo coletor pintados superficialmente com spray de grafite, à direita da figura

\subsection{Câmara de ionização à prova d'água, com eletrodo coletor de grafite: C5}

Câmaras de ionização à prova d'água vêm substituindo as câmaras de ionização mais antigas na dosimetria de feixes em aceleradores lineares em muitos hospitais do Brasil. Surgiu, portanto, a ideia se construir uma câmara de ionização à prova d'água.

A primeira tentativa foi construir uma câmara de ionização com rosca utilizando anel de borracha (o-ring) como sistema de vedação de água. Entretanto, o projeto não deu certo e a câmara de ionização não vedou a água. Esta câmara de ionização pode ser observada na Figura 6.15.

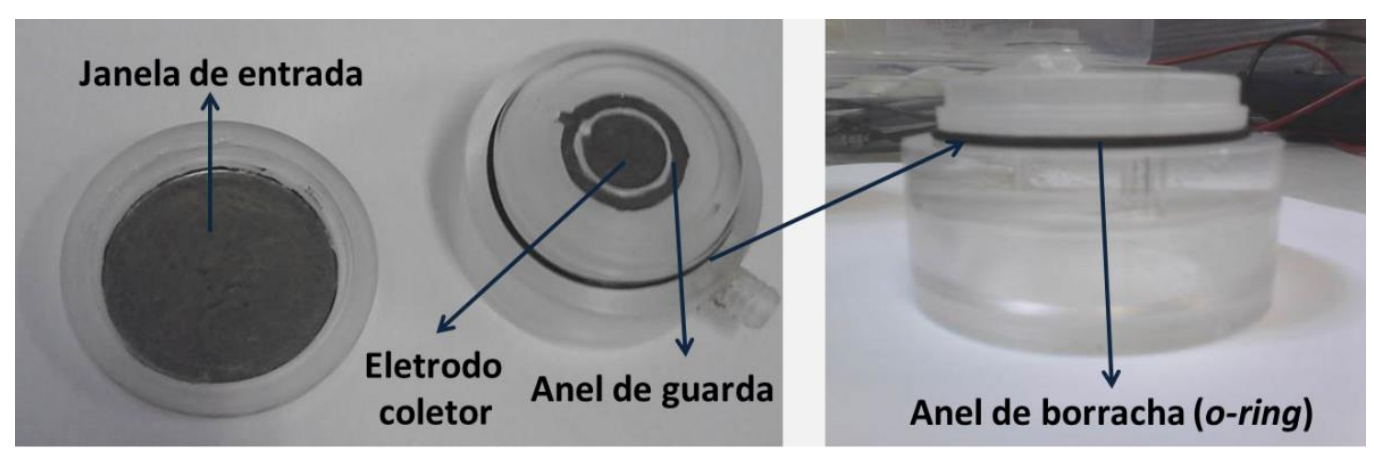

Figura 6.15 Primeira tentativa de construção de uma câmara de ionização à prova d'água

Posteriormente, foi projetada uma câmara de ionização à prova d’água com vedação de cola de acrílico entre as peças de acrílico; este projeto deu certo. Foi 
colocada uma mangueira de silicone para proteger os cabos; para isto, foi construído um adaptador na câmara de ionização para conectar a mangueira de silicone à câmara de ionização. Além disso, a janela de entrada também é de acrílico, para a vedação. A distância entre a janela de entrada e do eletrodo coletor ficou em $1 \mathrm{~mm}$ devido à dificuldade que os elétrons teriam em atravessar o acrílico e por apresentarem alcance curto, o que acarretou a diminuição do volume sensível da câmara de ionização quando comparada com as outras câmaras de ionização desenvolvidas. A quinta câmara de ionização C5 possui eletrodo coletor e anel de guarda pintados superficialmente com uma mistura de esmalte incolor de unha e grafite em pó; sua janela de entrada é de PMMA, com espessura de $1 \mathrm{~mm}$, sendo que o ponto efetivo de medição da câmara de ionização está situado logo abaixo do $1 \mathrm{~mm}$ de acrílico da janela de entrada. A câmara de ionização C5 apresenta um volume sensível de aproximadamente $0,20 \mathrm{~cm}^{3}$ e possui eletrodo coletor com $16 \mathrm{~mm}$ de diâmetro, anel de guarda com $3 \mathrm{~mm}$ de largura e a distância entre o eletrodo coletor e a janela de entrada de $1 \mathrm{~mm}$. A câmara de ionização C5, o eletrodo coletor e o anel de guarda estão apresentados na Figura 6.16.

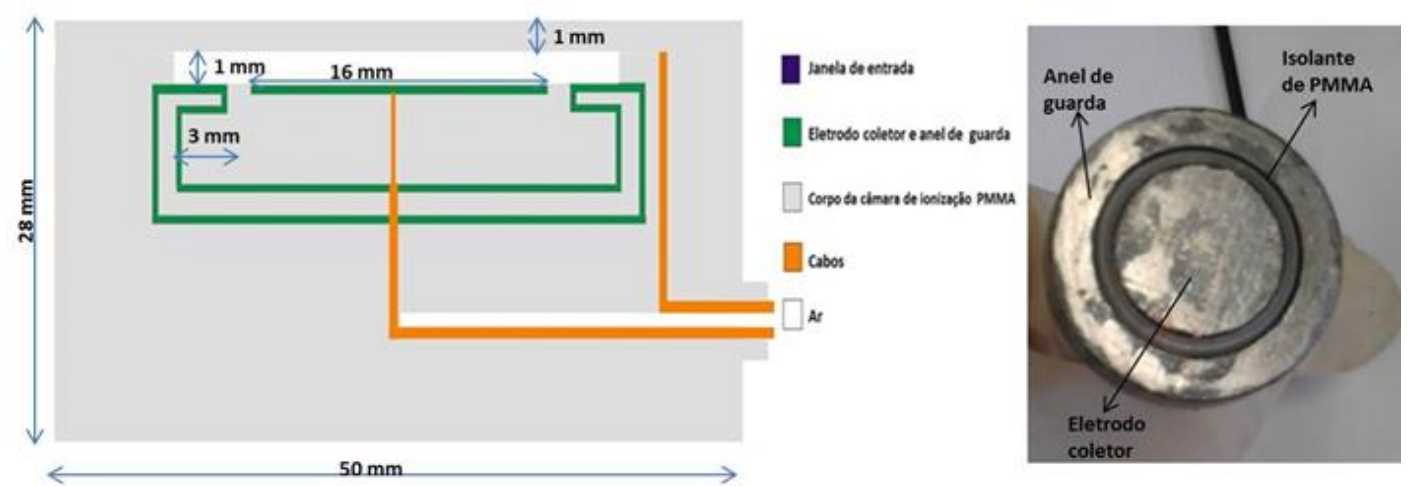

Figura 6.16 Esquema detalhado da câmara de ionização C5, à esquerda; e o anel de guarda e o eletrodo coletor pintados superficialmente com uma mistura de esmalte de unha incolor e grafite em pó, à direita da figura

O modelo exterior das câmaras de ionização C1, C2, C3 e C4 foi o mesmo para as quatro câmaras de ionização e pode ser observado na Figura 6.17. A câmara de ionização à prova d'água apresenta um modelo diferente e está apresentado na Figura 6.18. 

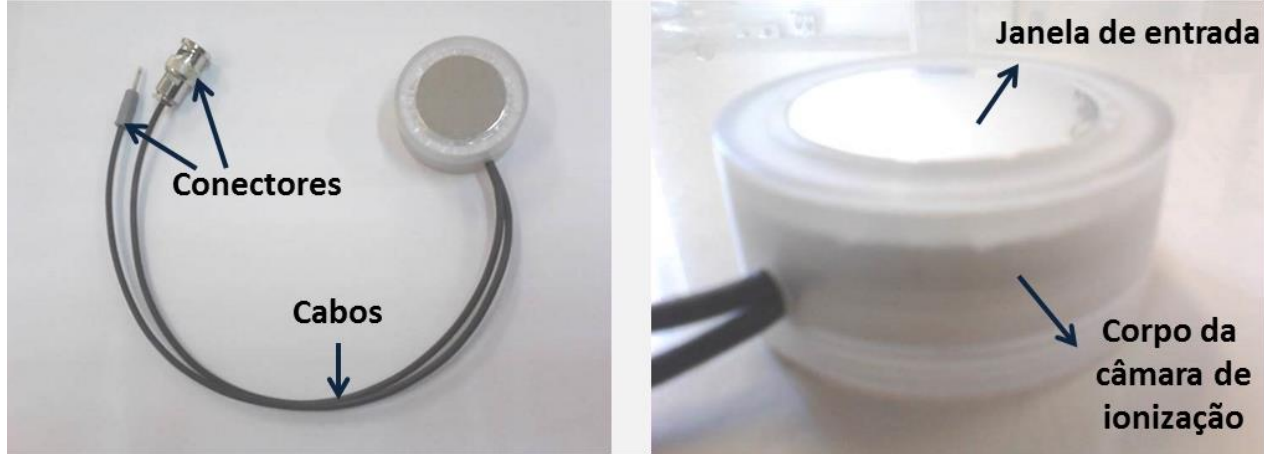

Figura 6.17 Câmara de ionização C1; as câmaras de ionização C2, C3 e C4 são similares externamente

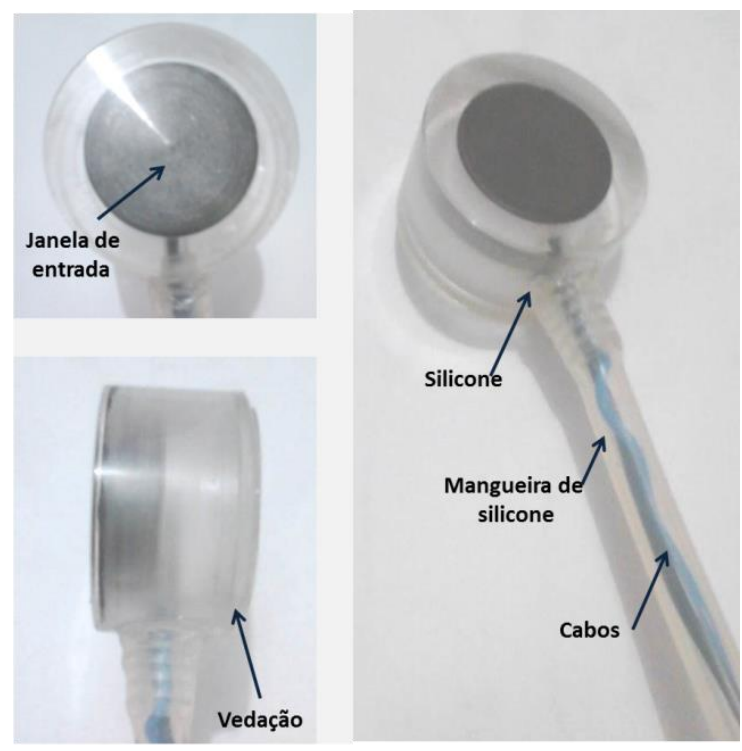

Figura 6.18 Câmara de ionização C5 


\section{Resultados: Caracterização das Câmaras de Ionização C1 a C5}

Neste capítulo serão apresentados os resultados dos testes de caracterização realizados no laboratório do IPEN e os testes realizados em clínicas de radioterapia na cidade de São Paulo para as cinco câmaras de ionização C1, C2, C3, C4 e C5. Este capítulo foi dividido em três partes: o item 7.1 apresenta os testes realizados com as câmaras C1 a C4; o item 7.2 apresenta os testes realizados com a câmara C5 que foi submetida aos mesmos testes das câmaras de ionização anteriores, mas em diferentes condições; por esta razão esta divisão ocorreu. Posteriormente, o item 7.3 apresenta as comparações realizadas entre as cinco câmaras de ionização. Todas as medições foram corrigidas para as condições de referência de temperatura e pressão (IAEA, 2006), e as incertezas foram estimadas de acordo com a norma ISO (ABNT, 2003).

\subsection{Caracterização das câmaras de ionização C1 a C4}

Neste item serão apresentados os testes realizados no Laboratório de Calibração de Instrumentos do IPEN e nos Hospitais Albert Einstein e ICESP.

\subsubsection{Testes de caracterização realizados no Laboratório de Calibração de Instrumentos do IPEN}

A seguir serão apresentados os testes de caracterização das quatro câmaras de ionização de $\mathrm{C} 1$ a $\mathrm{C} 4$ realizados com fontes de radiação gama e beta disponibilizadas no Laboratório de Calibração de Instrumentos do IPEN.

\subsubsection{Tempo de estabilização}

O teste do tempo de estabilização foi realizado utilizando-se a fonte de radiação gama de ${ }^{60} \mathrm{Co}$ (Siemens / Gammatron II S80). Após a aplicação de uma tensão de + $300 \mathrm{~V}$ às câmaras de ionização, foram obtidas três medições em 15 minutos, 1 hora e 2 horas mantendo o irradiador gama exposto continuamente, para cada câmara de ionização. A distância de cada câmara de ionização em relação à fonte de ${ }^{60} \mathrm{Co}$ foi de $100 \mathrm{~cm}$. Os resultados foram obtidos medindo-se a resposta das câmaras de ionização 
em carga e estão apresentados na Tabela 7.1. Para este teste foi utilizada uma capa de equilíbrio eletrônico com espessura de $4 \mathrm{~mm}$. Esta capa foi construída especificamente para a realização deste teste e funcionou de forma eficaz para as medições.

Tabela 7.1 Tempo de estabilização das câmaras de ionização em feixes de radiação gama. Incerteza máxima dos dados: menor que $0,37 \%$.

A:Variação da medição realizada entre 15 min e 1 h;

B: Variação da medição realizada entre 1 h e 2 h

\begin{tabular}{ccc}
\hline Câmara de ionização & $\mathbf{A}(\boldsymbol{\%})$ & $\mathbf{B}(\boldsymbol{\%})$ \\
\hline C1 & 1,46 & 0,36 \\
C2 & 0,68 & 0,39 \\
C3 & 0,38 & 0,25 \\
C4 & 0,40 & 0,10 \\
\hline
\end{tabular}

De acordo com a norma IEC 60731 (2011), as medições realizadas após 15 min e $2 \mathrm{~h}$, quando comparadas com as medições realizadas após 1h, não devem apresentar uma variação maior que $0,5 \%$. As câmaras de ionização C1 e C2 apresentaram uma variação maior que $0,5 \%$ quando suas medições foram obtidas após $15 \mathrm{~min}$ de polarização em relação às medições obtidas em 1 h; nesta situação, as câmaras C1 e C2 necessitam de um intervalo de tempo maior que $15 \mathrm{~min}$ para atingirem a estabilidade. $\mathrm{O}$ tempo de estabilização escolhido para todas as câmaras de ionização foi de 30 min para se garantir a estabilidade de resposta das câmaras de ionização.

\subsubsection{Repetibilidade da resposta}

$\mathrm{Na}$ avaliação da estabilidade da resposta a curto prazo foram realizadas 10 medições consecutivas para cada polaridade da tensão de $300 \mathrm{~V}$, utilizando-se a fonte de controle de ${ }^{90} \mathrm{Sr}+{ }^{90} \mathrm{Y}$; cada medição levou 30 s. O desvio padrão das 10 medições realizadas para cada polaridade de tensão não deve ser maior do que 0,5\% (IEC, 2011). Os resultados estão dentro do requisito da norma. Foram realizados nove testes de estabilidade a curto prazo; o maior desvio padrão $(\sigma)$ obtido para cada câmara de ionização está apresentado na Tabela 7.2. 
Tabela 7.2 Estudo da repetibilidade da resposta das câmaras de ionização

\begin{tabular}{cc}
\hline Câmara de ionização & Desvio padrão máximo (\%) \\
\hline C1 & 0,04 \\
C2 & 0,02 \\
C3 & 0,02 \\
C4 & 0,02 \\
\hline
\end{tabular}

De acordo com a norma IEC 60731 (2011) todas as câmaras de ionização atendem a um valor menor que $0,5 \%$ para o teste de repetibilidade ou estabilidade a curto prazo da resposta.

\subsubsection{Estabilidade a médio prazo}

O teste de estabilidade a médio prazo considera os resultados dos testes de estabilidade a curto prazo ao longo do tempo. Neste teste, as quatro câmaras de ionização $\mathrm{C} 1, \mathrm{C} 2, \mathrm{C} 3$ e C4 foram expostas à fonte de controle de ${ }^{90} \mathrm{Sr}+{ }^{90} \mathrm{Y}$. Cada câmara de ionização foi polarizada com uma tensão de $\pm 300 \mathrm{~V}$. Para cada polaridade de tensão foram obtidas 10 medições, sendo que cada medição levou $30 \mathrm{~s}$ para se coletar a carga. Posteriormente foram obtidos valores médios dessas 10 medições, totalizando 9 valores médios, durante 9 meses. Os valores obtidos normalizados para o valor médio estão apresentados na Figura 7.1 (para as polaridades positiva e negativa juntas) de cada câmara de ionização estudada. 

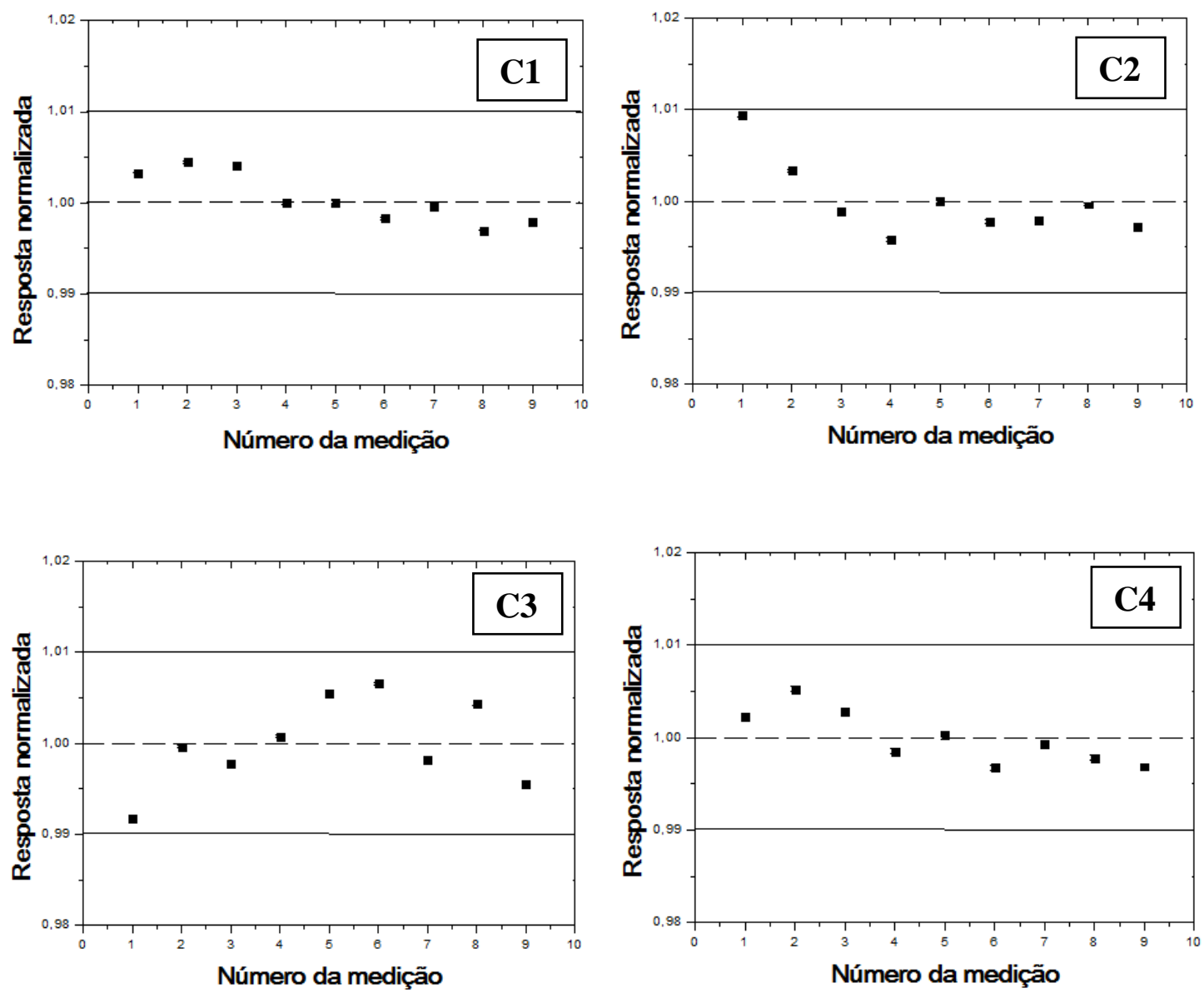

Figura 7.1 Estabilidade a médio prazo das câmaras de ionização C1, C2, C3 e C4. As incertezas foram menores que $0,03 \%$, não sendo visíveis nos gráficos. As linhas tracejadas representam os limites recomendados pela norma IEC 60731 (2011) (LCI/IPEN)

De acordo com a norma IEC 60731 (2011) a resposta das câmaras de ionização atendem a um valor menor que $1 \%$ para o teste de repetibilidade a médio prazo.

\subsubsection{Corrente de fuga}

Para o teste da corrente de fuga, foram coletadas as cargas das câmaras de ionização C1, C2, C3 e C4 durante 20 min sem a presença de uma fonte radioativa. Esta corrente foi comparada com a corrente obtida no teste de estabilidade (utilizando uma fonte de controle). A corrente de fuga para as câmaras C1, C2, C3 e C4 foi respectivamente de $0,03 \%, 0,02 \%, 0,05 \%$ e $0,03 \%$ para a polaridade positiva, e $0,03 \%$, $0,01 \%, 0,05 \%$ e $0,03 \%$ para a polaridade negativa. Os valores obtidos para a corrente de 
fuga das quatro câmaras de ionização estudadas são inferiores ao valor limite recomendado na norma IEC 60731 (2011), no qual a corrente de fuga pode sofrer uma variação de até $0,5 \%$.

\subsubsection{Corrente de saturação e eficiência de coleção de íons}

A corrente de saturação foi obtida variando-se a tensão aplicada a cada câmara de ionização entre $\pm 50 \mathrm{~V}$ a $\pm 400 \mathrm{~V}$ em passos de $\pm 50 \mathrm{~V}$. Para este trabalho, as câmaras de ionização $\mathrm{C} 1, \mathrm{C} 2, \mathrm{C} 3$ e C4 foram expostas à fonte de controle de ${ }^{90} \mathrm{Sr}+{ }^{90} \mathrm{Y}$; para cada valor de tensão foram obtidas 10 medições de $30 \mathrm{~s}$. Os resultados da corrente de saturação das quatro câmaras de ionização estão apresentados na Figura 7.2.

De acordo com a Figura 7.2, a saturação ocorre a partir de $50 \mathrm{~V}$, mas a tensão de polaridade escolhida para cada câmara de ionização foi de $+300 \mathrm{~V}$.

Com esses resultados foi possível obter a eficiência de coleção de íons $\left(\mathrm{k}_{\mathrm{s}}\right)$ para as quatro câmaras de ionização de acordo com a equação:

$$
k_{s}=\frac{\left(\frac{V_{1}}{V_{2}}\right)-1}{\left(\frac{V_{1}}{V_{2}}\right)^{2}-\left(\frac{M_{1}}{M_{2}}\right)}
$$

onde $\mathrm{V}_{1}= \pm 300 \mathrm{~V}, \mathrm{~V}_{1} / \mathrm{V}_{2}=2$ e $\mathrm{M}_{\mathrm{x}}$ é a carga coletada para $\mathrm{V}_{\mathrm{x}},(\mathrm{x}=1$ ou 2).

Os resultados de $\mathrm{k}_{\mathrm{s}}$ estão apresentados na Tabela 7.3. Todas as câmaras de ionização apresentam o valor de $\mathrm{k}_{\mathrm{s}}$ menor do que $1 \%$, atendendo às recomendações da norma IEC 60731 (2011). 

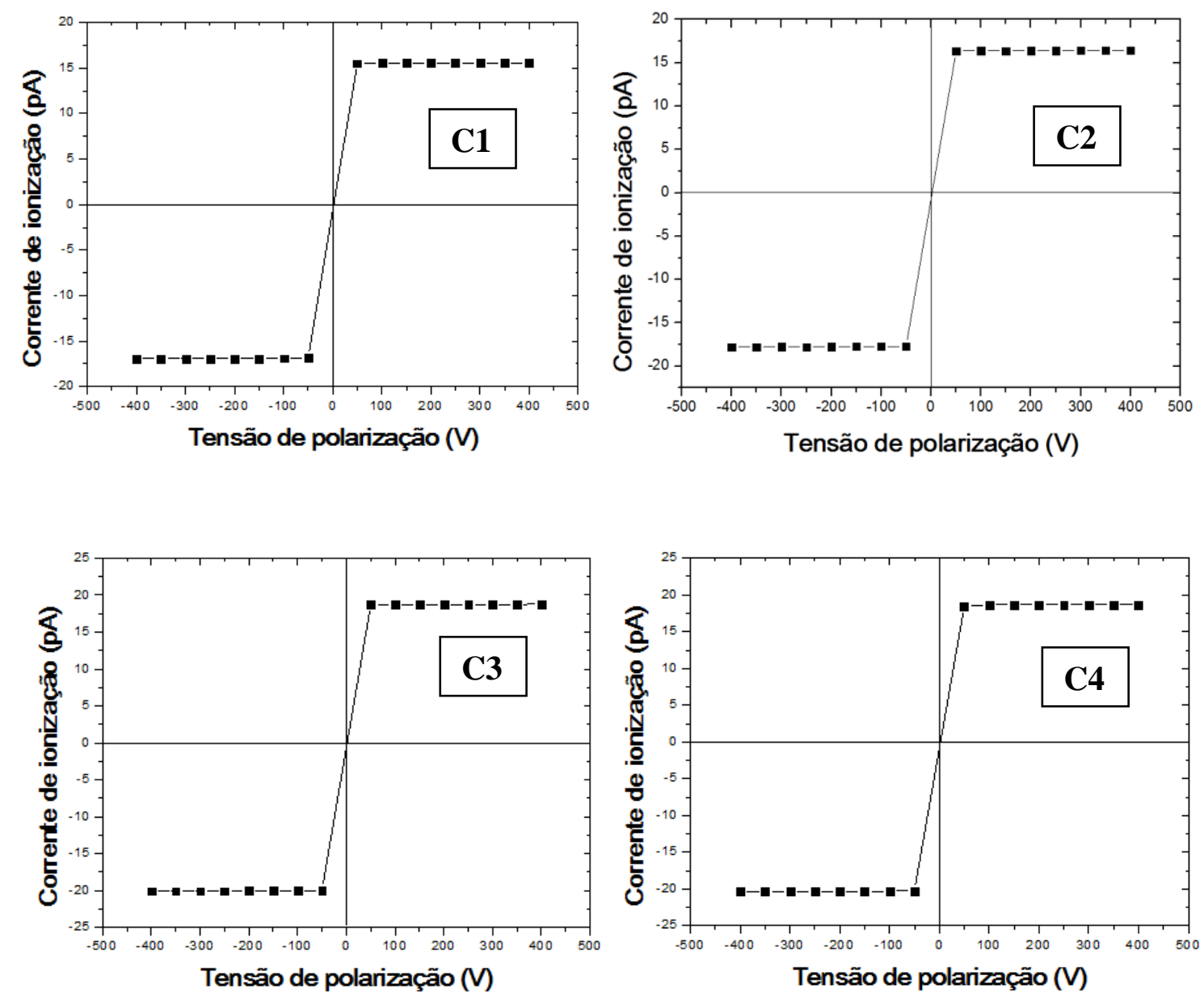

Figura 7.2 Curvas de saturação das câmaras de ionização C1, C2, C3, C4. As incertezas foram menores que $0,03 \%$, não sendo visíveis nos gráficos (LCI/IPEN)

Tabela 7.3 Eficiência de coleção de íons (ks) entre 150 V e 300 V. Todos os resultados apresentam incertezas menores que $0,02 \%$

\begin{tabular}{ccc}
\hline Câmara de ionização & $\mathbf{k}_{\mathbf{s +}}$ & $\mathbf{k}_{\mathbf{s}-}$ \\
\hline $\mathrm{C} 1$ & 1,00038 & 1,00040 \\
$\mathrm{C} 2$ & 1,00130 & 1,00072 \\
$\mathrm{C} 3$ & 1,00080 & 1,00048 \\
$\mathrm{C} 4$ & 1,00046 & 1,00043 \\
\hline
\end{tabular}

\subsubsection{Linearidade de resposta}

O teste da linearidade da resposta das câmaras de ionização desenvolvidas foi realizado obtendo-se 5 medições em diferentes intervalos de tempo : 15, 30, 60, 120 e $240 \mathrm{~s}$, utilizando-se fonte de ${ }^{90} \mathrm{Sr}+{ }^{90} \mathrm{Y}$ do irradiador beta, sem o filtro uniformizador de 
campo. A distância de referência entre a fonte e a câmara de ionização foi de $11 \mathrm{~cm}$. As curvas de linearidade de resposta das câmaras de ionização C1, C2, C3 e C4 em função da dose absorvida estão apresentadas na Figura 7.3.
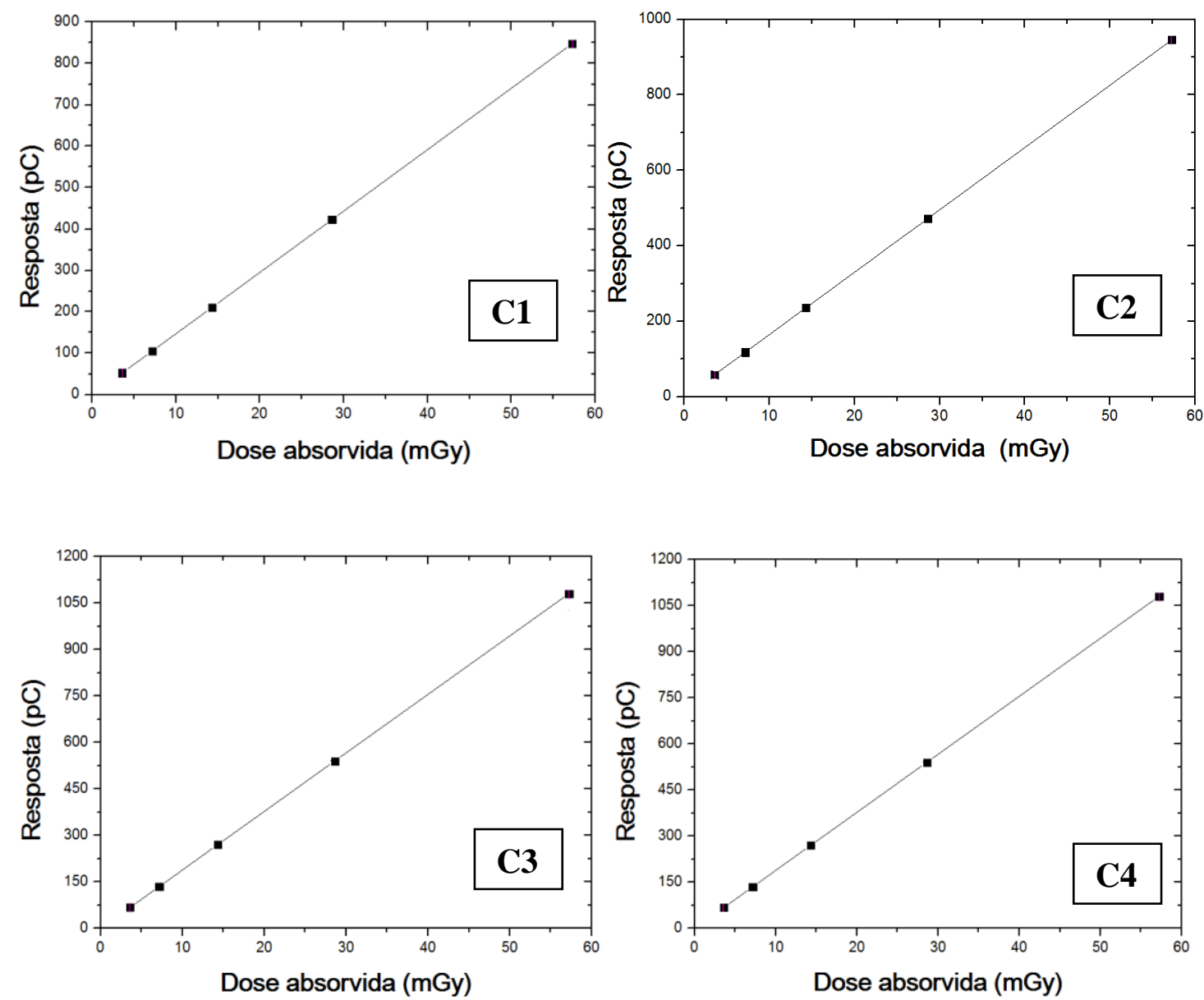

Figura 7.3 Curvas de linearidade da resposta das câmaras de ionização C1, C2, C3 e C4. As incertezas foram menores que $0,17 \%$, não sendo visíveis nos gráficos (LCI/IPEN)

De acordo com a Figura 7.3, todas as câmaras de ionização apresentam um comportamento linear quando expostas ao feixe de radiação em função do tempo de irradiação, apresentando coeficientes de correlação $\mathrm{R}^{2}$ iguais a 1,000 .

\subsubsection{Variação da resposta com a distância fonte-detector}

As câmaras de ionização C1, C2, C3 e C4 foram expostas à fonte de ${ }^{90} \mathrm{Sr}+{ }^{90} \mathrm{Y}$ do irradiador beta à distância de referência de $11 \mathrm{~cm}$ e também às distâncias de 15, 20, $25 \mathrm{e}$ 
$30 \mathrm{~cm}$, sem filtro. Cada medição durou $10 \mathrm{~min}$. Os resultados das respostas medidas das câmaras de ionização e os resultados esperados de acordo com a lei do inverso do quadrado da distância estão apresentados na Figura 7.4.
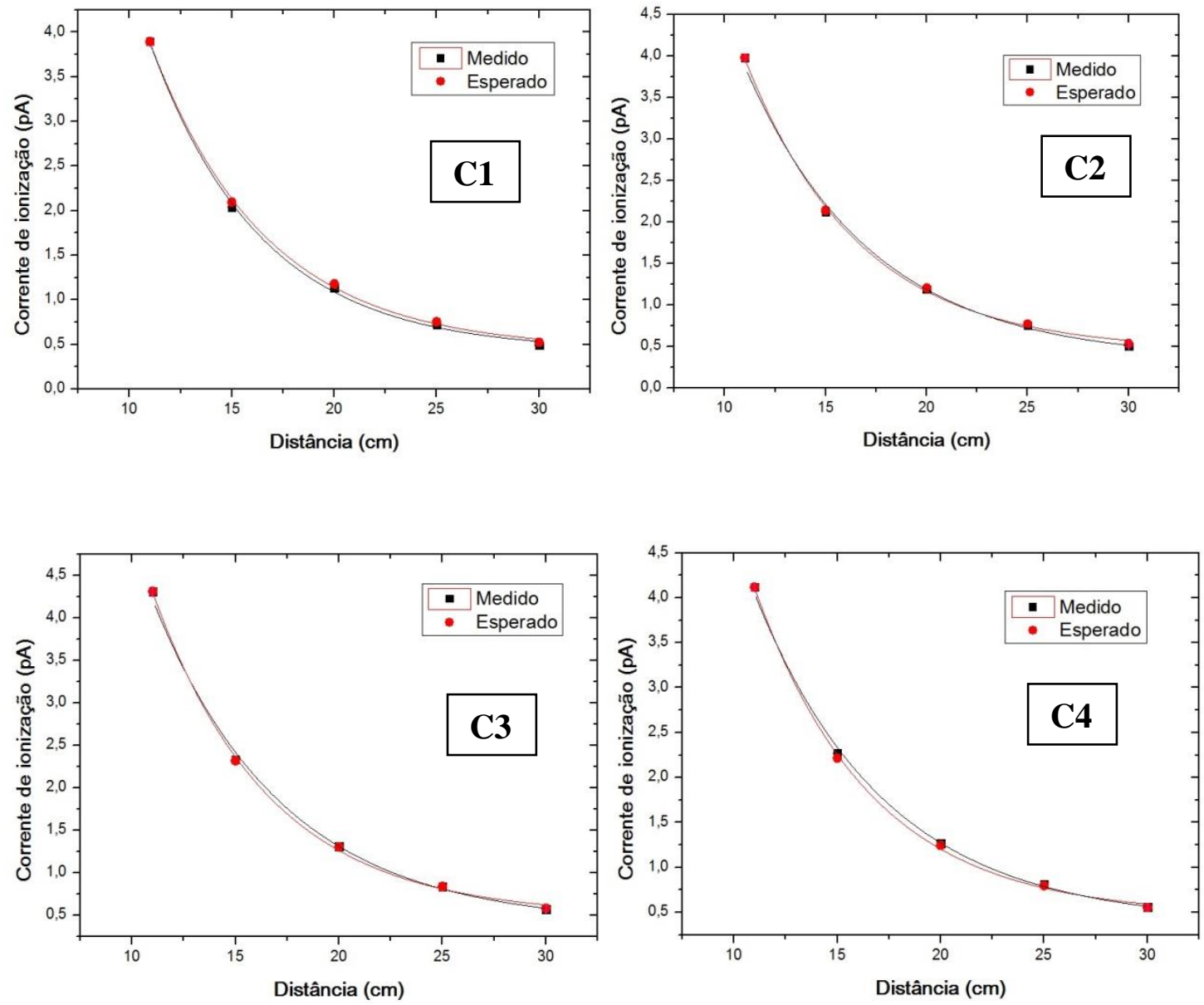

Figura 7.4 Resposta das câmaras de ionização $\mathrm{C1}, \mathrm{C} 2, \mathrm{C3}$ e $\mathrm{C4}$ em relação à variação da distância fonte-detector, sendo os dados experimentais representados pela legenda Medido e os dados das curvas esperadas pela lei do inverso do quadrado da distância representados pela legenda Esperado. A incerteza máxima das partes experimentais foi de 0,31\%, não visível no gráfico (LCI/IPEN)

O comportamento da resposta das câmaras de ionização em relação à variação com a distância obedeceu à lei do inverso do quadrado da distância, especialmente a câmara de ionização C3, onde os pontos medidos e esperados praticamente coincidiram, com exceção do último ponto à distância de $30 \mathrm{~cm}$. A máxima variação da resposta das câmaras de ionização $\mathrm{C} 1, \mathrm{C} 2, \mathrm{C} 3$ e C4 em relação à resposta esperada da lei do inverso 
do quadrado da distância foi respectivamente de 6,2\%, 6,3\%, 1,7\% e 2,5\% para o último ponto, à distância de $30 \mathrm{~cm}$. Os outros pontos, com exceção da câmara de ionização C1, sofreram uma variação menor que $2 \%$ para as demais distâncias.

\subsubsection{Calibração das câmaras de ionização em feixes de ${ }^{60} \mathrm{Co}$}

As quatro câmaras de ionização C1, C2, C3 e C4 foram calibradas em relação a uma câmara de ionização do tipo Farmer da PTW TN 30013 em feixe de ${ }^{60}$ Co do irradiador Gammatron II S 80. Na Figura 7.5 pode-se ver o arranjo de calibração da câmara de ionização C4 contra a câmara de ionização do tipo Farmer da PTW.

Primeiramente, a câmara de ionização do tipo Farmer foi irradiada centralizando o seu ponto de referência (centro da cavidade do volume sensível) em um objeto simulador de água com dimensões de $30 \times 30 \times 30 \mathrm{~cm}^{3}$. O campo de radiação foi de $10 \times 10 \mathrm{~cm}^{2}$ e a distância de referência foi de $5 \mathrm{~cm}\left(5 \mathrm{~g} / \mathrm{cm}^{2}\right)$ (IAEA, 2006) na água, de acordo com as condições de referência. Foram obtidas quatro medições, sendo cada uma de 3 min e foi calculado um valor médio.

Em seguida, as quatro câmaras de ionização também foram submetidas ao feixe de radiação gama, sendo que o volume sensível de cada uma das câmaras encontra-se na janela de entrada da câmara de ionização. Como as quatro câmaras de ionização não são à prova d'água, cada câmara de ionização foi protegida com uma capa emborrachada. Entretanto, somente a capa emborrachada não foi suficiente para a realização das medições, pois a pressão que a água exercia na janela de Mylar das câmaras de ionização impediu a tomada das medições. Foi então colocada à frente da janela de entrada de cada câmara de ionização uma folha fina de papel sulfite e logo por cima a capa de borracha. Com este sistema, as medições puderam ser realizadas. Foram obtidas quatro medições para cada câmara de ionização, sendo cada uma de 3 min e foi calculado o valor médio, como no caso da câmara de ionização do tipo Farmer.

De acordo com a Equação 17 do capítulo 4, foi possível obter os coeficientes de calibração das câmaras de ionização C1, C2, C3 e C4. Esses coeficientes estão apresentados na Tabela 7.4, juntamente com o coeficiente de calibração da câmara de ionização Farmer. 
Tabela 7.4 Coeficientes de calibração das câmaras de ionização

\begin{tabular}{cc}
\hline Câmara de ionização & $\begin{array}{c}\text { Coeficiente de calibração } \\
(\mathbf{m G y} / \mathbf{n C})\end{array}$ \\
\hline C1 & $89,83 \pm 1,34$ \\
C2 & $67,17 \pm 1,00$ \\
C3 & $76,75 \pm 1,15$ \\
C4 & $79,18 \pm 1,18$ \\
Farmer TN 30013 & $53,59 \pm 0,80$ \\
\hline
\end{tabular}

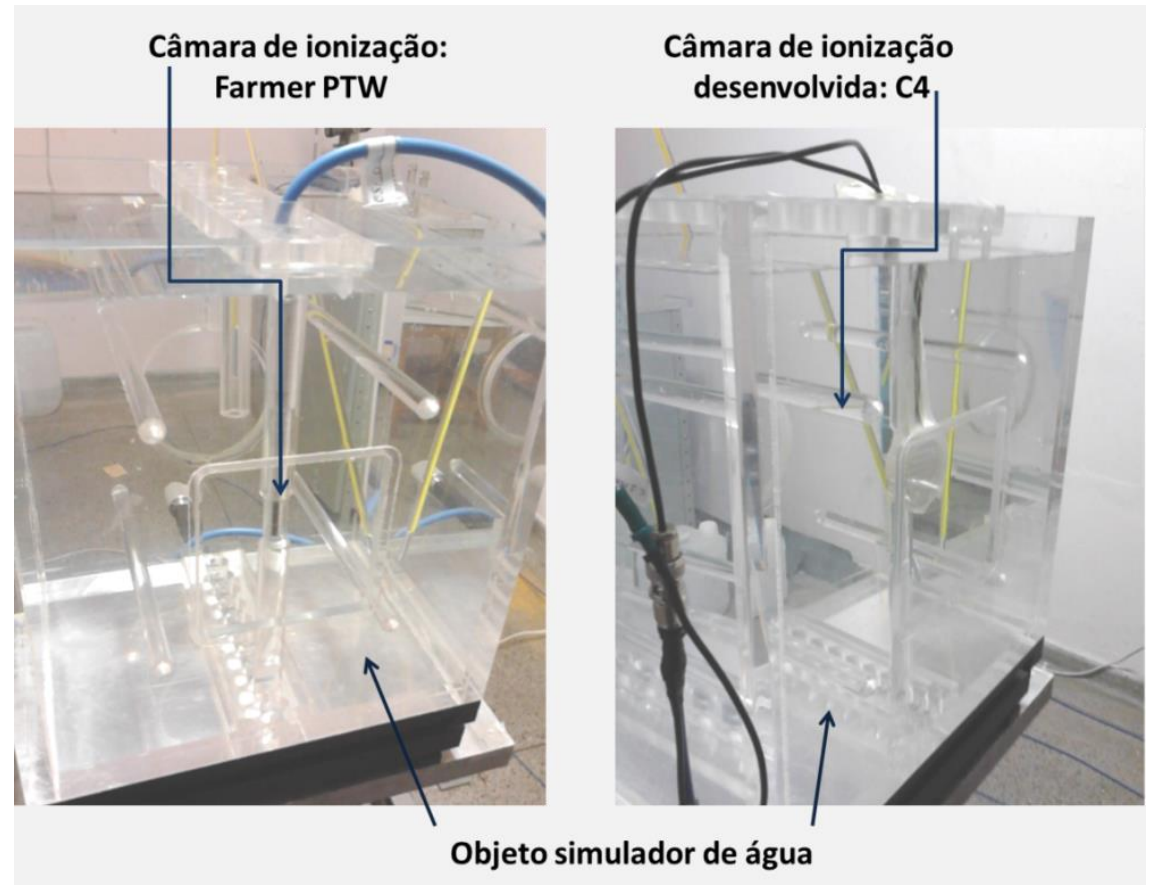

Figura 7.5 Calibração da câmara de ionização $\mathrm{C4}$ em relação à câmara de ionização Farmer (PTW) em feixes de ${ }^{60} \mathrm{Co}$ do irradiador Gammatron II S 80 (LCI/IPEN)

7.1.2 Testes de caracterização realizados em Serviços de Radioterapia de São Paulo, utilizando feixes de elétrons

Neste tópico serão apresentados os resultados dos testes realizados com as quatro câmaras de ionização C1, C2, C3 e C4 em dois Serviços de Radioterapia da cidade de São Paulo. Todas as medições foram corrigidas para as condições de referência de temperatura e pressão (IAEA, 2006), e as incertezas foram estimadas de acordo com a norma ISO (ABNT, 2003). 


\subsubsection{Linearidade de resposta}

O teste da linearidade da resposta foi realizado no ICESP para as quatro câmaras de ionização. O feixe de elétrons do acelerador linear Elekta Synergy do setor de radioterapia do hospital foi utilizado para este teste. Foram realizadas 3 medições cada vez para 100, 200, 400, 600, 800 e $1000 \mathrm{UM}$ para as duas energias, $6 \mathrm{MeV}$ e $9 \mathrm{MeV}$. As unidades monitoras (UM) representam a leitura da carga integrada de uma câmara de ionização de placas paralelas em feixes do acelerador linear; a leitura é proporcional à intensidade média do feixe. A distância de referência entre a fonte de elétrons e as câmaras de ionização foi de $100 \mathrm{~cm}$ e a taxa de dose foi de $400 \mathrm{UM} / \mathrm{min}$. O estudo de linearidade de resposta para as energias de $6 \mathrm{MeV}$ e $9 \mathrm{MeV}$ das câmaras de ionização C1, C2, C3 e C4 está apresentada respectivamente nas Figuras 7.6 e 7.7.
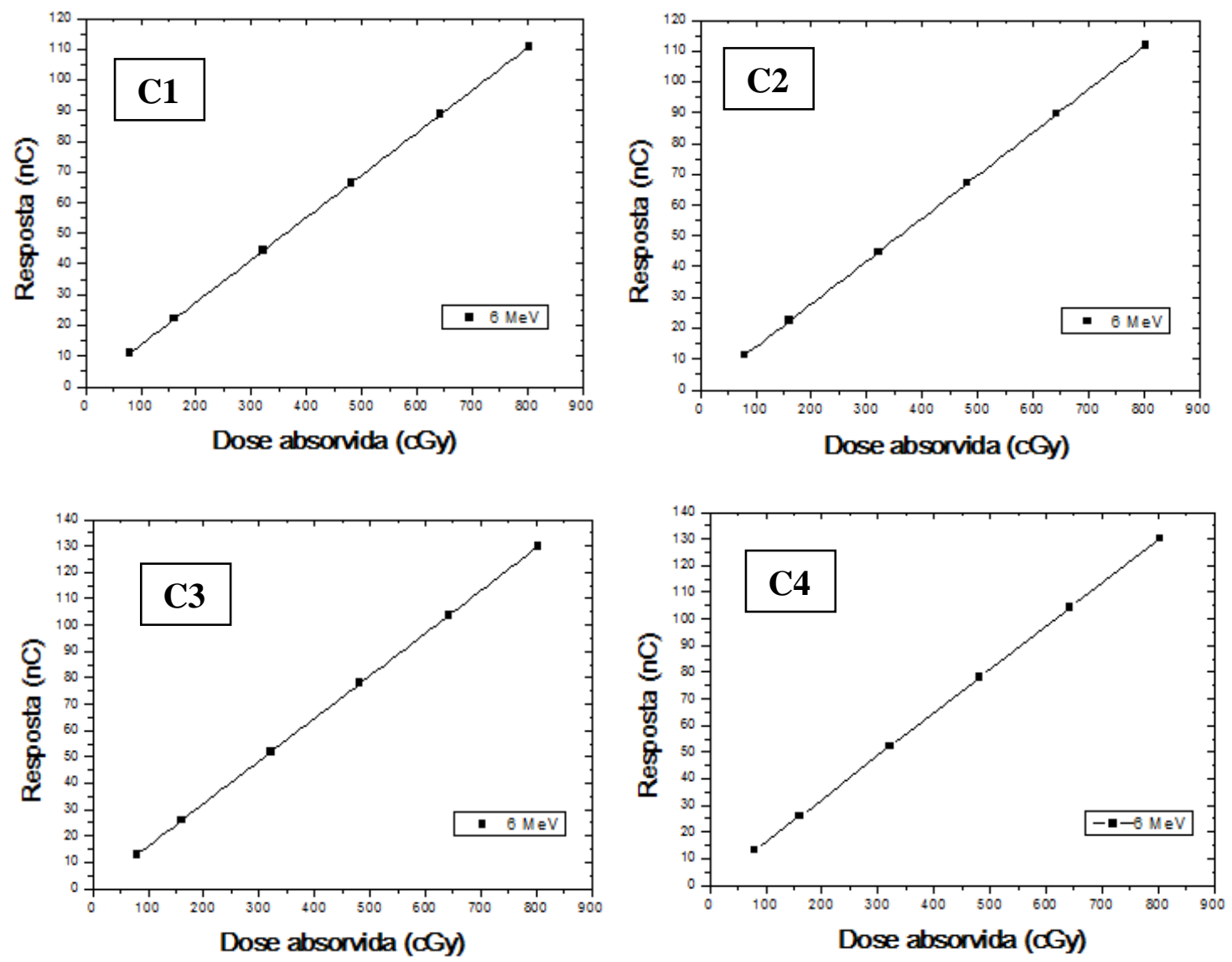

Figura 7.6 Linearidade de resposta das câmaras de ionização C1, C2, C3 e C4 em feixes de elétrons com energia de $6 \mathrm{MeV}$. As incertezas foram menores que $0,21 \%$, não sendo visíveis nos gráficos (ICESP) 

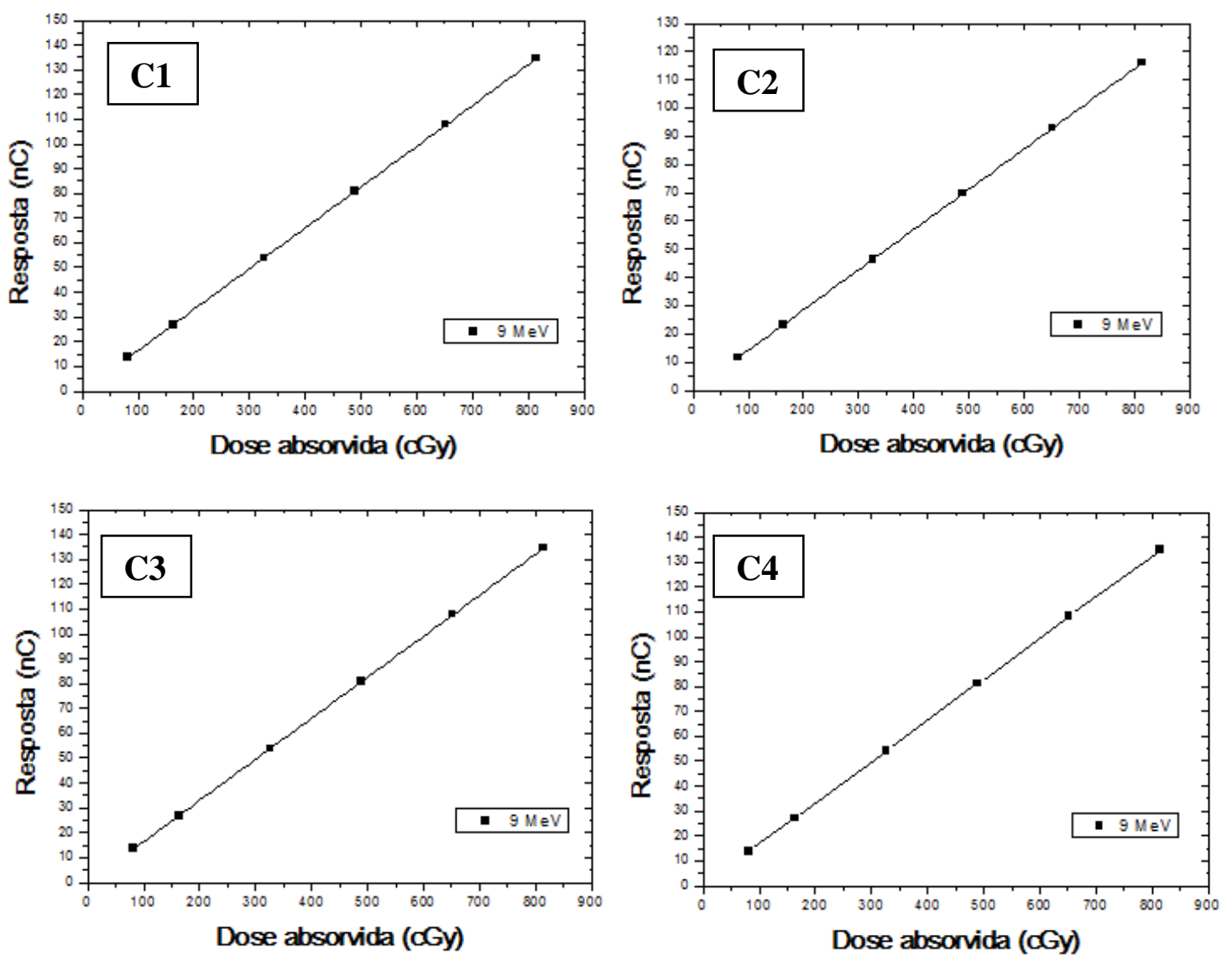

Figura 7.7 Linearidade de resposta das câmaras de ionização C1, C2, C3 e C4 em feixes de elétrons com energia de $9 \mathrm{MeV}$. As incertezas foram menores que $0,22 \%$, não sendo visíveis nos gráficos (ICESP)

De acordo com as Figuras 7.6 e 7.7, todas as câmaras de ionização apresentam um comportamento linear quando expostas ao feixe de radiação em função da dose absorvida, apresentando coeficientes de correlação $\mathrm{R}^{2}$ iguais a 1,000.

\subsubsection{Efeito de polaridade em relação ao alcance prático}

De acordo com a norma IEC 60731 (2011), o efeito de polaridade pode ser determinado utilizando-se feixes de elétrons às profundidades de $0,1 \mathrm{Rp}, 0,3 \mathrm{Rp}, 0,5 \mathrm{Rp}$ e 0,7 Rp, onde Rp é o alcance prático do feixe de elétrons. Para se determinar as profundidades do alcance prático foi necessário utilizar um objeto simulador de placas de água sólida, pois as câmaras de ionização não são à prova d'água; também foi utilizado um suporte de placas de acrílico para acoplar as câmaras de ionização. As placas de água sólida foram acrescentadas acima do suporte das placas de acrílico, de 
acordo com o alcance prático desejado. De acordo com a norma, primeiramente deve-se tomar as medições com a polaridade positiva às profundidades determinadas e posteriormente tomar as medições com a polaridade negativa. Após as medições, devese estimar a diferença percentual entre os resultados com as polaridades negativa e positiva, que não deve ser maior que $0,3 \%$ para cada profundidade. Se isso ocorrer, deve-se tomar a média entre as medições realizadas com a polaridade positiva e a polaridade negativa para cada profundidade.

Devido à limitação de disponibilidade das clínicas de radioterapia, uma parte do teste do efeito de polaridade foi realizada no Hospital Albert Einstein e a outra parte no ICESP.

Primeiramente, serão apresentados os testes realizados no Hospital Albert Einstein, onde foi possível realizar o teste do efeito de polaridade para as quatro câmaras de ionização C1, C2, C3 e C4. Posteriormente, foram realizados testes do efeito de polaridade no ICESP para a câmara de ionização C1 e o teste de efeito polaridade em relação ao tamanho de campo para as câmaras de ionização C1 e C2.

O teste do efeito de polaridade foi realizado no Hospital Albert Einstein, em feixes de elétrons do acelerador linear LINAC 2100C, utilizando as duas energias, de $6 \mathrm{MeV}$ e de $12 \mathrm{MeV}$, às profundidades já determinadas pela norma (IEC, 2011) para as quatro câmaras de ionização $\mathrm{C} 1, \mathrm{C} 2, \mathrm{C} 3$ e C4; a taxa de dose absorvida foi de 4,0 Gy/min (400 UM/min). Além de se utilizar um objeto simulador de placas de água sólida e de um suporte de placas de acrílico para as câmaras de ionização, também foram colocadas placas de água sólida $(5 \mathrm{~cm})$ embaixo do suporte de placas de acrílico para evitar o retroespalhamento, como está mostrado na Figura 7.8. Foram tomadas 5 medições para cada profundidade e polaridade aplicada, utilizando 100 UM em cada medição.

O cone do feixe de elétrons utilizado para as duas energias disponibiliza um campo de radiação $15 \times 15 \mathrm{~cm}^{2}$. Os materiais utilizados para a realização do teste de efeito de polaridade estão apresentados na Figura 7.8. O efeito de polaridade está apresentado na Figura 7.9 para as 4 câmaras de ionização C1, C2, C3 e C4, em termos de razão de polaridade, que é a razão entre a medição obtida com a polaridade negativa e a medição obtida com a polaridade positiva, para cada profundidade de alcance prático. 
De acordo com a Figura 7.9, o efeito de polaridade foi menor para a energia de $12 \mathrm{MeV}$ em relação à energia de $6 \mathrm{MeV}$; este comportamento está de acordo com a norma TRS 398 (IAEA, 2006).

À medida que o alcance prático se aproxima de $0,7 \mathrm{Rp}$, o efeito de polaridade aumenta para ambas as energias, pois a leitura da câmara de ionização, ao se aproximar desse ponto, torna-se bem menor. Portanto, uma pequena diferença na medição entre as polaridades positiva e negativa pode ser mais expressiva em percentagem, quando se toma a razão entre as medições de polaridades positiva e negativa.

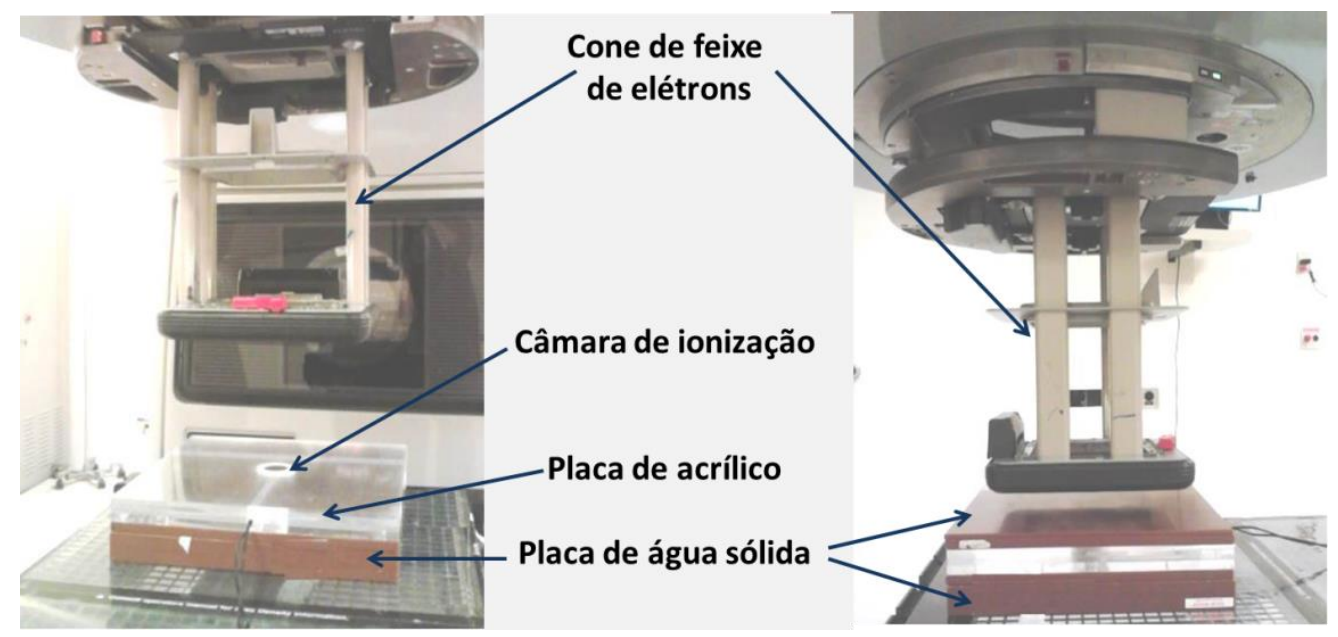

Figura 7.8 Materiais utilizados para determinação do efeito de polaridade da resposta das câmaras de ionização (Hospital Albert Einstein)

Mesmo o efeito de polaridade sendo maior que o limite estabelecido pela norma, de 0,3\% (IEC, 2011), para as quatro câmaras de ionização, este comportamento das curvas das quatro câmaras de ionização para a energia de $6 \mathrm{MeV}$ é similar ao comportamento do efeito de polaridade apresentado pelas câmaras de ionização Capintec e Memorial no trabalho de Gerbi e Khan (GERBI e KHAN, 1987), sendo que o campo utilizado no presente trabalho foi maior do que o campo utilizado por Gerbi e Khan. Além disso, de acordo com a publicação TRS 469 (IAEA, 2009), uma câmara de ionização que apresente em sua resposta um valor de efeito de polaridade significante não é um problema, caso a câmara de ionização seja sempre utilizada na mesma polaridade e com o mesmo potencial. Isto é o que acontece com o uso das câmaras de ionização em Serviços de Radioterapia. 
Para a energia de $12 \mathrm{MeV}$, o efeito de polaridade foi menor do que $2 \%$, um comportamento similar à da câmara de ionização Calcam apresentada por Havercroft e Klevenhagen (1994).
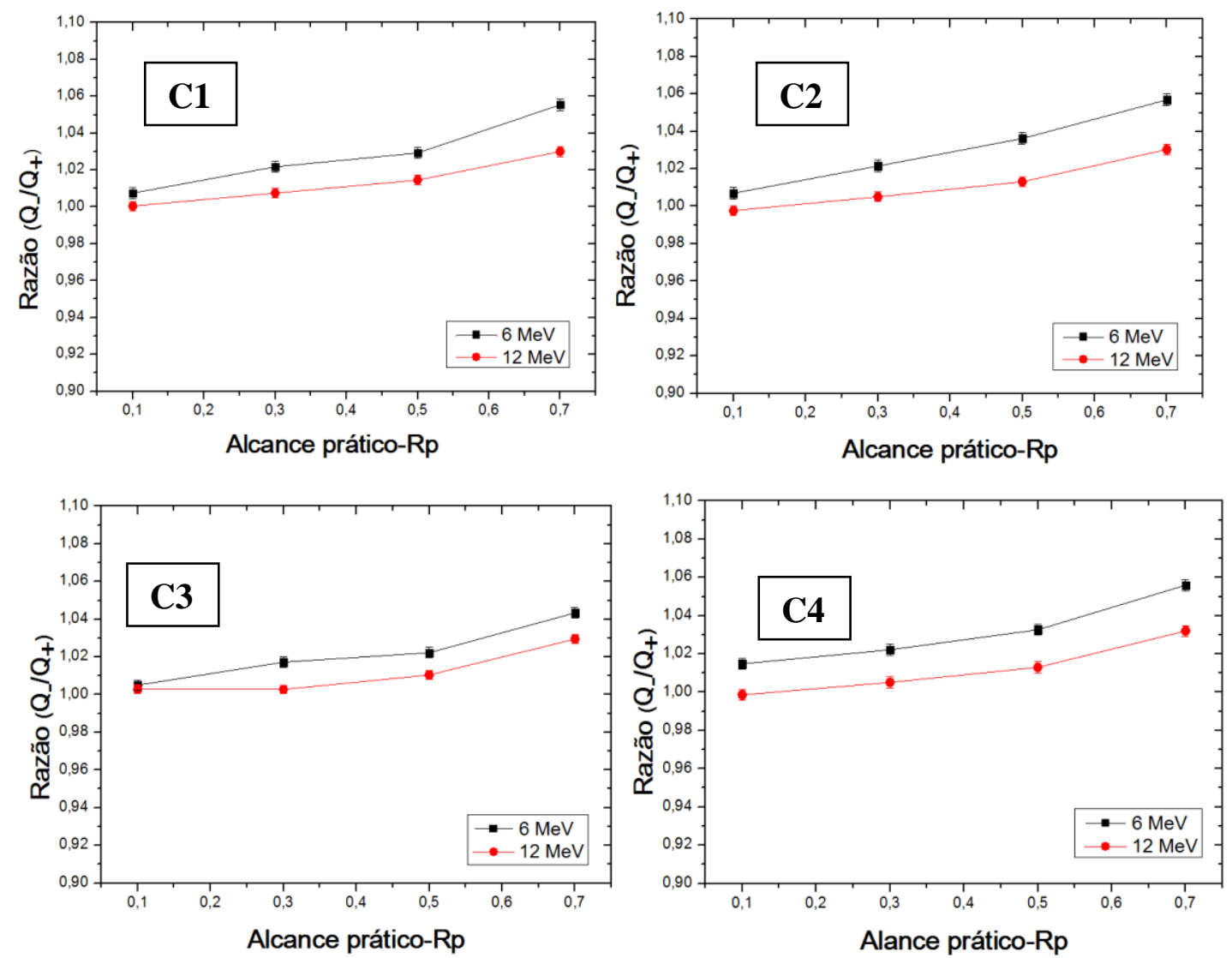

Figura 7.9 Efeito de polaridade das câmaras de ionização C1, C2, C3 e C4 em feixes de elétrons com energias de $6 \mathrm{MeV}$ e $12 \mathrm{MeV}$. As incertezas foram menores que $0,30 \%$, não sendo visíveis nos gráficos (Hospital Albert Einstein)

O efeito de polaridade também foi estudado no ICESP, utilizando feixes de elétrons do acelerador linear Elekta Synergy, para duas energias, de $6 \mathrm{MeV}$ e de $9 \mathrm{MeV}$, às profundidades já determinadas pela norma (IEC, 2011); entretanto, só foi possível realizar este teste com a câmara de ionização $\mathrm{C} 1$ devido à falta de disponibilidade de agenda para a realização de testes no acelerador linear. A taxa de dose absorvida foi de 3,21 Gy/min para $6 \mathrm{MeV}$ e 3,63 Gy/min para $9 \mathrm{MeV}$, o que corresponde a $400 \mathrm{UM} / \mathrm{min}$. Foram tomadas 5 medições para cada profundidade e polaridade aplicada, utilizando 100 UM em cada medição. O cone do feixe de elétrons utilizado para as duas energias apresenta um campo de 14 x $14 \mathrm{~cm}^{2}$. Foram utilizadas espessuras de $1 \mathrm{~cm}$ e $5 \mathrm{~cm}$ de 
placas de água sólida para observar o efeito do retroespalhamento; as placas de água sólida estão apresentadas na Figura 7.10. O efeito de polaridade para as energias de $6 \mathrm{MeV}$ e $9 \mathrm{MeV}$ está apresentado na Figura 7.11 para a câmara de ionização C1.

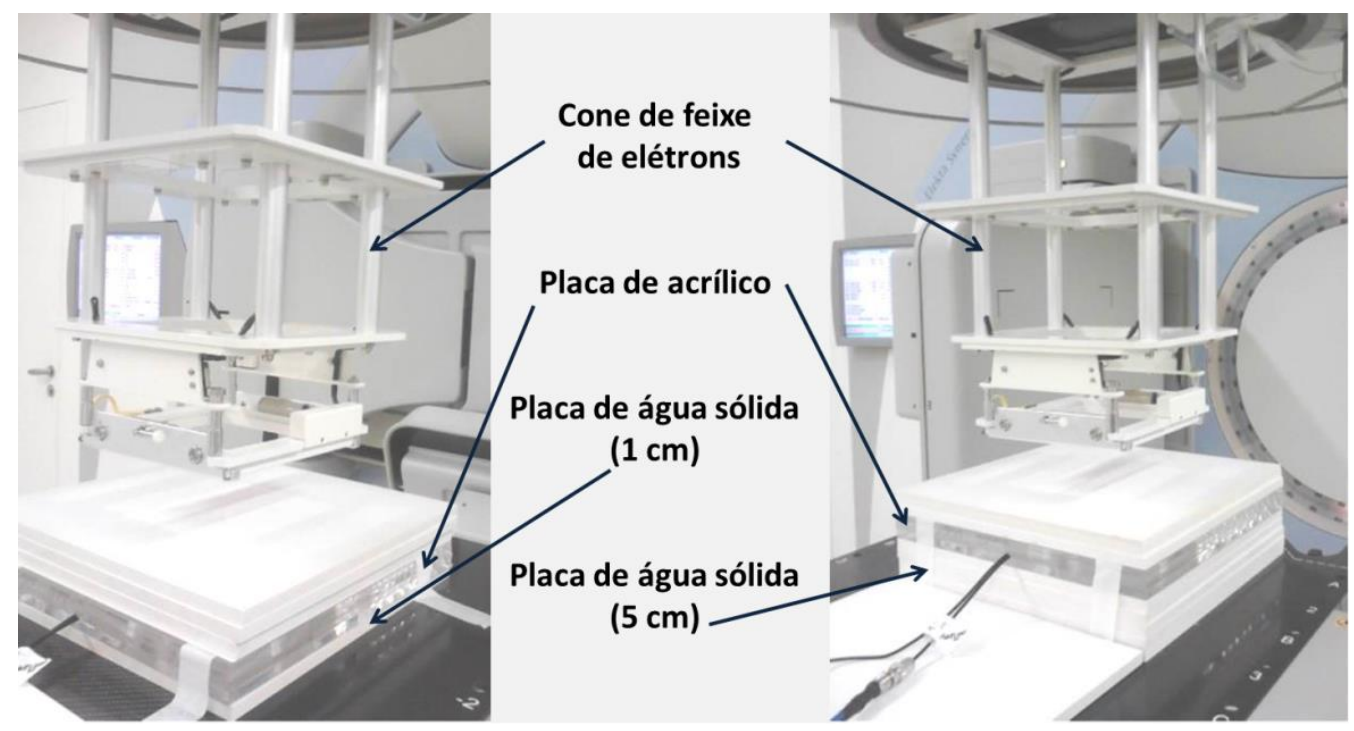

Figura 7.10 Materiais utilizados para o estudo do efeito do retroespalhamento da resposta das câmaras de ionização (ICESP)

A Fig. 7.11 (c) foi obtida colocando-se as curvas da Fig. 7.11 (a) e 7.11 (b) em um mesmo gráfico. Com isso foi possível observar na Fig. 7.11 (c) que a razão do efeito de polaridade para $1 \mathrm{~cm}$ e $5 \mathrm{~cm}$ para uma mesma energia são bem próximos, com exceção do ponto $0,5 \mathrm{R}_{\mathrm{p}}$.

Um aumento significativo do efeito de polaridade nas medições não é um problema, visto que a câmara de ionização nos Serviços de Radioterapia é sempre utilizada em uma mesma polaridade (IAEA, 2009). O fator de correção para o efeito de polaridade pode ser aplicado, de acordo com a norma internacional TRS 398 (IAEA, 2009):

$$
K_{p o l}=\frac{\left|M_{+}\right|+\left|M_{-}\right|}{2 M}
$$

onde M+ e M- são as medições obtidas com as polaridades positiva e negativa respectivamente, e M é a medição obtida com a polaridade escolhida no uso rotineiro da câmara de ionização. 

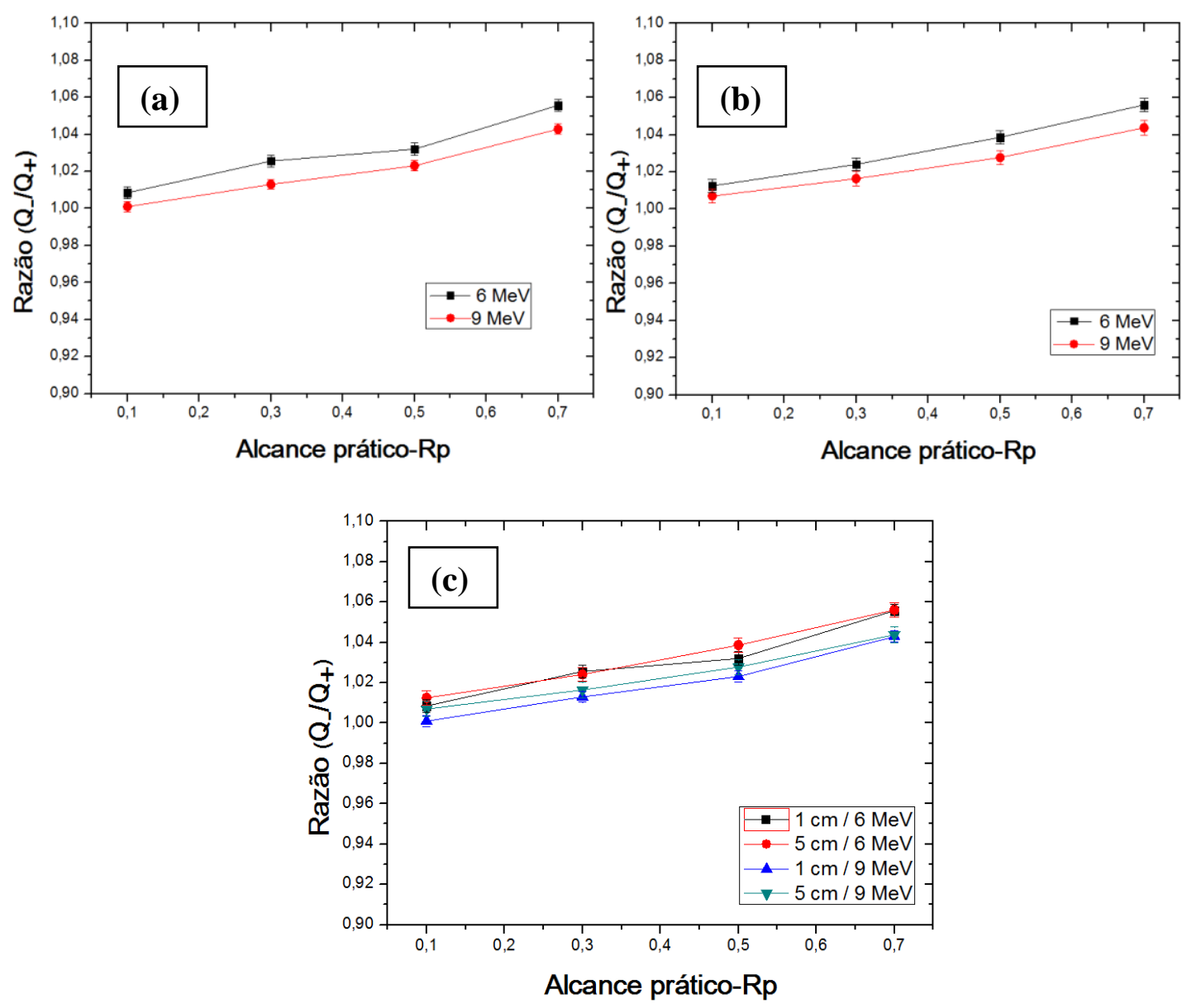

Figura 7.11 Efeito de polaridade da câmara de ionização C1 em feixes de elétrons com energias de $6 \mathrm{MeV}$ e $9 \mathrm{MeV}$, utilizando espessura de água sólida de $1 \mathrm{~cm}$ (a) e de $5 \mathrm{~cm}$ (b) embaixo do suporte de acrílico da câmara de ionização; o terceiro gráfico apresenta os resultados para as duas espessuras com as duas energias (c). As incertezas foram menores que 0,34\%, não sendo visíveis nos gráficos (ICESP)

A câmara de ionização C1 quando submetida a feixes de elétrons no Hospital Albert Einstein para o feixe de elétrons de $6 \mathrm{MeV}$ (utilizando $5 \mathrm{~cm}$ de água sólida para retroespalhamento na Figura 7.9) no ponto de 0,5 Rp teve o mesmo comportamento quando foi submetida a feixes de elétrons de $6 \mathrm{MeV}$ do ICESP (utilizando $1 \mathrm{~cm}$ água sólida para retroespalhamento na Figura 7.11 (a)). Este comportamento já não ocorre para energias mais altas tanto na Figura 7.9 como na Figura 7.11 (a) e (b) onde o comportamento em todos os alcances práticos foram similares.

Também foi realizado o teste de efeito de polaridade com relação ao tamanho do campo de radiação, no ICESP, para as câmaras de ionização C1 e C2. Foram utilizados 
feixes de elétrons do acelerador linear Elekta Synergy de $6 \mathrm{MeV}$ e de $9 \mathrm{MeV}$ para determinar o efeito de polaridade com relação ao campo de radiação. Desta vez, não foram utilizadas placas de água sólida em cima do suporte de placas de acrílico para a câmara de ionização, mas somente placas de água sólida embaixo do suporte da câmara devido ao retroespalhamento. Os campos utilizados foram $6 \times 6 \mathrm{~cm}^{2}, 10 \times 10 \mathrm{~cm}^{2}$, $14 \times 14 \mathrm{~cm}^{2}, 20 \times 20 \mathrm{~cm}^{2}$. Foram tomadas 5 medições para cada polaridade aplicada e em cada medição foram aplicadas 100 UM, a uma taxa de dose absorvida de 3,21 Gy/min para $6 \mathrm{MeV}$ e 3,63 Gy/min para $9 \mathrm{MeV}$, o que corresponde a $400 \mathrm{UM} / \mathrm{min}$. A distância entre as câmaras de ionização e a fonte do feixe de elétrons foi de $100 \mathrm{~cm}$ (posição de referência do feixe de elétrons). As câmaras utilizadas para este teste foram C1 e C2 e suas respostas estão apresentadas na Figura 7.12.
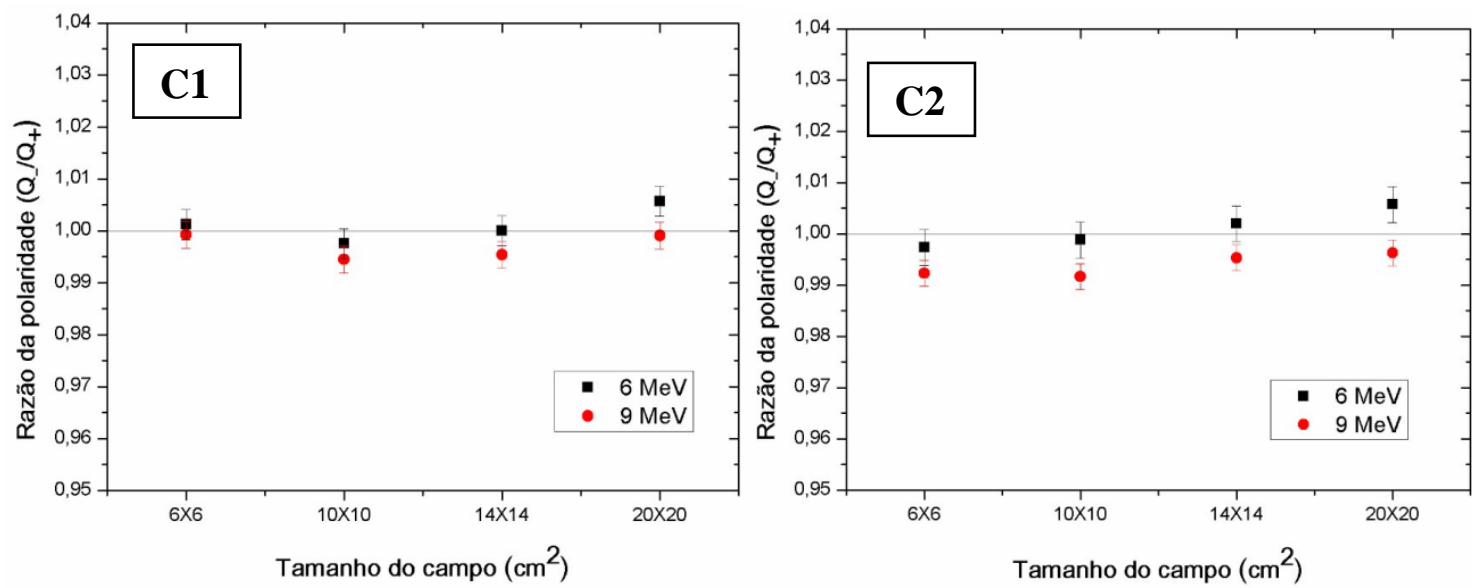

Figura 7.12 Efeito de polaridade em relação ao tamanho do campo de radiação para as câmaras de ionização $\mathrm{C} 1$ e $\mathrm{C} 2$, para as energias de $6 \mathrm{MeV}$ e $9 \mathrm{MeV}$. As incertezas foram menores que $0,35 \%$, não sendo visíveis nos gráficos (ICESP)

De acordo com a Figura 7.12, o efeito de polaridade é maior para campos maiores e é menor para energias mais altas.

\subsubsection{Efeito do cabo}

O teste do efeito do cabo foi realizado no setor de radioterapia do ICESP, utilizando feixes de elétrons do acelerador linear Elekta Synergy para as energias de $6 \mathrm{MeV}$ e $9 \mathrm{MeV}$. A câmara de ionização, primeiramente, foi exposta aos feixes de 
elétrons com o cabo protegido e posteriormente com o cabo desprotegido, sendo o cabo irradiado juntamente com a câmara de ionização. Foram tomadas 5 medições para cada situação, com o cabo com proteção e sem proteção. Esta proteção foi realizada com as próprias placas de acrílico utilizadas como suporte da câmara de ionização e pode ser observada na Figura 7.13. Foram utilizadas 100 UM, a uma taxa de dose absorvida de 3,21 Gy/min para $6 \mathrm{MeV}$ e 3,63 Gy/min para $9 \mathrm{MeV}$, o que corresponde a $400 \mathrm{UM} / \mathrm{min}$. A distância de referência entre as câmaras de ionização e a fonte de feixe de elétrons foi de $100 \mathrm{~cm}$. $\mathrm{O}$ fator cabo $\left(\mathrm{F}_{\text {cabo }}\right)$ foi determinado para as 4 câmaras de ionização $\mathrm{C} 1, \mathrm{C} 2$, $\mathrm{C} 3$ e $\mathrm{C} 4$ e os valores estão apresentados na Tabela 7.5. $\mathrm{O}$ fator cabo $\mathrm{F}_{\text {cabo }}$ é definido como a razão entre os valores médios das medições obtidas com cabo sem proteção e as medições obtidas com o cabo protegido.
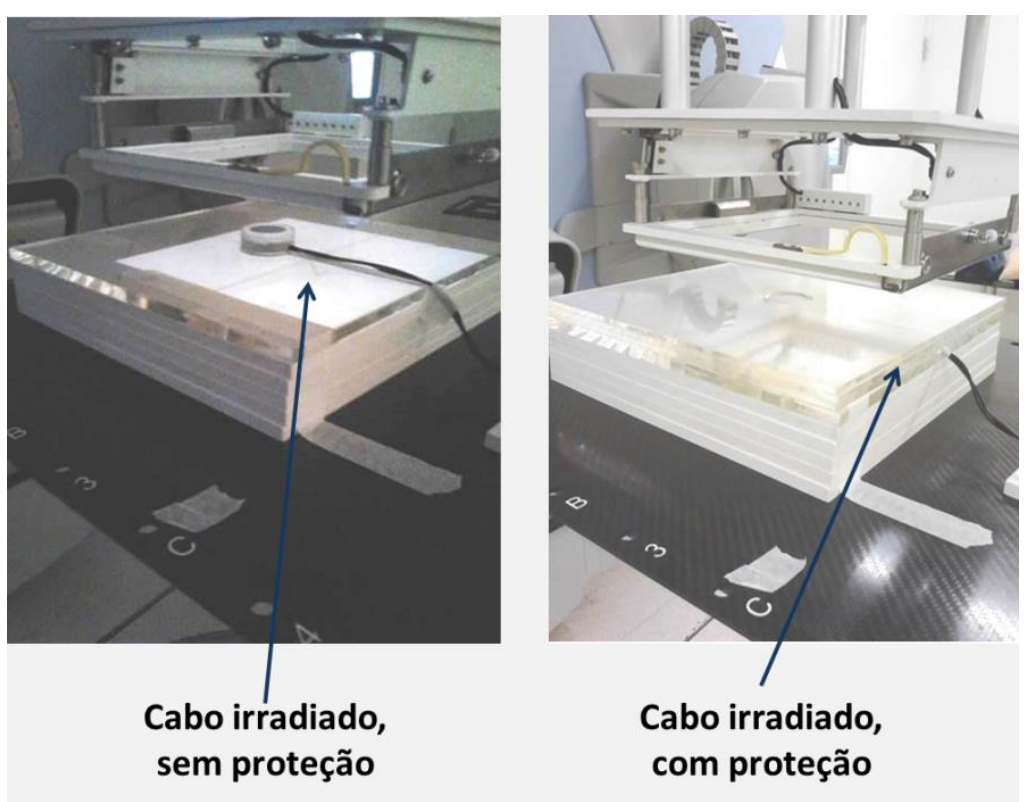

Figura 7.13 Câmara de ionização com o cabo protegido e desprotegido da irradiação dos feixes de elétrons

Tabela 7.5 Fator cabo das câmaras de ionização

\begin{tabular}{ccc}
\hline Câmara de ionização & \multicolumn{2}{c}{ Energia de radiação } \\
& $6 \mathrm{MeV}$ & $9 \mathrm{MeV}$ \\
\hline $\mathrm{C} 1$ & $1,002 \pm 0,003$ & $1,000 \pm 0,004$ \\
$\mathrm{C} 2$ & $1,000 \pm 0,004$ & $1,000 \pm 0,004$ \\
$\mathrm{C} 3$ & $1,002 \pm 0,003$ & $0,999 \pm 0,003$ \\
$\mathrm{C} 4$ & $1,002 \pm 0,003$ & $1,000 \pm 0,002$ \\
\hline
\end{tabular}


Pode-se observar que o fator cabo não interfere nas medições realizadas com as câmaras de ionização; além disso, o suporte construído para as câmaras de ionização protege os cabos da radiação.

\subsubsection{Simetria da resposta das câmaras de ionização}

O estudo da simetria da resposta da câmara de ionização tem como objetivo verificar se a camada de tinta não totalmente uniforme (microscopicamente), aplicada ao eletrodo coletor, interfere na coleção de cargas da câmara de ionização. $O$ teste foi realizado no setor de radioterapia do ICESP, para as quatro câmaras de ionização C1, C2, C3 e C4, utilizando feixes de elétrons do acelerador linear Elekta Synergy para as energias de $6 \mathrm{MeV}$ e $9 \mathrm{MeV}$. Neste teste, o gantry do acelerador linear foi rotacionado em torno da câmara de ionização em ângulos de $0^{\circ}, \pm 5^{\circ}, \pm 10^{\circ}, \pm 15^{\circ}, \pm 20^{\circ}, \pm 25^{\circ}, \pm 30^{\circ}$. Este teste pode ser observado na Figura 7.14 Cada medição foi de 100 UM, a uma taxa de dose absorvida de 3,21 Gy/min para $6 \mathrm{MeV}$ e 3,63 Gy/min para $9 \mathrm{MeV}$, o que corresponde a $400 \mathrm{UM} / \mathrm{min}$. A distância entre as câmaras de ionização e a fonte de feixe de elétrons foi de $100 \mathrm{~cm}$. A resposta das câmaras de ionização está apresentada na Figura 7.15.

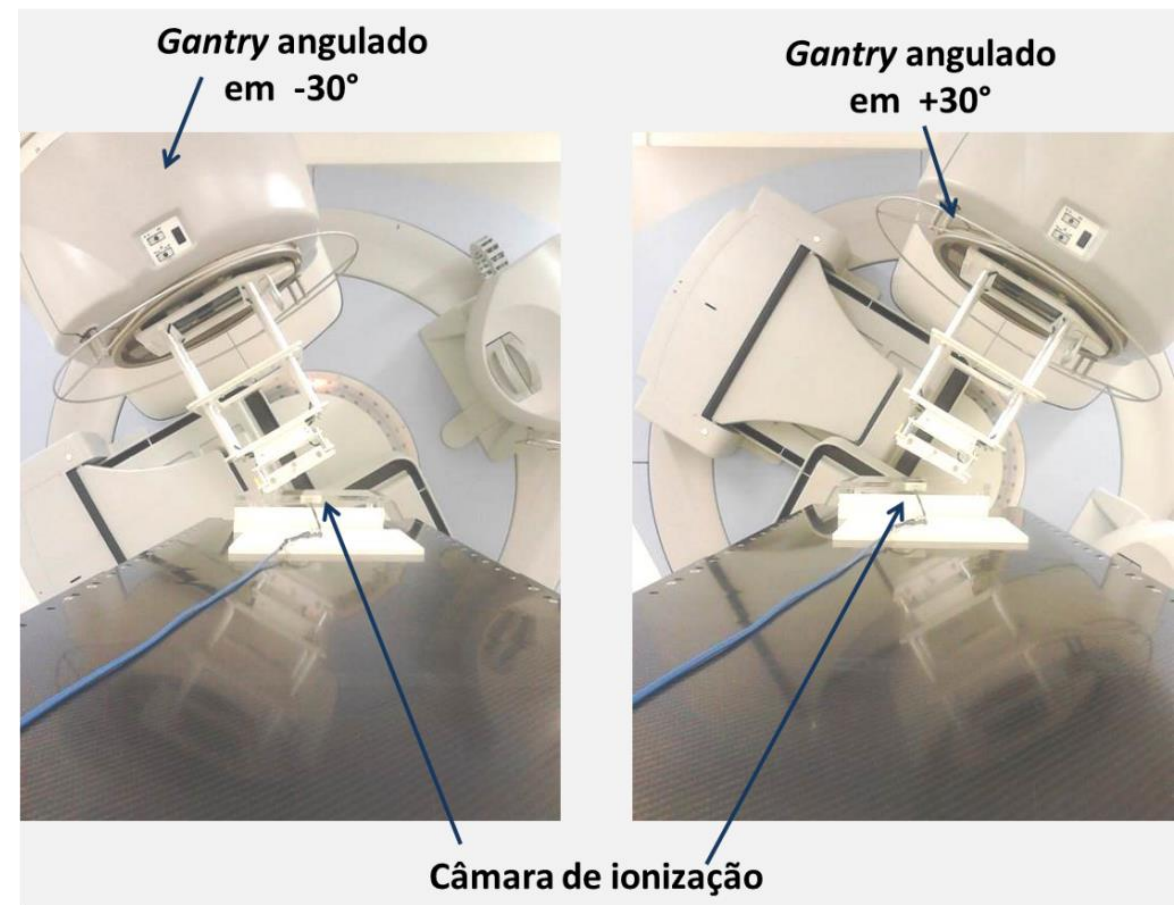

Figura 7.14 Teste de simetria da resposta das câmaras de ionização, apresentando o gantry angulado $\mathrm{em} \pm 30^{\circ}($ ICESP $)$ 

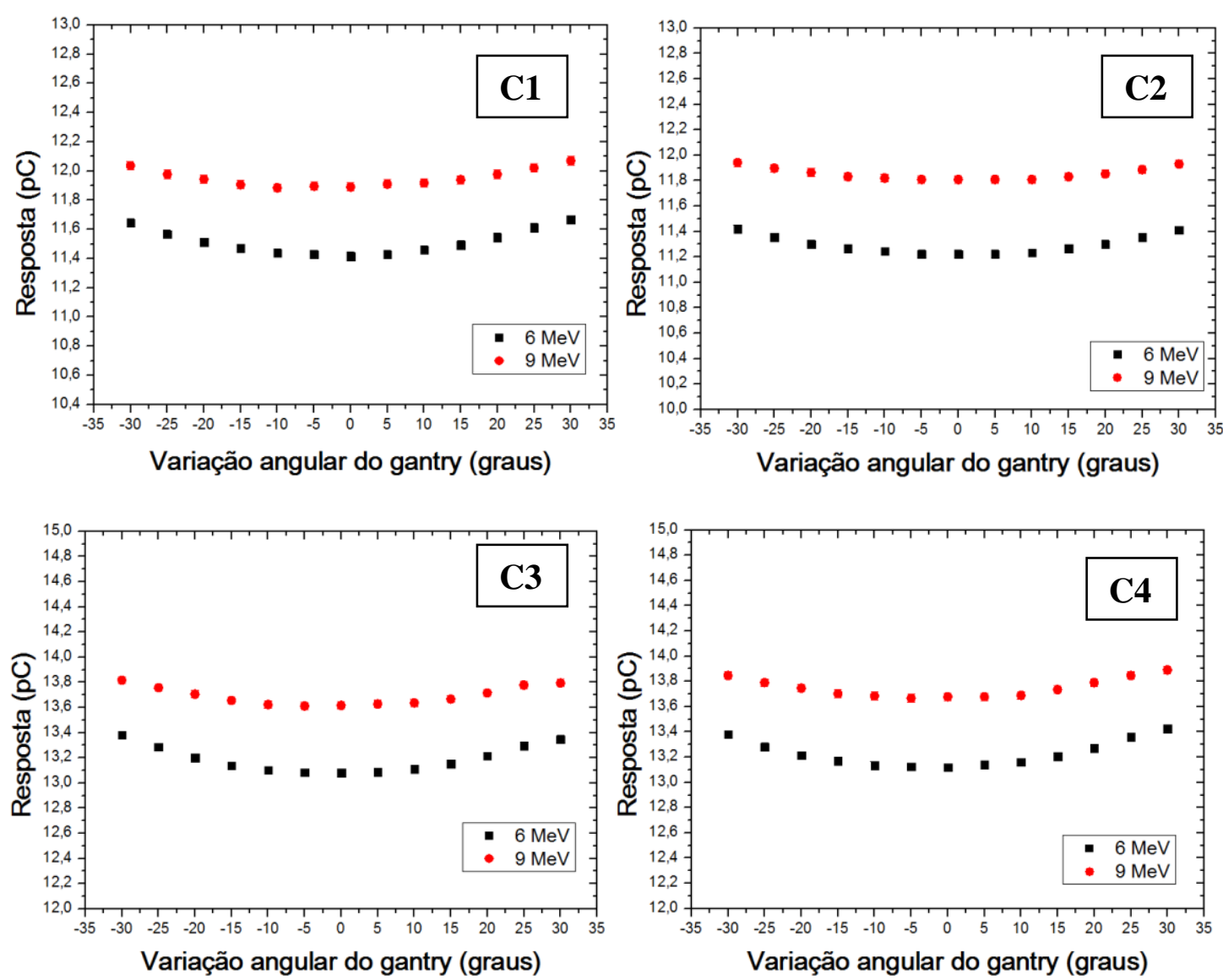

Figura 7.15 Simetria da resposta das câmaras de ionização C1, C2, C3 e C4 para feixes de elétrons com energias de $6 \mathrm{MeV}$ e $9 \mathrm{MeV}$ em função da rotação do gantry. As incertezas foram menores que $0,26 \%$, não sendo visíveis nos gráficos (ICESP)

De acordo com a Figura 7.15, as quatro câmaras de ionização apresentaram simetria quando obtidas as medições alternando-se os ângulos positivos e negativos, como por exemplo $+5^{\circ}$ e $-5^{\circ}$, sendo que a maior diferença nas medições para as quatro câmaras de ionização $\mathrm{C} 1, \mathrm{C} 2, \mathrm{C} 3$ e C4 foi de $0,6 \%$; a câmara de ionização $\mathrm{C} 2$, que possui eletrodo coletor de prata, apresentou a menor diferença, $0,1 \%$. e até nula para vários ângulos, para as duas energias de $6 \mathrm{MeV}$ e $9 \mathrm{MeV}$.

\subsubsection{Dependência angular}

O teste da dependência angular da resposta das quatro câmaras de ionização $\mathrm{C} 1$, C2, C3 e C4 foi realizado, utilizando-se os feixes de elétrons do acelerador linear Elekta Synergy para as energias de $6 \mathrm{MeV}$ e $9 \mathrm{MeV}$, no ICESP. Um goniômetro de acrílico foi 
utilizado para se estudar a variação da resposta das câmaras de ionização com relação ao ângulo de incidência do feixe de radiação de elétrons. O sistema de radiação para o estudo da dependência angular da resposta das câmaras de ionização está apresentado na Figura 7.16. O ângulo de incidência da radiação variou de $0^{\circ}$ a $315^{\circ}$ em torno do eixo central da câmara, em intervalos de $45^{\circ}$. Cada medição foi de $100 \mathrm{UM}$, a uma taxa de dose absorvida de 3,21 Gy/min para $6 \mathrm{MeV}$ e 3,63 Gy/min para $9 \mathrm{MeV}$, o que corresponde a $400 \mathrm{UM} / \mathrm{min}$. A distância de referência entre as câmaras de ionização e a fonte de feixe de elétrons foi de $100 \mathrm{~cm}$. O comportamento da resposta relativa em relação ao ângulo $0^{\circ}$, das câmaras de ionização está apresentado na Tabela 7.6 para as energias de $6 \mathrm{MeV}$ e $9 \mathrm{MeV}$.

De acordo com a Tabela 7.6, todas as câmaras de ionização apresentaram dependência angular menor que 0,1\%. A câmara de ionização C2 apresentou uma dependência angular nula para a energia de $9 \mathrm{MeV}$. Os resultados mostram que a dependência angular da resposta das câmaras de ionização no feixe de $9 \mathrm{MeV}$ foi menor que no feixe de $6 \mathrm{MeV}$ e foi insignificante para as duas energias. De acordo com a norma IEC 60731 (2011), o limite de variação angular é de $1 \%$.

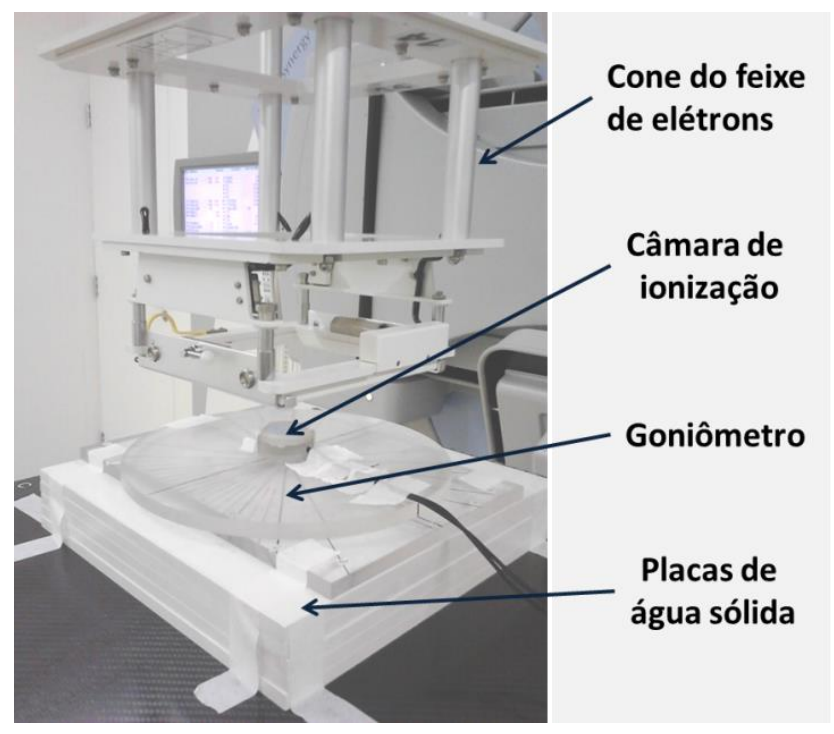

Figura 7.16 Sistema de radiação para o estudo da dependência angular da resposta das câmaras de ionização (ICESP) 
Tabela 7.6 Dependência angular da resposta das câmaras de ionização C1, C2, C3 e C4 em feixes de elétrons com energias de $6 \mathrm{MeV}$ e $9 \mathrm{MeV}$ (ICESP)

\begin{tabular}{c|cccc}
\hline Câmara de ionização & $\mathrm{C} 1$ & $\mathrm{C} 2$ & $\mathrm{C} 3$ & $\mathrm{C} 4$ \\
\hline Ângulo (graus) & \multicolumn{4}{|c}{ Resposta relativa em relação a $0^{\circ}}$, \\
para energia de 6 MeV \\
\hline $0^{\circ}$ & $1,00 \pm 0,30$ & $1,00 \pm 0,30$ & $1,00 \pm 0,30$ & $1,00 \pm 0,30$ \\
$45^{\circ}$ & $0,99 \pm 0,29$ & $0,99 \pm 0,29$ & $1,00 \pm 0,30$ & $0,99 \pm 0,29$ \\
$90^{\circ}$ & $0,99 \pm 0,29$ & $1,00 \pm 0,30$ & $1,00 \pm 0,30$ & $0,99 \pm 0,29$ \\
$135^{\circ}$ & $0,99 \pm 0,29$ & $1,00 \pm 0,30$ & $1,00 \pm 0,30$ & $0,99 \pm 0,29$ \\
$180^{\circ}$ & $1,00 \pm 0,30$ & $1,00 \pm 0,30$ & $1,00 \pm 0,30$ & $0,99 \pm 0,29$ \\
$225^{\circ}$ & $1,00 \pm 0,30$ & $1,00 \pm 0,30$ & $1,00 \pm 0,30$ & $0,99 \pm 0,29$ \\
$270^{\circ}$ & $1,00 \pm 0,30$ & $1,00 \pm 0,30$ & $0,99 \pm 0,29$ & $0,99 \pm 0,29$ \\
$315^{\circ}$ & $1,00 \pm 0,30$ & $1,00 \pm 0,30$ & $0,99 \pm 0,29$ & $0,99 \pm 0,29$ \\
$360^{\circ}$ & $1,00 \pm 0,30$ & $1,00 \pm 0,30$ & $0,99 \pm 0,29$ & $1,00 \pm 0,30$ \\
\cline { 2 - 5 } & Resposta relativa em relação a $0^{\circ}$, \\
$0^{\circ}$ & $1,00 \pm 0,30$ & $1,00 \pm 0,30$ & $1,00 \pm 0,30$ & $1,00 \pm 0,30$ \\
$45^{\circ}$ & $1,00 \pm 0,30$ & $1,00 \pm 0,30$ & $1,00 \pm 0,30$ & $1,00 \pm 0,30$ \\
$90^{\circ}$ & $1,00 \pm 0,30$ & $1,00 \pm 0,30$ & $1,00 \pm 0,30$ & $1,00 \pm 0,30$ \\
$135^{\circ}$ & $1,00 \pm 0,30$ & $1,00 \pm 0,30$ & $0,99 \pm 0,29$ & $0,99 \pm 0,29$ \\
$180^{\circ}$ & $1,00 \pm 0,30$ & $1,00 \pm 0,30$ & $0,99 \pm 0,29$ & $1,00 \pm 0,30$ \\
$225^{\circ}$ & $1,00 \pm 0,30$ & $1,00 \pm 0,30$ & $1,00 \pm 0,30$ & $1,00 \pm 0,30$ \\
$270^{\circ}$ & $1,00 \pm 0,30$ & $1,00 \pm 0,30$ & $0,99 \pm 0,29$ & $0,99 \pm 0,29$ \\
$315^{\circ}$ & $1,00 \pm 0,30$ & $1,00 \pm 0,30$ & $1,00 \pm 0,30$ & $1,00 \pm 0,30$ \\
$360^{\circ}$ & $1,00 \pm 0,30$ & $1,00 \pm 0,30$ & $1,00 \pm 0,30$ & $1,00 \pm 0,30$ \\
\cline { 2 - 5 }
\end{tabular}

As câmaras de ionização C1, C2, C3 e C4 foram caracterizadas em feixes padronizados de radiação do Laboratório de Calibração de Instrumentos do IPEN e também foram testadas em feixes de elétrons do IPEN para se observar o comportamento de suas respostas como preparação para a construção da câmara de ionização à prova d'água; além disso, as câmaras de ionização foram calibradas em feixes padronizados de ${ }^{60} \mathrm{Co}$, o que também possibilita a sua aplicação em dosimetria de feixes de elétrons. Apesar de hoje se utilizar muito a câmara de ionização à prova d'água, muitos hospitais utilizam câmaras de ionização que não são à prova d'água nos testes rotineiros semanais devido à utilização do objeto simulador de água demandar mais tempo de uso do acelerador linear de elétrons. 


\subsection{Caracterização da câmara de ionização C5}

Neste item serão apresentados os resultados dos testes de caracterização realizados no Laboratório de Calibração de Instrumentos do IPEN e os testes realizados nos Serviços de Radioterapia na cidade de São Paulo para a câmara de ionização C5. Todas as medições foram corrigidas para as condições de referência de temperatura e pressão (IAEA, 2006), e as incertezas foram estimadas de acordo com a norma ISO (ABNT, 2003). A maioria dos testes foi realizada utilizando um objeto simulador à prova d'água.

\subsubsection{Testes de caracterização realizados no Laboratório de Calibração do IPEN}

A seguir serão apresentados os testes de caracterização da câmara de ionização C5. Todos os testes foram realizados em feixes de ${ }^{60} \mathrm{Co}$ do irradiador Gammatron II S80 no Laboratório de Calibração de Instrumentos do IPEN, utilizando um objeto simulador de água. A temperatura medida foi da água dentro do objeto simulador, pois apesar da câmara de ionização ser à prova d'água ela possui contato com o ar através do cabo.

Não foi possível utilizar a fonte de controle de ${ }^{90} \mathrm{Sr}+{ }^{90} \mathrm{Y}$ para a realização de alguns testes de caracterização devido à fonte de controle de radiação beta possuir baixa atividade; além disso, a janela de entrada da câmara de ionização C5 é de acrílico, o que dificulta a passagem dos elétrons, provenientes desta fonte de controle.

Todos os testes foram realizados utilizando o objeto simulador de água com dimensões de $30 \times 30 \times 30 \mathrm{~cm}^{3}$. O campo de radiação foi de $10 \times 10 \mathrm{~cm}^{2}$ e a distância de referência foi de $5 \mathrm{~cm}\left(5 \mathrm{~g} / \mathrm{cm}^{2}\right)$ na água, de acordo com as condições de referência. $\mathrm{O}$ sistema de irradiação está apresentado na Figura 7.17. 


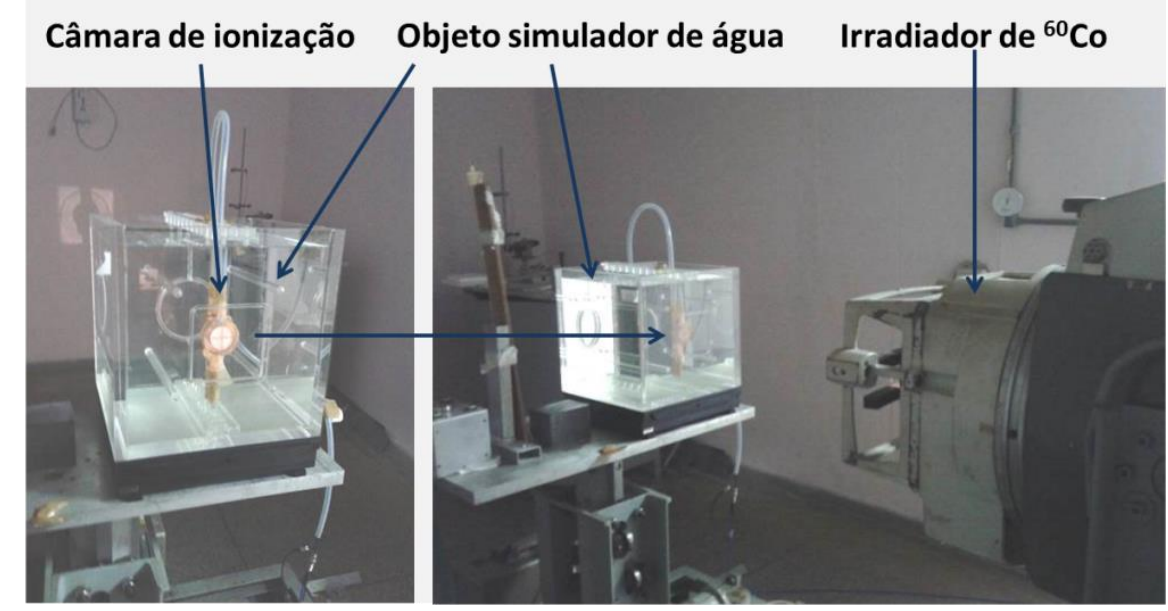

Figura 7. 17 Sistema de radiação com feixes de ${ }^{60}$ Co e objeto simulador de água utilizando a câmara de ionização C5 (LCI/IPEN)

\subsubsection{Tempo de estabilização}

O teste do tempo de estabilização foi realizado utilizando-se a fonte de radiação gama de ${ }^{60} \mathrm{Co}$ (Siemens / Gammatron II S80) juntamente com o objeto simulador de água. O método de polarização do eletrômetro e da obtenção das medições foi o mesmo utilizado no teste de estabilização apresentado no item 7.1.1.1.

A câmara de ionização C5 apresentou uma variação na medição entre 15 min e 1 hora de $0,72 \%$ e a variação da medição entre 1 hora e 2 horas foi de $0 \%$. A câmara de ionização C5 apresentou uma variação maior que $0,5 \%$ quando obtidas suas medições após 15 min de polarização em relação às medições obtidas em 1 h; a câmara de ionização necessita de um intervalo de tempo maior que 15 min para se estabilizar. O tempo de estabilização escolhido foi de $30 \mathrm{~min}$.

\subsubsection{Repetibilidade da resposta}

Utilizando a fonte de radiação gama de ${ }^{60} \mathrm{Co}$ (Siemens / Gammatron II S80) juntamente com o objeto simulador de água foi realizado o teste de repetibilidade da resposta da câmara de ionização C5. Foram realizadas 10 medições consecutivas para cada polaridade da tensão de $300 \mathrm{~V}$ e cada medição levou 30 s. A maior variação do desvio padrão das 10 medições realizadas para cada polaridade de tensão foi de $0,07 \%$ 
para a polaridade positiva e $0,08 \%$ para a polaridade negativa. Estes resultados estão de acordo com o desvio padrão de 0,5\% recomendado pela norma IEC 60731 (2011).

\subsubsection{Estabilidade a médio prazo}

O teste da repetibilidade apresentado no item 7.2.1.2 foi repetido oito vezes e o resultado está apresentado na Figura 7.18.

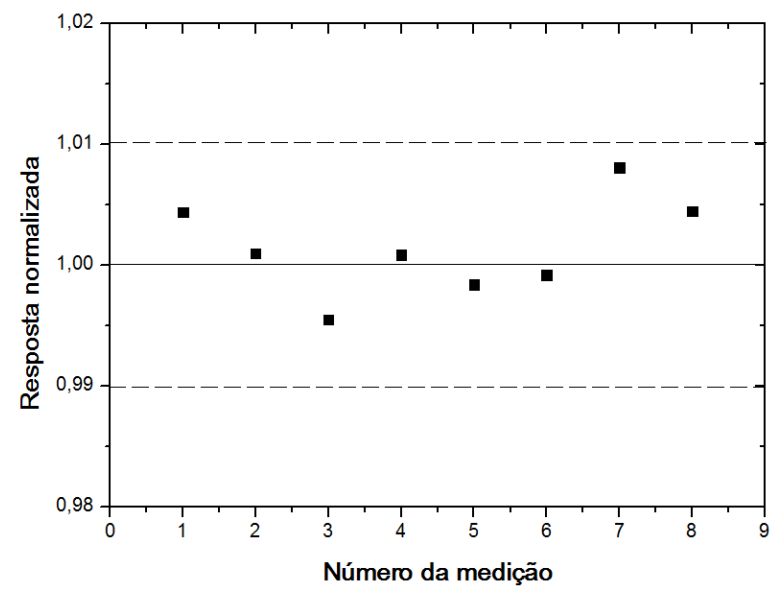

Figura 7.18 Estabilidade a médio prazo da resposta da câmara de ionização C5. As incertezas foram menores que $0,06 \%$, não sendo visíveis nos gráficos. As linhas tracejadas representam os limites recomendados pela norma IEC 60731 (2011) (LCI/IPEN)

De acordo com a Figura 7.18, a câmara de ionização C5 apresenta em sua resposta uma variação de sua estabilidade menor que $1 \%$, e este valor está dentro do limite estabelecido pela norma IEC 60731 (2011).

\subsubsection{Corrente de fuga}

A corrente de fuga foi determinada coletando-se as cargas da câmara de ionização C5 durante $20 \mathrm{~min}$ sem a exposição de feixes de ${ }^{60}$ Co. Esta corrente foi comparada com a corrente obtida no teste de estabilidade no item 7.2.1.3. A maior 
corrente de fuga foi de $0,09 \%$ para as polaridades positiva e negativa. Os valores obtidos estão abaixo do valor limite (0,5\%) da norma IEC 60731 (2011).

\subsubsection{Corrente de saturação e eficiência de coleção de íons}

A câmara de ionização C5 foi exposta a feixes de radiação de ${ }^{60} \mathrm{Co}$, variando-se a tensão aplicada entre $\pm 50 \mathrm{~V}$ e $\pm 400 \mathrm{~V}$, em passos de $\pm 50 \mathrm{~V}$. Foram realizadas 10 medições de 30 s. Os resultados da corrente de saturação estão apresentados na Figura 7.19.

De acordo com a Figura 7.19, a câmara de ionização apresenta um comportamento simétrico para as polaridades positiva e negativa. A tensão de polaridade escolhida para esta câmara de ionização foi de $+300 \mathrm{~V}$.

A eficiência de coleção de íons foi de 1,000 para a polaridade positiva e de 0,999 para a polaridade negativa.

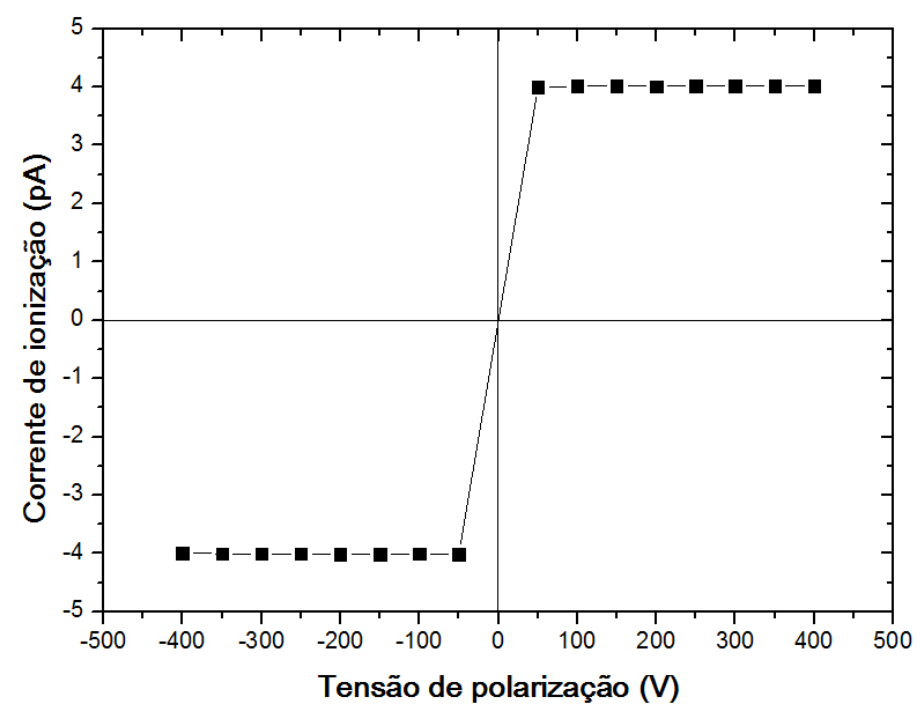

Figura 7.19 Curva de saturação da câmara de ionização C5. As incertezas foram menores que 0,09\%, não sendo visíveis nos gráficos (LCI/IPEN)

\subsubsection{Linearidade de resposta}

No teste de linearidade da resposta da câmara de ionização C5 foi utilizado o irradiador de ${ }^{60} \mathrm{Co}$, e as doses absorvidas na água foram variadas entre 6,23 $\mathrm{mGy}$ a 99,74 mGy, o que corresponde a um intervalo de tempo de irradiação de $15 \mathrm{~s} \mathrm{a} 240 \mathrm{~s}$. A 
curva de linearidade de resposta da câmara de ionização C5 está apresentada na Figura 7.20; de acordo com o ajuste linear da curva, o coeficiente de correlação foi exatamente igual a 1,000, o que significa que a resposta da câmara de ionização C5 apresenta um comportamento linear quando exposta ao feixe de radiação de ${ }^{60} \mathrm{Co}$.

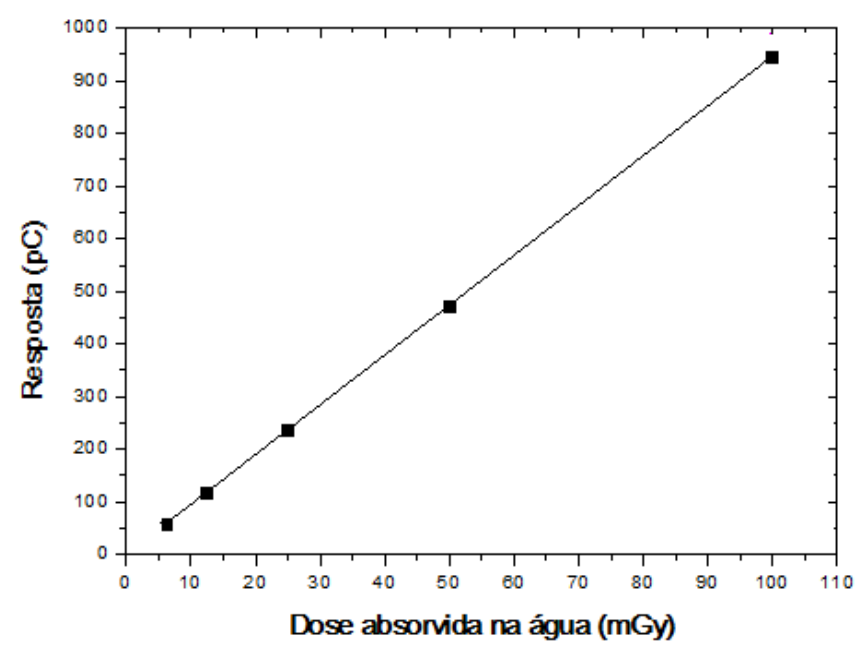

Figura 7.20 Curva de linearidade da resposta da câmara de ionização C5 em feixes de ${ }^{60}$ Co. A maior incerteza foi de $0,06 \%$, não sendo visível no gráfico (LCI/IPEN)

\subsubsection{Calibração da câmara de ionização em feixe de ${ }^{60} \mathrm{Co}$}

A câmara de ionização C5 foi calibrada em relação a uma câmara de ionização do tipo Farmer da PTW TN 30013, da mesma forma que a calibração tratada no item 7.1.1.8. Como a câmara de ionização C5 é à prova d'água não houve a necessidade de utilizar uma capa protetora de borracha. O ponto efetivo da câmara de ionização C5 encontra-se abaixo da espessura de $1 \mathrm{~mm}$ de acrílico da janela de entrada.

Utilizando os parâmetros fornecidos pela Equação 4.17 do capítulo 4 foi obtido o coeficiente de calibração, $N_{D, W}$, da câmara de ionização C5 que foi de $112,65 \mathrm{mGy} / \mathrm{nC}$ sendo o $N_{D, W}$ da câmara de ionização Farmer de 53,59 mGy/nC.

\subsubsection{Testes de caracterização realizados em Serviços de Radioterapia de São} Paulo, utilizando feixes de elétrons

Neste tópico serão apresentados os resultados dos testes realizados com a câmara de ionização C5 no ICESP e no InRad. Como esta câmara de ionização foi desenvolvida 
com o objetivo de utilizá-la dentro de água, todos os testes foram realizados utilizando um objeto simulador de água com exceção do teste da dependência angular do item 7.2.2.4.

As Figuras 7.21, 7.22 e 7.23 ilustram os arranjos experimentais utilizando o objeto simulador de água no ICESP.

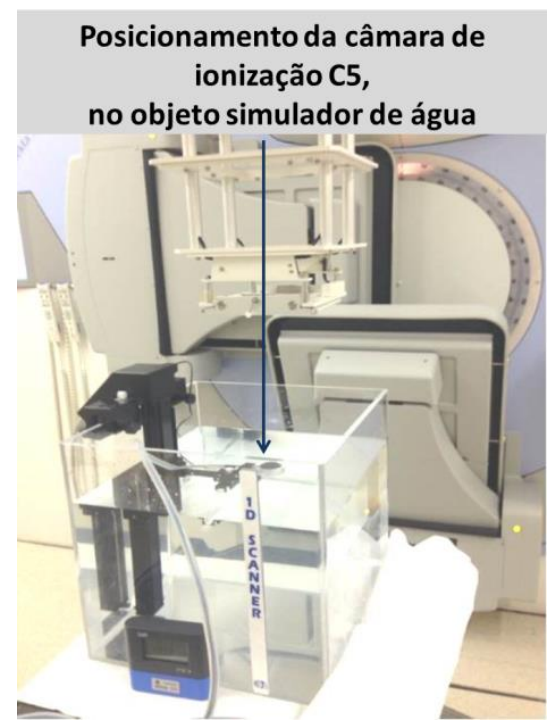

Figura 7.21 Esquema de posicionamento da câmara de ionização C5 no objeto simulador de água do ICESP

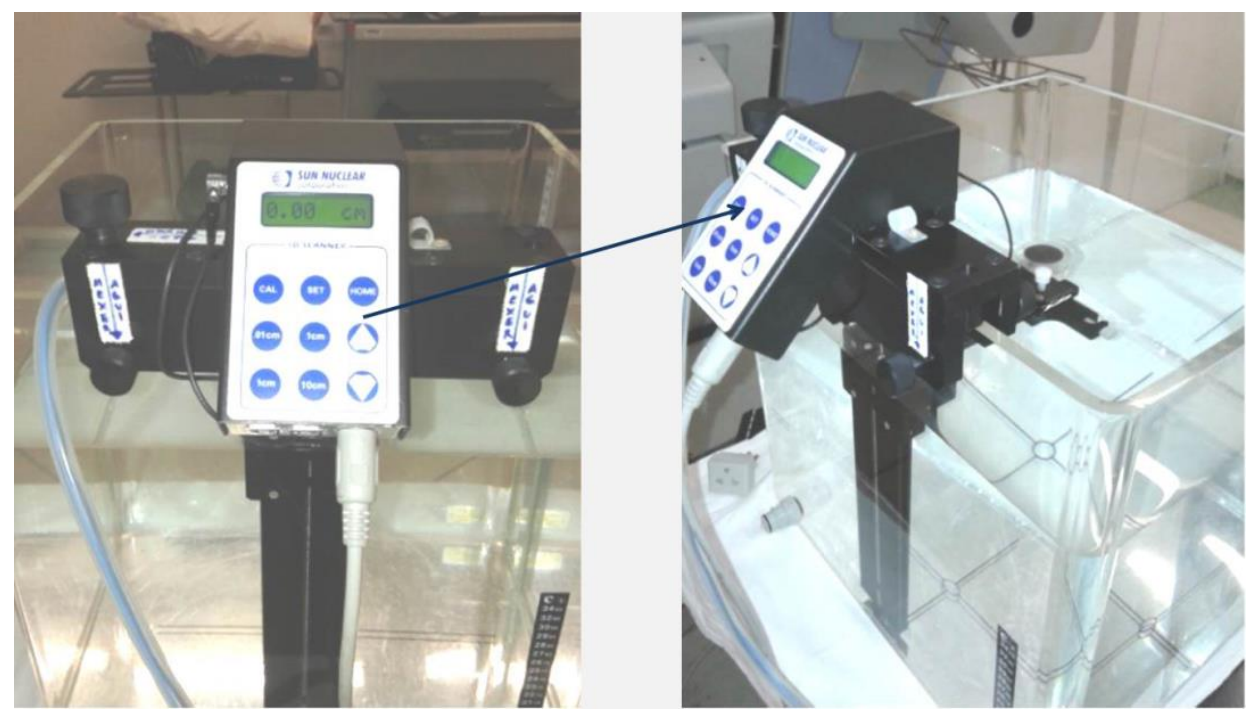

Figura 7.22 Dispositivo de posicionamento automático da câmara de ionização, que ajusta a profundidade da câmara de ionização em mm (ICESP) 


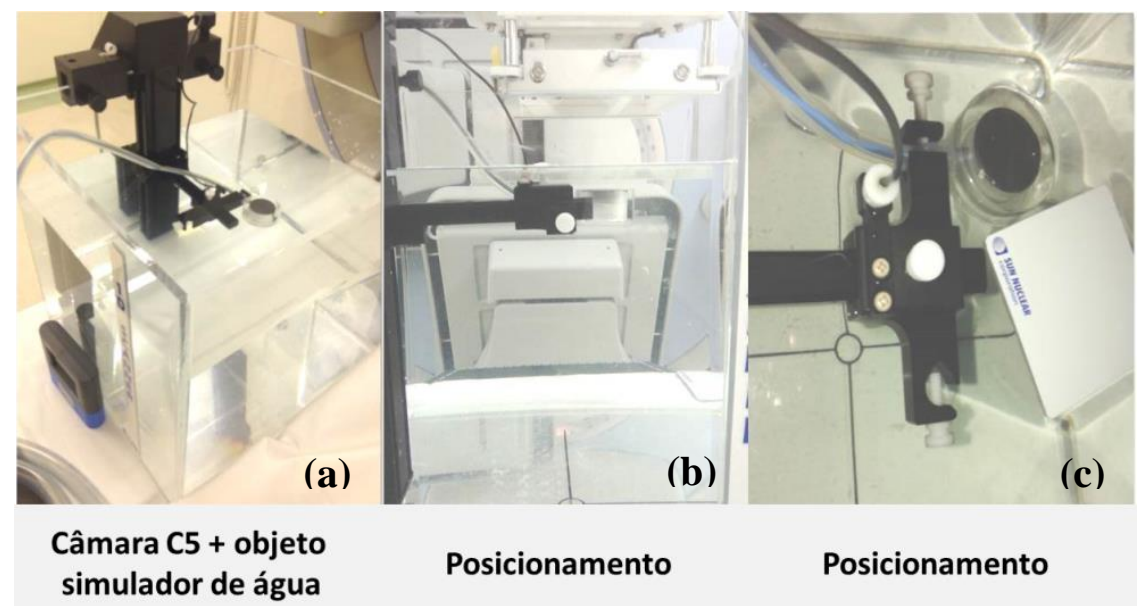

Figura 7.23 Visualização da câmara de ionização C5 dentro do objeto simulador de água (a); verificação da câmara de ionização na posição horizontal (b); verificação da distância fonte - detector e alinhamento e centralização da câmara de ionização em relação ao feixe de radiação (c) (ICESP)

\subsubsection{Linearidade de resposta}

O teste da linearidade foi realizado no ICESP utilizando o acelerador linear Elekta Synergy com feixes de elétrons com energias de $12 \mathrm{MeV}$ e $15 \mathrm{MeV}$, com uma taxa de dose absorvida de 3,63 Gy/min para $12 \mathrm{MeV}$ e 3,58 Gy/min para $15 \mathrm{MeV}$, o que corresponde a $400 \mathrm{UM} / \mathrm{min}$. Também foi utilizado um objeto simulador de água. Foram tomadas 3 medições para 100, 200, 400, 600, 800 e 1000 UM utilizando um sistema denominado cone de elétrons de referência, com campo de $14 \times 14 \mathrm{~cm}^{2}$. A distância de referência entre a fonte de elétrons e as câmaras de ionização foi de $100 \mathrm{~cm}$. As curvas de linearidade da resposta da câmara de ionização C5 para feixes de elétrons com energias de $12 \mathrm{MeV}$ e $15 \mathrm{MeV}$ estão apresentadas na Figura 7.24. Foi realizado o ajuste linear das curvas obtidas e os coeficientes de correlação foram exatamente iguais a 1,000 . 

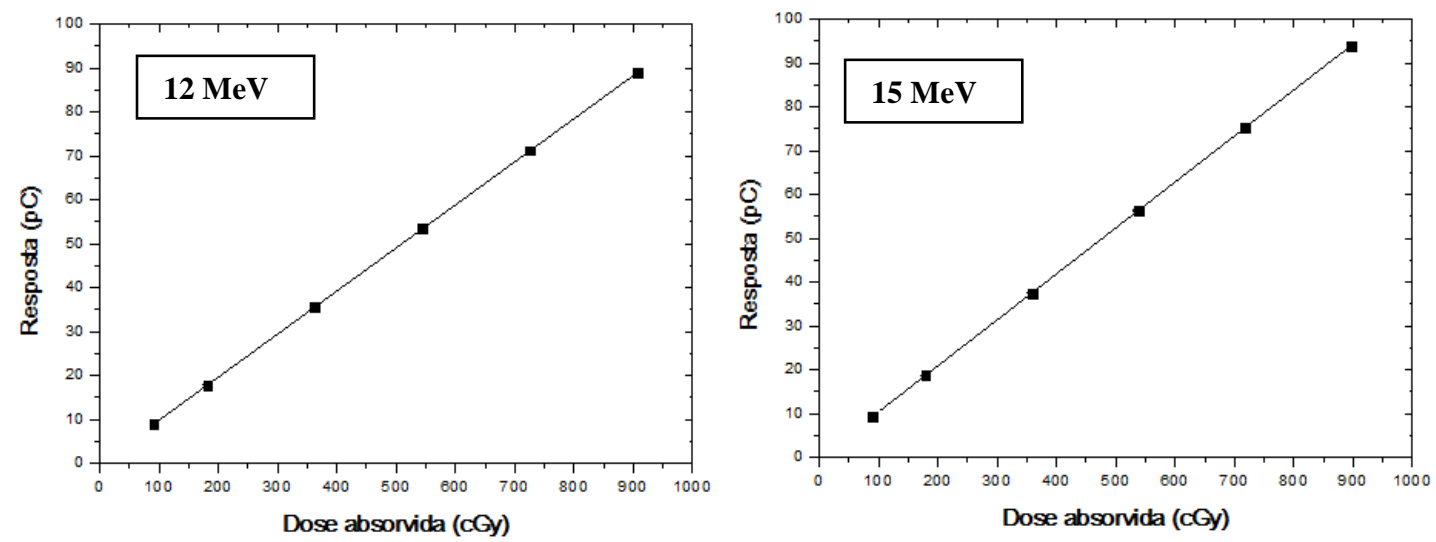

Figura 7.24 Linearidade de resposta da câmara de ionização C5 em feixes de elétrons com energias de $12 \mathrm{MeV}$ e $15 \mathrm{MeV}$. As incertezas foram menores que 0,34\%, não sendo visíveis nos gráficos (ICESP)

\subsubsection{Efeito de polaridade em relação ao alcance prático}

Foi realizado o teste do efeito de polaridade às profundidades de $0,1 \mathrm{Rp}$, 0,3 Rp, 0,5 Rp e 0,7 Rp do alcance prático, especificadas na norma IEC 60731 (2011). O alcance prático foi determinado utilizando o dispositivo de posicionamento da câmara de ionização, apresentado na Figura 7.22. Um sistema denominado cone de elétrons de referência, com campo de $14 \times 14 \mathrm{~cm}^{2}$ foi utilizado neste teste.

Primeiramente, foram obtidas medições na polaridade positiva e posteriormente na polaridade negativa. De acordo com a norma IEC 60731 (2011), a diferença percentual entre os resultados com as polaridades negativa e positiva não deve ser maior que $0,3 \%$ para cada profundidade. De acordo com a Figura 7.25, a diferença percentual foi maior que $0,3 \%$; este comportamento é semelhante ao apresentado pelas câmaras de ionização C1, C2, C3 e C4, de acordo com a Figura 7.9. No caso da câmara de ionização C5 essa diferença foi menor 3\%. Mas isto não é um problema se a câmara de ionização for sempre utilizada em uma mesma polaridade e com o mesmo potencial, o que está de acordo com a rotina das câmaras de ionização utilizadas em Serviços de Radioterapia. 


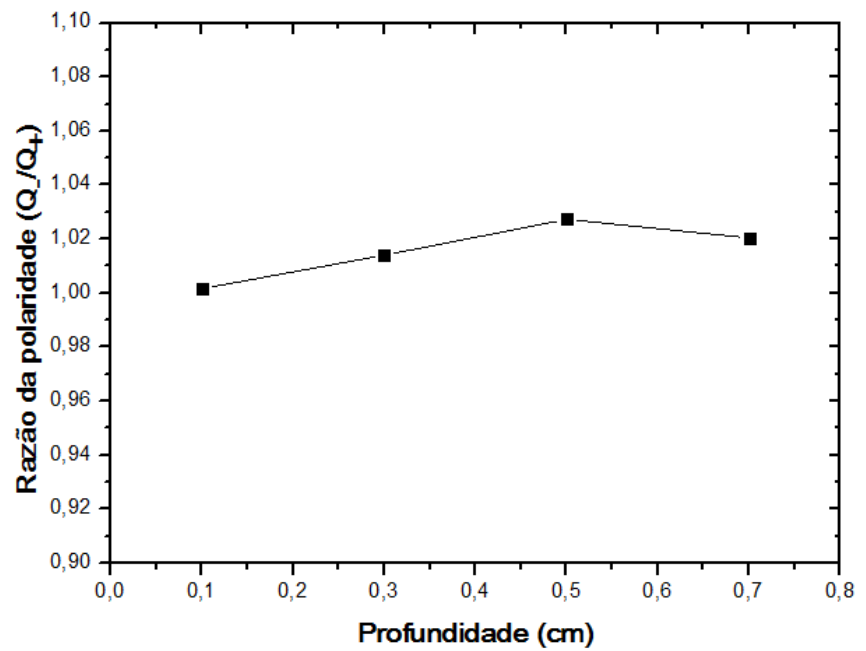

Figura 7.25 Efeito de polaridade da câmara de ionização C5 em feixes de elétrons com energia de $12 \mathrm{MeV}$. As incertezas foram menores que $0,30 \%$, não sendo visíveis no gráfico (ICESP)

\subsubsection{Dependência angular}

O teste da dependência angular foi realizado utilizando o goniômetro de acrílico apresentado na Figura 7.26, em feixes de elétrons do acelerador linear Elekta Synergy para as energias de $12 \mathrm{MeV}$ e $15 \mathrm{MeV}$, no ICESP. O ângulo de incidência da radiação variou de $0^{\circ}$ a $315^{\circ}$ em torno do eixo central da câmara, em intervalos de $45^{\circ}$. O campo de radiação de referência foi de $14 \times 14 \mathrm{~cm}^{2}$ e cada medição foi de $100 \mathrm{UM}$, a uma taxa de dose absorvida de 3,632 Gy/min para $12 \mathrm{MeV}$ e 3,584 Gy/min para $15 \mathrm{MeV}$, o que corresponde a $400 \mathrm{UM} / \mathrm{min}$. A distância de referência entre a câmara de ionização e a fonte de feixe de elétrons foi de $100 \mathrm{~cm}$. A câmara de ionização C5 apresentou um ótimo desempenho, com dependência angular nula para as duas energias utilizadas, em todos os ângulos. 

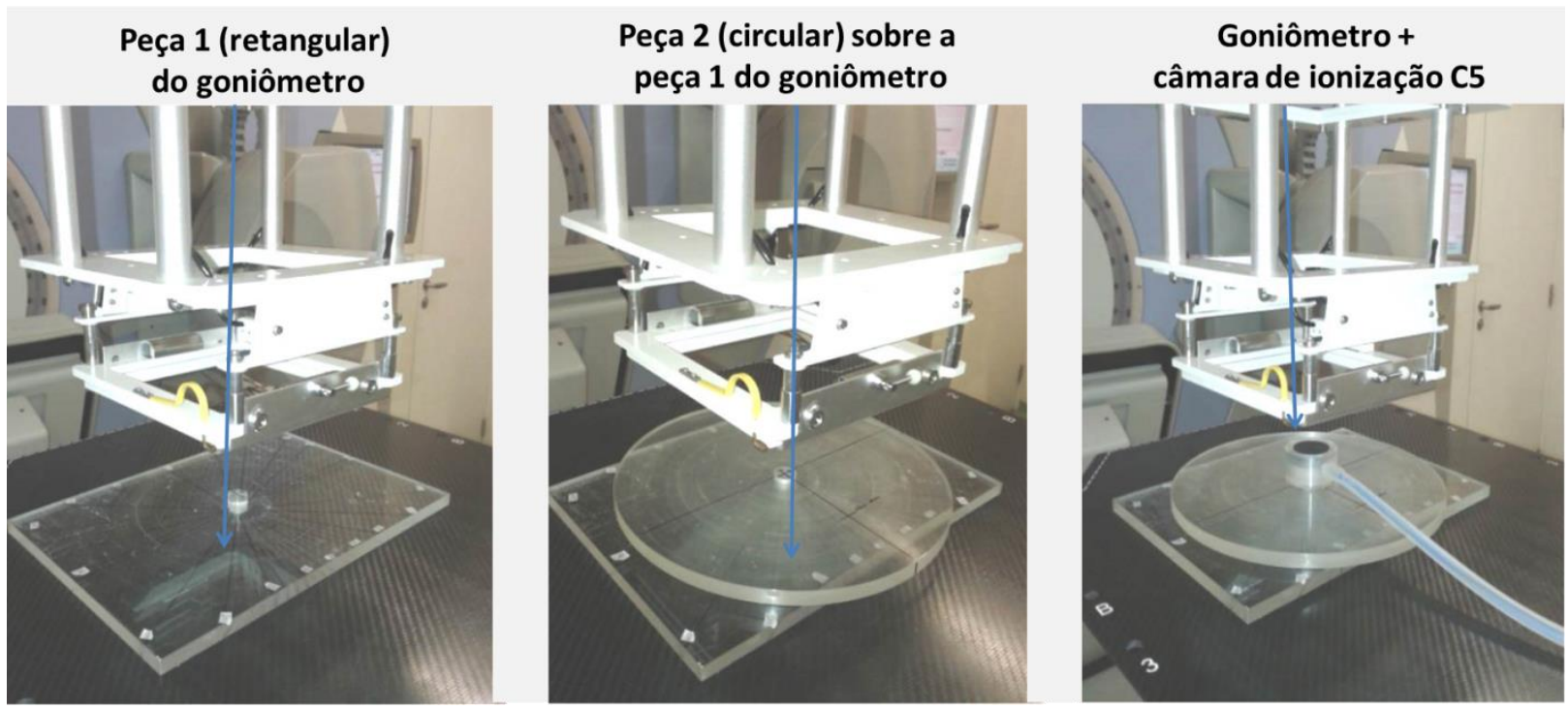

Figura 7.26 Esquema de montagem do goniômetro para a realização do teste da dependência angular (ICESP)

\subsubsection{Calibração da câmara de ionização C5 em feixes de elétrons do InRad}

As Figuras 7.27 e 7.28 mostram os arranjos experimentais do método de calibração e também para a construção da curva de ionização da câmara de ionização C5, do item 7.2.2.5.

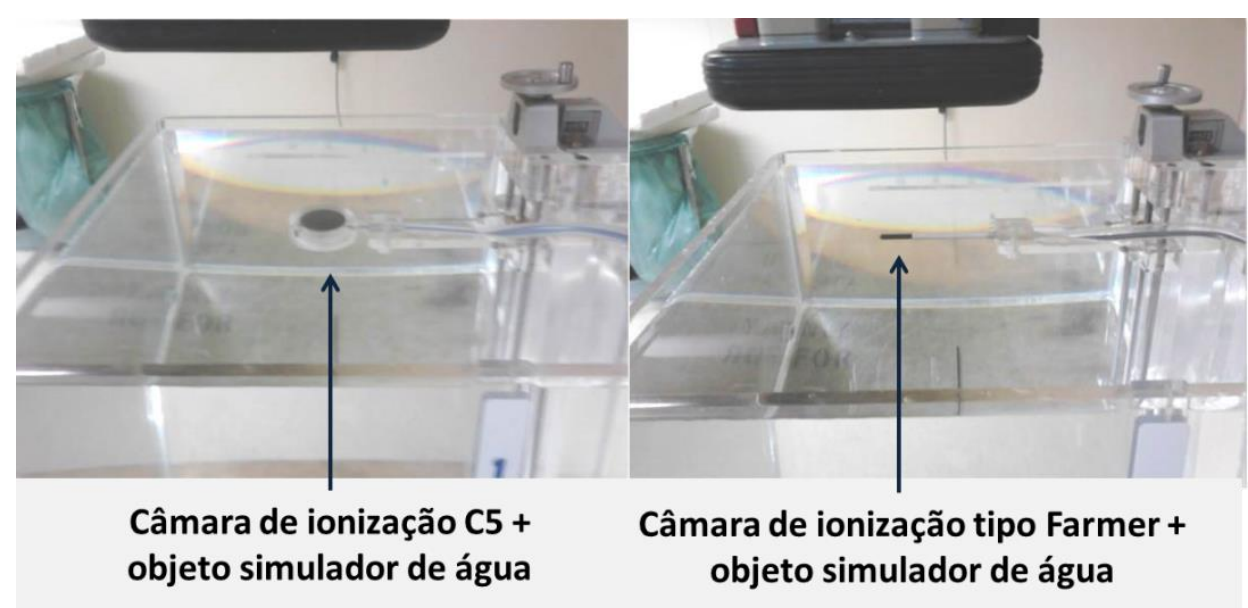

Figura 7.27 Posicionamento da câmara de ionização C5 e câmara de ionização tipo do Farmer (InRad) 


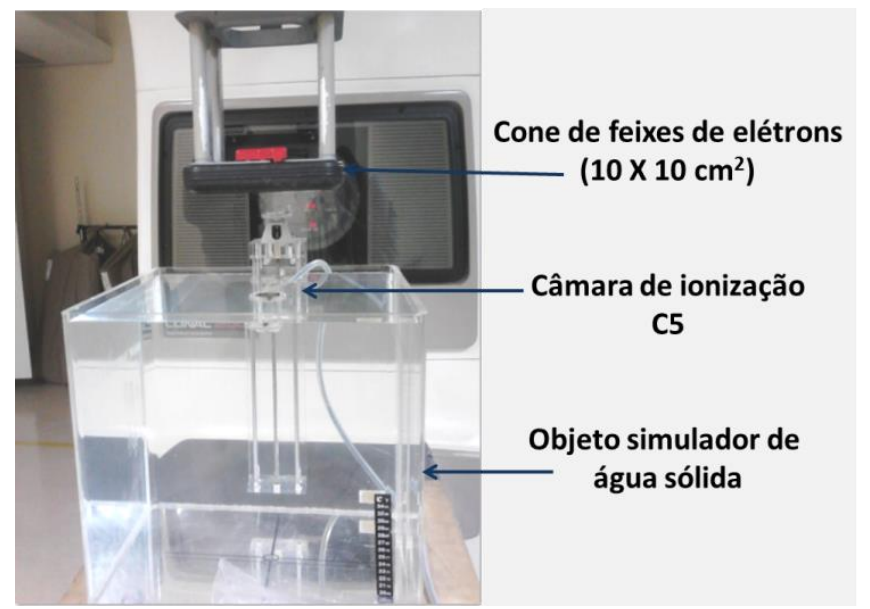

Figura 7.28 Esquema de irradiação da câmara de ionização C5 no acelerador linear do InRad

A câmara de ionização C5 foi calibrada em relação à câmara de ionização do tipo Farmer Scanditronix, FC-65P. A câmara de ionização do tipo Farmer foi irradiada centralizando o seu ponto de referência em um objeto simulador de água com dimensões de $30 \times 30 \mathrm{~cm}^{2}$. O campo de radiação foi de $10 \times 10 \mathrm{~cm}^{2}$ e a profundidade de referência em água foi de 3,64 cm, sendo a distância fonte-detector de $100 \mathrm{~cm}$, de acordo com as condições de referência. Foram obtidas cinco medições, sendo cada medição de $100 \mathrm{UM}$ a uma taxa de 3,20 Gy/min (320 UM/min), utilizando o feixe de $15 \mathrm{MeV}$. Da mesma forma, a câmara de ionização C5 foi irradiada, centralizando o seu ponto de referência após a espessura de $1 \mathrm{~mm}$ de acrílico da janela de entrada. $\mathrm{O}$ valor de tensão utilizado para a câmara de ionização do tipo Farmer foi de $-300 \mathrm{~V}$ e para a câmara de ionização C5 foi de $+300 \mathrm{~V}$.

De acordo com os parâmetros apresentados na Equação 4.17, foi obtido o coeficiente de calibração, $N_{D, W}$, da câmara de ionização C5, que foi de 111,9 mGy/nC, sendo que o coeficiente de calibração $N_{D, W}$ da câmara de ionização do tipo Farmer é de $48,4 \mathrm{mGy} / \mathrm{nC}$.

\subsubsection{Curva de ionização da câmara de ionização C5}

Foram realizadas medições em diferentes profundidades em água com o objetivo de se obter a curva de ionização da câmara de ionização C5. As condições de referência foram: campo de radiação foi de $10 \times 10 \mathrm{~cm}^{2}$; profundidade de referência de 3,64 cm; 
distância fonte-detector de $100 \mathrm{~cm}$; e energia do feixe de $15 \mathrm{MeV}$. A variação da profundidade de medição foi de 0 a $7 \mathrm{~cm}$ de profundidade em água. Para cada profundidade foram obtidas cinco leituras, sendo cada leitura de 100 UM a uma taxa de dose absorvida 3,20 Gy/min (320 UM/min).

A curva de ionização da câmara de ionização C5, formada por 20 pontos de diferentes profundidades, está apresentada na Figura 7.29 e pôde ser comparada com a curva de ionização da câmara de ionização do tipo Farmer, formada por mais de 96 pontos de diferentes profundidades, de 0 a $7 \mathrm{~cm}$. As medições da resposta da câmara de ionização Farmer foram gentilmente cedidas pelo InRad, e estão apresentadas na Figura 7.30.

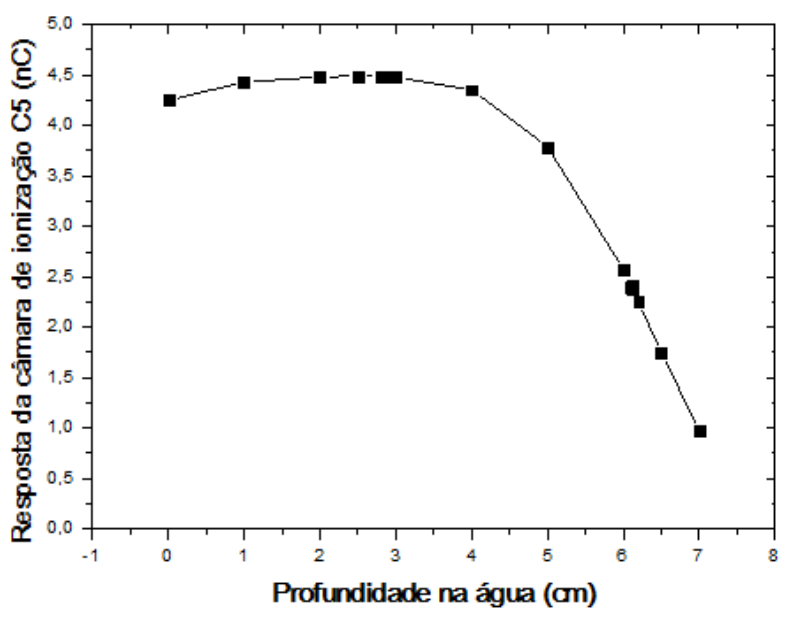

Figura 7.29 Curva de ionização da câmara de ionização C5 (InRad)

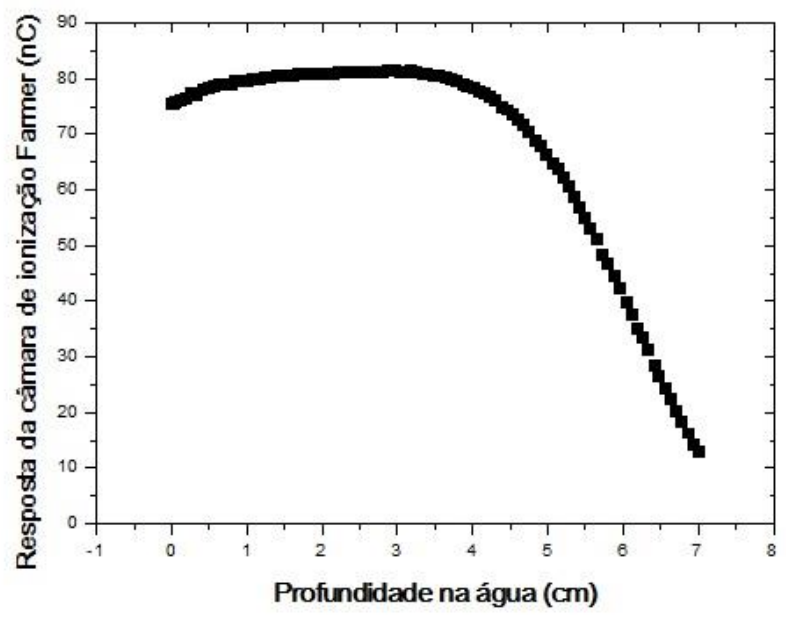

Figura 7.30 Curva de ionização da câmara de ionização do tipo Farmer. Dados fornecidos pelo InRad 
De acordo com a Figura 7.29, a curva de ionização da câmara de ionização C5 apresenta um comportamento semelhante ao da curva de ionização da câmara de ionização do tipo Farmer apresentada na Figura 7.30. Como as profundidades utilizadas foram só até $7 \mathrm{~cm}$, não é possível observar nas duas curvas a profundidade do alcance prático como na Figura 4.4.

De acordo com os dados obtidos na curva de ionização da câmara de ionização C5, foi possível obter algumas informações adicionais, utilizando uma planilha de um CR-ROM oferecido pelo curso à distância da Fundação Oswaldo Cruz Fiocruz e elaborado pelo setor de controle de qualidade em radioterapia do Instituto Nacional do Câncer (INCA, 2014a). Essas informações foram comparadas com os parâmetros obtidos da calibração do feixe de elétrons, fornecido pelo InRad, para a energia de $15 \mathrm{MeV}$. As informações estão apresentadas na Tabela 7.7.

\section{Tabela 7.7 Comparação entre os parâmetros obtidos pela curva de ionização da câmara de ionização C5 e os parâmetros fornecidos pelo InRad}

\begin{tabular}{lcc}
\hline Parâmetros da curva & $\begin{array}{c}\text { Câmara de } \\
\text { ionização C5 }\end{array}$ & $\begin{array}{c}\text { Informações do } \\
\text { feixe de elétrons } \\
\text { (InRad) }\end{array}$ \\
\hline Energia & $15 \mathrm{MeV}$ & $15 \mathrm{MeV}$ \\
$\mathrm{R}_{50}$ & $6,32 \mathrm{~cm}$ & $6,23 \mathrm{~cm}$ \\
$\mathrm{Z}_{\text {referência }}$ & $3,69 \mathrm{~cm}$ & $3,64 \mathrm{~cm}$ \\
Porcentagem de dose em $\mathrm{Z}_{\text {referência }}$ & $99,27 \%$ & $99,5 \%$ \\
Profundidade para dose máxima em & $2,91 \mathrm{~cm}$ & $2,93 \mathrm{~cm}$ \\
$Z_{\text {máximo }}$ & & \\
\hline
\end{tabular}

Os valores obtidos para a câmara de ionização C5 estão próximos aos valores de referência dos feixes de elétrons com energia de $15 \mathrm{MeV}$ do acelerador linear Varian 2100 do InRad, com uma diferença máxima de 1,45\% entre os valores obtidos para a profundidade $\mathrm{R}_{50}$. Deve-se levar em consideração que para se obter os valores de referência do feixe de radiação de elétrons com $15 \mathrm{MeV}$, pelo InRad, foram obtidos mais de 96 pontos enquanto que com a câmara de ionização C5 foi possível obter somente 20 pontos para montar a curva de ionização.

O teste do efeito do cabo não foi realizado para a câmara de ionização C5, pois esta possui, além dos cabos elétricos, um cabo de silicone, que dificulta a interferência da radiação de elétrons nas medições; além disso, este teste com as outras câmaras de ionização demonstrou que cabos elétricos dificilmente recebem interferência da radiação de elétrons em seu sinal. 
Também não foi realizado o teste de simetria da câmara de ionização C5, porque foi utilizado um objeto simulador de água, que dificultaria a realização do teste e o teste de simetria já tinha sido realizado nas duas câmaras de ionização $\mathrm{C} 1$ e C3, que possuem eletrodo coletor com o mesmo material do eletrodo coletor da câmara de ionização C5.

\subsection{Caraterísticas comparativas entre as câmaras de ionização desenvolvidas}

Este tópico trata da comparação entre as características e o comportamento das câmaras de ionização desenvolvidas.

A tabela 7.8 apresenta as caraterísticas de cada câmara de ionização. Com exceção da câmara de ionização C5, as outras câmaras de ionização apresentam volumes sensíveis bem próximos.

As Tabelas 7.9 e 7.10 apresentam um resumo das respostas das câmaras de ionização em relação a alguns testes realizados no LCI/IPEN e nos Serviços de Radioterapia do Hospital Albert Einstein, ICESP e InRad.

De acordo com a Tabela 7.9 as câmaras de ionização C1, C2, C3 e C4 apresentam um comportamento bem semelhante na maioria dos testes, apesar dos eletrodos coletores serem de materiais diferentes, exceto no caso das câmaras de ionização C1 e C3, que possuem o mesmo material, mas volumes sensíveis diferentes.

Particularmente, a câmara de ionização C2 apresenta um tempo de resposta mais rápido que as outras câmaras de ionização quando se observa no eletrômetro. O mesmo deu-se no momento da confecção das câmaras de ionização $\mathrm{C} 1$ a C4: a câmara de ionização C2 apresentou uma maior condutividade no material de tinta de prata, utilizado para pintar o eletrodo coletor, quando testada por um multímetro. A tinta de prata conseguiu ficar espalhada no eletrodo coletor de forma mais homogênea em relação aos outros materiais utilizados nos eletrodos coletores das demais câmaras de ionização. De forma diferente da tinta de prata, o grafite em pó deixava o eletrodo coletor com pequenas granulações e o grafite em spray não espalhava de forma muito homogênea num material de área pequena.

Neste contexto, a câmara de ionização C2 possui uma predileção, pois apresenta uma resposta mais rápida em relação às outras câmaras de ionização $\mathrm{C} 1, \mathrm{C} 3$ e C4.

Outro ponto a ser apresentado sobre o desenvolvimento das câmaras de ionização é de que existe uma importância na utilização do material de grafite em pó 
misturado com esmalte de unha; esta mistura é um material diferente dos materiais que normalmente são utilizados pelo grupo do LCI do IPEN na confecção das câmaras de ionização, além de ser barato e de fácil aquisição e preparação. No início houve uma certa preocupação, durante a primeira tentativa, de que a mistura poderia não apresentar condutividade elétrica, mas felizmente este material funcionou e de forma eficaz.

A câmara de ionização C5 foi a mais esperada de todas, por ser à prova d'água. Imaginar como seria a vedação desta câmara de ionização não foi muito fácil, ainda mais se pensando na construção de uma câmara de ionização de baixo custo. A câmara de ionização C5 foi construída, após uma tentativa anterior não ter dado certo. Apesar de algumas dificuldades no design da câmara de ionização C5, ela foi desenvolvida e apresentou resultados satisfatórios nos testes realizados.

Apesar da câmara de ionização C2 com eletrodo coletor de prata apresentar um tempo de resposta mais rápido em relação às câmaras de ionização $\mathrm{C} 1, \mathrm{C} 2, \mathrm{C} 3$ e C4, para a escolha do material do eletrodo coletor da câmara de ionização C5, foi levado em conta a necessidade da câmara de ionização apresentar em sua estrutura materiais próximos à da densidade da água. Por isto, a câmara de ionização C5 possui eletrodo coletor de grafite.

Todas as câmaras de ionização foram desenvolvidas buscando-se materiais com custo reduzido, mas sempre com a preocupação de qualidade do produto final. A estimativa do custo da confecção das câmaras de ionização e dos demais acessórios utilizados neste trabalho estão apresentados na Tabela 7.11, sem contabilizar o custo do desenvolvimento. Pode-se ver que todas as câmaras de ionização apresentaram um custo muito baixo. 
Tabela 7.8 Características das câmaras de ionização desenvolvidas

\begin{tabular}{cccccc}
\hline \multirow{2}{*}{ Características } & \multicolumn{5}{c}{ Câmaras de ionização desenvolvidas } \\
\cline { 2 - 6 } & C1 & C2 & C3 & C4 & C5 \\
\hline Corpo & PMMA & PMMA & PMMA & PMMA & PMMA \\
Eletrodo coletor pintado & $\begin{array}{c}\text { Esmalte de } \\
\text { unha incolor+ }\end{array}$ & $\begin{array}{c}\text { Tinta de } \\
\text { prata } \\
\text { grafite em pó }\end{array}$ & $\begin{array}{c}\text { Esmalte de } \\
\text { unha incolor+ } \\
\text { grafite em pó }\end{array}$ & $\begin{array}{c}\text { Spray de } \\
\text { grafite }\end{array}$ & $\begin{array}{c}\text { Esmalte de } \\
\text { unha incolor+ } \\
\text { grafite em pó }\end{array}$ \\
Janela de entrada & Mylar & Mylar & Mylar & Mylar & PMMA \\
Diâmetro do eletrodo $(\mathrm{mm})$ & 17,0 & 17,0 & 16,0 & 16,0 & 16,0 \\
Largura do anel de guarda $(\mathrm{mm})$ & 3,0 & 3,0 & 3,0 & 3,0 & 3,0 \\
Separação dos eletrodos $(\mathrm{mm})$ & 1,5 & 1,5 & 2,0 & 2,0 & 1,0 \\
Volume sensível $\left(\mathrm{cm}^{3}\right)$ & 0,34 & 0,34 & 0,40 & 0,40 & 0,20 \\
\hline
\end{tabular}

Tabela 7.9 Resultados comparativos das câmaras de ionização C1, C2, C3 e C4

\begin{tabular}{|c|c|c|c|c|c|}
\hline \multirow[b]{2}{*}{ Teste } & \multicolumn{5}{|c|}{ Câmaras de ionização desenvolvidas } \\
\hline & C1 & $\mathbf{C 2}$ & C3 & $\mathrm{C4}$ & $\begin{array}{c}\text { Concordâcia } \\
\text { com a } \\
\text { norma } \\
\text { IEC } 60731 \\
\end{array}$ \\
\hline \multicolumn{6}{|l|}{ LCI/IPEN } \\
\hline Tempo de estabilização (min) & 30 & 30 & 30 & 30 & $*$ \\
\hline Repetibilidade da resposta (\%) & 0,04 & 0,02 & 0,02 & 0,02 & $\checkmark$ \\
\hline Estabilidade a médio prazo (\%) & $<1$ & $<1$ & $<1$ & $<1$ & $\checkmark$ \\
\hline Corrente de fuga $(\%)$ & $<0,03$ & $<0,02$ & $<0,05$ & $<0,03$ & $\checkmark$ \\
\hline Tensão escolhida (V) & +300 & +300 & +300 & +300 & - \\
\hline Eficiência de coleção de íons (\%) & $<1$ & $<1$ & $<1$ & $<1$ & $\checkmark$ \\
\hline $\begin{array}{l}\text { Coeficiente de correlação da } \\
\text { linearidade da resposta }\end{array}$ & 1,000 & 1,000 & 1,000 & 1,000 & - \\
\hline $\begin{array}{l}\text { Variação da resposta em } \\
\text { distância fonte-detector (\%) }\end{array}$ & 6,2 & 6,3 & 1,7 & 2,5 & - \\
\hline$N_{D, W} / \mathrm{Co}(\mathrm{mGy} / \mathrm{nC})$ & 89,83 & 67,17 & 76,75 & 79,18 & - \\
\hline \multicolumn{6}{|l|}{ Serviços de Radioterapia } \\
\hline $\begin{array}{l}\text { Coeficiente de correlação da } \\
\text { linearidade da resposta }\end{array}$ & 1,000 & 1,000 & 1,000 & 1,000 & - \\
\hline $\begin{array}{l}\text { Efeito polaridade/ } \\
\text { alcance prático }(\%)\end{array}$ & $<6$ & $<6$ & $<5$ & $<6$ & $* *$ \\
\hline Efeito de polaridade/campo (\%) & $<1$ & $<1$ & $<1$ & $<1$ & - \\
\hline Efeito do cabo $(\%)$ & $<0,2$ & $<0,2$ & $<0,2$ & $<0,2$ & - \\
\hline Simetria $(\%)$ & $<0,6$ & $<0,6$ & $<0,6$ & $<0,6$ & - \\
\hline Dependência angular (\%) & $<0,1$ & $<0,1$ & $<0,1$ & $<0,1$ & - \\
\hline
\end{tabular}


Tabela 7.10 Resultados comparativos da câmara de ionização C5

\begin{tabular}{ccc}
\hline & \multicolumn{2}{c}{ Câmara de ionização } \\
\cline { 2 - 3 } Teste & C5 & $\begin{array}{c}\text { Concordância } \\
\text { com a norma } \\
\text { IEC 60731 }\end{array}$ \\
\hline IPEN & 30 & $*$ \\
\hline Tempo de estabilização (min) & $<0,08$ & $\checkmark$ \\
Repetibilidade da resposta (\%) & $<1$ & $\checkmark$ \\
\hline Estabilidade a médio prazo (\%) & $<0,09$ & $\checkmark$ \\
Corrente de fuga (\%) & +300 & - \\
Tensão escolhida (V) & 1,000 & - \\
Coeficiente de correlação da \\
linearidade da resposta \\
$N_{D, W}$ / Co (mGy/nC) & 112,65 & - \\
Serviços de Radioterapia & & $* *$ \\
Coeficiente de correlação da \\
linearidade da resposta \\
Efeito polaridade/ \\
alcance prático (\%)
\end{tabular}

*C5 está de acordo com a norma, nas medições realizadas entre $1 \mathrm{~h}$ e $2 \mathrm{~h}$ de irradiação.

**está acima de 0,3\%, mas na norma TRS 469 (IAEA, 2009) o efeito de polaridade não é um problema. 
Tabela 7.11 Estimativa do custo da confecção das câmaras de ionização e demais acessórios

\begin{tabular}{|c|c|c|c|c|c|}
\hline \multirow{2}{*}{ Materiais } & \multicolumn{5}{|c|}{ Câmaras de ionização desenvolvidas } \\
\hline & $\mathrm{C} 1$ & $\mathrm{C} 2$ & $\mathrm{C} 3$ & $\mathrm{C} 4$ & $\mathrm{C} 5$ \\
\hline Acrílico PMMA (R\$) & 148,00 & 148,00 & 148,00 & 148,00 & 148,00 \\
\hline Usinagem $(\mathrm{R} \$)$ & 302,20 & 302,20 & 302,20 & 302,20 & $*$ \\
\hline Cabo e conector $(\mathrm{R} \$)$ & 15,00 & 15,00 & 15,00 & 15,00 & 58,72 \\
\hline Spray de grafite $(\mathrm{R} \$)$ & - & - & - & 50,00 & - \\
\hline $\begin{array}{l}\text { Esmalte de unhat pó de grafite } \\
(\mathrm{R} \$)\end{array}$ & 3,00 & - & 3,00 & - & 3,00 \\
\hline Tinta de prata $(\mathrm{R} \$)$ & - & 40,00 & - & - & - \\
\hline Total $(\mathbf{R} \$)$ & 468,20 & 505,20 & 468,20 & 515,20 & 209,72 \\
\hline Acrílico PMMA + usinagem $(\mathrm{R} \$)$ & Objeto $\mathrm{s}$ & mulador & e acrílico & Figura 5 & \\
\hline Usinagem $(\mathrm{R} \$)$ & Mesa de & acrílico ( & $\begin{array}{r}\text { igura } 5.8 \\
112,0\end{array}$ & & \\
\hline Usinagem (R\$) & Suporte & ara câm & $\begin{array}{r}\text { a de ioni- } \\
86,00 \\
\end{array}$ & ção (Fig & a 5.8) \\
\hline
\end{tabular}

*Oficina Mecânica do IPEN 


\section{Conclusões}

Este trabalho teve como objetivos projetar, construir e caracterizar sistemas de referência para feixes de elétrons de aceleradores clínicos. Foram projetadas e construídas cinco câmaras de ionização. Os materiais utilizados para a confecção das câmaras de ionização foram adquiridos no mercado nacional, com um custo baixo e de fácil acesso. As tintas utilizadas para dar condutividade aos eletrodos coletores de acrílico das câmaras de ionização foram mistura de grafite em pó com esmalte de unha, spray de grafite e tinta de prata. Todas deram a condutividade necessária para que o eletrodo coletor pudesse coletar as cargas geradas no volume sensível das câmaras de ionização. Todas as câmaras de ionização foram projetadas obedecendo às diretrizes de normas internacionais (IAEA, 1995; IAEA, 2006) para desenvolvimento de câmaras de ionização utilizadas em feixes de elétrons.

As quatro primeiras câmaras de ionização apresentam design semelhante. Os volumes sensíveis das câmaras de ionização C1, C2, C3 e C4 foram respectivamente: $0,34 \mathrm{~cm}^{3}, 0,34 \mathrm{~cm}^{3}, 0,40 \mathrm{~cm}^{3}$ e $0,40 \mathrm{~cm}^{3}$.

A quinta câmara de ionização C5 é uma câmara de ionização à prova d'água, com volume sensível bem menor em relação às anteriores, de $0,20 \mathrm{~cm}^{3}$, e sua janela de entrada é de acrílico, diferente das demais câmaras de ionização que possuem janela de entrada de Mylar.

As câmaras de ionização desenvolvidas foram caracterizadas segundo as diretrizes da norma internacional IEC 60731 (2011); além disso, os testes dosimétricos também foram aplicados. Os testes foram realizados no Laboratório de Calibração de Instrumentos do IPEN, no Hospital Albert Einstein, no Instituto de Câncer do Estado de São Paulo e no Instituto de Radiologia do Hospital das Clínicas da Faculdade de Medicina da Universidade de São Paulo. Os testes aplicados foram: tempo de estabilização, repetibilidade da resposta, estabilidade a curto e médio prazos, corrente de fuga, corrente de saturação, eficiência de coleção de íons, linearidade de resposta, variação da resposta com a distância fonte-detector, efeito de polaridade, efeito cabo, simetria das câmaras de ionização, dependência angular. As respostas das cinco câmaras de ionização foram satisfatórias para todos os testes realizados, com exceção do efeito de polaridade; entretanto, isto não é um problema de acordo com a publicação TRS 469 (IAEA, 2009) para a câmara de ionização que for sempre utilizada com a mesma polaridade e com a mesma tensão, que condiz com a realidade do uso das câmaras de 
ionização na rotina dos Serviços de Radioterapia. Além disso, as respostas das câmaras de ionização apresentaram respostas semelhantes a câmaras de ionização comerciais, em relação ao teste de efeito de polaridade.

Além da caracterização das câmaras de ionização, para que elas possam ser utilizadas na rotina de um Serviço de Radioterapia em dosimetria de feixes de elétrons em aceleradores clínicos, foi necessário calibrar as câmaras de ionização em um feixe de radiação de referência e obter o coeficiente de calibração. As cinco câmaras de ionização foram calibradas em feixe de radiação gama, ${ }^{60} \mathrm{Co}$, e foram obtidos os coeficientes de calibração de dose absorvida na água. A câmara de ionização C5 foi também calibrada em relação a uma câmara de ionização do tipo Farmer, obtendo-se o coeficiente de calibração para dose absorvida na água em feixes de elétrons. Foi ainda obtida uma curva de ionização da resposta da câmara de ionização C5, que foi similar à curva de ionização apresentada pela câmara de ionização do tipo Farmer.

Atualmente os Serviços de Radioterapia realizam a dosimetria dos feixes de elétrons dos seus aceleradores lineares utilizando uma câmara de ionização à prova d'água. Portanto, o desenvolvimento da câmara de ionização C5 teve grande importância neste contexto.

O êxito dos resultados apresentados pelas respostas das cinco câmaras de ionização desenvolvidas neste trabalho, demostram que elas possuem potencial para uso em feixes de elétrons de aceleradores lineares de Serviços de Radioterapia. 


\section{Referências Bibliográficas}

AAPM (1999), AMERICAN ASSOCIATION OF PHYSICS IN MEDICINE. Task Group 51: Protocol for clinical reference dosimetry of high-energy photon and electron beams, Medical Physics, v. 26, pp. 1847-1870.

ABNT (2003), ASSOCIAÇÃO BRASILEIRA DE NORMAS TÉCNICAS. Guia para a expressão da incerteza de medição - 3 Edição - Edição revisada em 2003, Rio de Janeiro, ABNT, IMETRO.

ANKERHOLD et al (1999). ANKERHOLD, U.; BEHRENS, R.; AMBROSI, P. A prototype ionisation chamber as a secondary standard for the measurement of personal dose equivalent, $H_{p}(10)$, on a slab phantom. Radiation Protection Dosimetry, v. 86, n. 3, p. 167-173.

ALBUQUERQUE e CALDAS (1989). ALBUQUERQUE, M.P.P.; CALDAS, L.V.E. New ionization chambers for beta and X-radiation. Nuclear Instruments and Methods in Physics Research, v.280, pp. 310-313.

ALMOND et al (1994). ALMOND, P.R.; ATTIX, F.H.; HUMPHRIES, L.J. The calibration and use of plane-parallel ionization chambers for dosimetry of electron beams: an extension of the 1983 AAPM protocol report of AAPM Radiation Therapy Committee Task Group No. 39, Medical Physics, v. 21, pp. 1251-1260.

ANDREO (1992). ANDREO, P. Absorbed dose beam quality factors for the dosimetry of high-energy photon beams, Physics in Medicine and Biology, v. 37, pp. 2189 2211.

ARBABI et al (2010). ARBABI, K.; LARIJANI, M. M.; RAMAZANOV, M. Evaluation of a new ionisation chamber fabricated with carbon nanotubes. Radiation Protection Dosimetry. v. 141, p. 222-227. 
ATTIX (2004). F. H. Introduction to Radiological Physics and Radiation Dosimetry. Weinheim: WILEY-VCH Verlag GmbH \& Co.

BULSKI et al (2007). BULSKI, W.; ULKOWSKI, P.; GWIAZDOWSKA, B. Analysis of calibration coefficients of plane-parallel Markus type ionization chambers calibrated in ${ }^{60} \mathrm{Co}$ and electron beams, Polish Journal of Medical Physics and Engineering, v. 13, pp. 163-174.

CALDAS e ALBUQUERQUE (1992). CALDAS, L.V.E.; ALBUQUERQUE, M.P.P. Calibration of parallel plate ionization chambers in different kinds of radiation, Proceedings of the $8^{\text {th }}$ International Congress of IRPA, Canada.

CHMIELEWSKI (2011). CHMIELEWSKI, A. G. Electron accelerators for environmental protection, Word Scientific, v. 4, pp. 147-159.

COSTA e CALDAS (2008). COSTA, A.M.; CALDAS, L.V.E. Câmara de ionização de placas paralelas para radiação X de radiografia convencional e mamografia, Radiologia Brasileira, v. 41, pp. 39-43.

CULBERSON et al (2006). CULBERSON, W. S.; DeWERD, L. A.; ANDERSON, D. R.; MICKA J. A. Large-volume ionization chamber with variable apertures for airkerma measurements of low-energy radiation sources, Review of Scientific Instruments, v. 77, pp. 015105-1 - 015105-9.

DeWERD e MACKIE (2003). DeWERD, L. A.; MACKIE, R. Comment on "Comparison of ionization chambers of various volumes for IMRT absolute dose verification”. Medical Physics, v.30, p. 119-123.

DeWERD et al (2002). DeWERD, L. A.; MICKA, J. A.; LAIRD, R. W.; PEARSON, D. W.; O'BRIEN, M.; LAMPERTI, P. The effect of spectra on calibration and measurement with mammographic ionization chambers. Medical Physics, v.29, p. 2649-2654. 
DIAS e CALDAS (2001). DIAS, S.K.; CALDAS, L.V.E. Extrapolation chamber response in low-energy X radiation standard beams, Journal of Applied Physics, v. 89, n. 1, pp. 669-671.

DIN (1997). DEUTSCHES INSTITUT FÜR NORMUNG, Dosimessverfahren nach der Sondenmethode für Photonen und Elektronenstrahlung, Teil 2: Ionisationsdosimetrie, Deutsche Norm DIN 6800 - 2, Deutsches Institut fur Normung, Berlin.

EHRLICH e LAMPERTI (1976). EHRLICH, M.; LAMPERTI, P. J. Electron-therapy dosimetry, Proceedings of the National Bureau of Standards Symposium (NBS), NBS SP456, Washington, March.

EISBERG e RESNICK (1983). EISBERG, R.; RESNICK, R. Física Quântica. Átomos, Moléculas, Sólidos, Núcleos e Partículas, Rio de Janeiro, Editora Campus Ltda.

GERBI e KHAN (1987). GERBI, B. I.; KHAN, F. M. The polarity effect for commercially available plane-parallel ionization chambers. Medical Physics, v. 14, p. $210-215$.

HAVERCROFT e KLEVENHAGEN (1993). HAVERCROFT, J. M.; KLEVENHAGEN, S.C. Ion recombination corrections for plane-parallel and thimble chambers in electron and photon radioation, Physics in Medicine and Biology, v. 38, pp. 25-38.

HAVERCROFT, J. M. e KLEVENHAGEN (1994). HAVERCROFT, J. M.; KLEVENHAGEN, S. C. Polarity effect of plane-paralIeI ionization chambers in electron radiation. Physics in Medicine and Biology, v. 39, p. 299-304.

HOHLFELD (1998). HOHLFELD, K. The standard DIN 6800: procedures for absorbed dose determination in radiology by the ionization method, Dosimetry in radioterapy. Proceedings of a Symposium, Vienna 1987, v. 1, pp. 1-22, IAEA, Vienna. 
IAEA (1979). INTERNATIONAL ATOMIC ENERGY AGENCY. Calibration of dose meters used in radiotherapy. IAEA, Vienna, (IAEA-TRS-185).

IAEA (1987). INTERNATIONAL ATOMIC ENERGY AGENCY. Absorbed dose determination in photon and electron beams: an international code of practice. IAEA, Vienna, (IAEA-TRS-277).

IAEA (1995). INTERNATIONAL ATOMIC ENERGY AGENCY. The use of planeparallel ionization chambers in high energy electron and photon beams: An international code of practice for dosimetry. IAEA, Vienna, (IAEA TRS-381).

IAEA (2000). INTERNATIONAL ATOMIC ENERGY AGENCY. Calibration of radiation protection monitoring instruments. IAEA, Vienna, (IAEA SRS-16).

IAEA (2005). INTERNATIONAL ATOMIC ENERGY AGENCY. Radiation oncology physics: A handbook for teachers and students. IAEA, Vienna.

IAEA (2006). INTERNATIONAL ATOMIC ENERGY AGENCY. Absorbed dose determination in external beam radiotherapy: An international code of practice for dosimetry based on standards of absorbed dose to water. IAEA, Vienna, 2006, v.12 (IAEA-TRS-398).

IAEA (2009). INTERNATIONAL ATOMIC ENERGY AGENCY. Calibration of reference dosimeters for external beam radiotherapy. IAEA, Vienna, (IAEA-TRS-469).

ICRU (1976). INTERNATIONAL COMMISSION ON RADIATION UNITS AND MEASUREMENTS. Determination of absorbed dose in a patient irradiated by beams of X or gamma rays in radiotherapy procedures. Maryland, (ICRU 24).

ICRU (1984). INTERNATIONAL COMMISSION ON RADIATION UNITS AND MEASUREMENTS. Radiation dosimetry: electron beams with energies between 1 and $50 \mathrm{MeV}$, Maryland, (ICRU 35). 
ICRU (1998). INTERNATIONAL COMMISSION ON RADIATION UNITS AND MEASUREMENTS. Fundamental quantities and units for ionization radiation. Maryland, (ICRU 60).

IEC (2011). INTERNATIONAL ELECTROTECHNICAL COMMISSION, Medical electrical equipment-dosemeters with ionization chambre as used in radiotherapy, Geneve (IEC 60731).

INCA (2014a). INSTITUTO NACIONAL DE CÂNCER. Radioterapia. Disponível em: http://www.inca.gov.br/conteudo_view.asp?ID=100. Acesso em 14 de setembro de 2014.

INCA (2014b). INSTITUTO NACIONAL DE CÂNCER. Ministério da Saúde conclui encomenda de 80 aceleradores lineares. Disponível em: http://www2.inca.gov.br/wps/wcm/connect/agencianoticias/site/home/noticias/2013/sau de_conclui_encomenda_de_oitenta_aceleradores_lineares. Acesso em 21 de junho de 2014.

IPEM (2003). INSTITUTE OF PHYSICS AND ENGINEERING IN MEDICINE, The IPEM code of practice for electron dosimetry for radiotherapy beams of initial energy from 4 to $25 \mathrm{MeV}$ based on an absorbed dose to water calibration, Physics in Medicine and Biology, v. 48, pp. 2929-2970.

IPSM (1990). INSTITUTE OF PHYSICAL SCIENCES IN MEDICINE, Code of practice for high-energy photon therapy dosimetry based in the npl absorbed dose calibration service, Physics in Medicine and Biology, v. 35, pp.1355-1360.

JOHNS e CUNNINGHAM (1983). JOHNS, H. E.; CUNNINGHAM, J. R. The Physics of Radiology. 4th. ed. Springfield: Charles C. Thomas Publisher.

KNOLL (1989). KNOLL, G. F. Radiation Detection and Measurement. 2 ed. New York: Wiley. 
MAIA e CALDAS (2006). MAIA, A.F.; CALDAS, L.V.E. Evaluation of the operational characteristics of a CT ionization chamber, Radiation Measurements, v. 41 , pp. 65-71.

MATTSSON et al (1981). MATTSSON, L. O.; JOHANSSON, K. A.; SVENSSON, H. Calibration and use of plane-parallel ionization chambers for the determination of absorbed dose in electron beams, Acta Radiologica Oncology, v. 20, pp. 385-399.

McNIVEN et al (2006). McNIVEN, A. L.; MULLIGAN, M.; KRON, T.; BATISTA, J. $\mathrm{J}$. The response of prototype plane-parallel ionization chambers in small megavoltage x-ray fields, Medical Physics, v. 33, pp. 3997-4004.

MEGER et al (1987). MEGER, C. M.; DeLUCA.Jr, P. M.; PEARSON, D. W.; ATTIX, F. H.; VENCI, R. The effects of air humidity on ionization chamber response, Radiation Protection Dosimetry, v. 20, pp. 175-179.

MUIR e ROGERS (2011). MUIR, B. R.; ROGERS, D. W. The central electrode correction factor for high-Z electrodes in small ionization chambers, Medical Physics, v. 38, p. 1081-1088.

NEVES et al (2012). NEVES, L. P.; PERINI, A. P.; XAVIER, M.; KHOURY, H. J.; CALDAS, L. V. E. Pre-evaluation of an ionization chamber for clinical radiotherapy dosimetry. Radioprotecção, v. 2, p. 133-138.

OLIVEIRA e CALDAS (2006). OLIVEIRA, M.L.; CALDAS, L.V.E. A new mini extrapolation chamber for beta source uniformity measurements. Proceedings of the Second European International Radiation Protection Association (IRPA) Congress, Paris.

OKUNO e YOSHIMURA (2010). OKUNO, E; YOSHIMURA, E, M. Física das Radiações. São Paulo, Editora Oficina dos Textos. 
PEARCE et al (2006). PEARCE, J.; THOMAS, R.; DUSAUTOY, A. The characterization of the advanced Markus ionization chamber for use in reference electron dosimetry in the UK, Physics in Medicine and Biology, v. 51, pp. 473-483.

PERINI (2013). PERINI, A. P.; NEVES, L. P.; FERNANDEZ-VAREA, J. M.; BUERMANN, L.; CALDAS, L. V. E. Evaluation and simulation of a new ionization chamber design for use in computed tomography beams. IEEE Transactions on Nuclear Science, v. 60, p. 768-773.

POLACZEK-GRELIK e KARACZYN (2011). POLACZEK-GRELIK, K.; KARACZYN, B. Activation of linear medica accelerators - an overview. International Conference on Development and Applications of Nuclear Technologies (NUTECH, 2011), pp. 1, Cracóvia, Polônia, 11 a 14 de setembro.

RODRIGUES et al (2006). RODRIGUES, L. N.; CRUZ, J. C.; CECÍLIO, P. J.; CAPRIOGLIO, L. Implementação do Protocolo TRS-398 para feixes de elétrons no Hospital Israelita Albert Einstein, Radiologia Brasileira, v. 39, pp.45-49.

ROGERS (1992). ROGERS, D. W. O.. The advantages of absorbed-dose calibration factors, Medical Physics, v. 19, pp. 1227-1239.

ROGERS (2002). ROGERS, D. W. O., Monte Carlo techniques in radiotherapy, Physics in Canada, v. 58, pp. 63-70.

SILVA e CALDAS (2012). SILVA, J. O.; CALDAS, L. V. E. Establishment of a tandem ionization chamber system in standard mammography beams. Radioprotecção, S. João da Talha, v. 2, p. 125-132.

SIQUEIRA (2006). SIQUEIRA, P. M. Implantação do novo protocolo de dosimetria da IAEA no LCI/IPEN/CNEN. São Paulo. Dissertação (Mestrado em Tecnologia Nuclear) - Instituto de Pesquisas Energéticas e Nucleares, Universidade de São Paulo. 
SNOW et al (2013). SNOW, J. R.; MICKA, J. A.; DEWERD, L. A. Microionization chamber air-kerma calibration coefficients as a function of photon energy for $\mathrm{x}$-ray spectra in the range of $20-250 \mathrm{kVp}$ relative to 60Co, Medical Physics, v. 40, p. 041711-1 - 041711-5.

SOUZA et al (1996). SOUZA, C.N.; CALDAS, L.V.E.; SIBATA, C.H.; HO, A.K.; SHIN, K.H. Two new parallel-plate ionization chambers for electron beam dosimetry. Radiation Measurements, v. 26, n. 1, pp. 65-74.

SPENCER e ATTIX (1995). SPENCER, L. V.; ATTIX, F. H. A theory of cavity ionization. Radiation and Research, v. 3, p. 239-358.

SVENSSON e BRAHME (2004). SVENSSON, H.; BRAHME, A. Recent Advances in Electron and Photon Dosimetry, New York, ORTON C. G.

TURNER (2007). TURNER, J. E. Atoms, Radiation, and Radiation Protection, 3rd ed. Weinheim: WILEY-VCH Verlag GmbH \& Co.

VIVOLO (2006). VIVOLO, V. Desenvolvimento de um sistema de referência para determinação do equivalente de dose pessoal e da constância de feixes de radiação $\mathbf{X}$, São Paulo. Tese (Doutorado em Tecnologia Nuclear) - Instituto de Pesquisas Energéticas e Nucleares, Universidade de São Paulo.

WAGNER et al (2013). WAGNER, A.; CROP, F.; LACORNERIE, T.; VANDEVELDE, F.; REYNAERT, N. Use of a liquid ionization chamber for stereotactic radiotherapy dosimetry, Physics in Medicine and Biology, v. 8, p. 2445-2459.

YI et al (2006). YI, C.Y.; HAH, S.H.; YEOM, M. S. Monte Carlo calculation of the ionization chamber response to ${ }^{60} \mathrm{Co}$ beam using PENELOPE, Medical Physics, v.33, pp. 1213-1221. 
YOSHIZUMI e CALDAS (2010). YOSHIZUMI, M.T.; CALDAS, L.V.E. A new ringshaped graphite monitor ionization chamber, Nuclear Instruments and Methods in Physics Research, A 619, 207-210.

YOSHIZUMI et al (2010). YOSHIZUMI, M. T.; YORIYAZ, H.; CALDAS, L. V. E. Backscattered radiation into a transmission ionization chamber: measurement and Monte Carlo simulation, Applied Radiation and Isotopes, v. 68, n. 1, pp. 586-588.

\section{Anexo A}

Trabalhos publicados no período do desenvolvimento da tese

\section{Artigos completos publicados em periódicos}

1. SILVA, J.O; NONATO, F. B. C; CALDAS, L.V.E. Characterization tests of a homemade ionization chamber in mammography standard radiation beams. Radiation Physics and Chemistry, v. 95, p.151-153, 2013.

2. NONATO, F. B. C; CESCON, C. T; CALDAS, L. V. E. Calibrating pen dosimeters with and without a phantom. Radioproteção, v. 2, p. 173-178, 2012.

3. NONATO, F. B. C; SAKURABA, R K ; CRUZ, J C ; CALDAS, L. V. E. Characterization testes of a new parallel plate ionization chamber for use in electron beams. Radiation Physics and Chemistry, v. 104, p. 244-247, 2014.

\section{Trabalho completo submetido a publicação em periódico}

Radiation Physics and Chemistry:

1. NONATO, F. B. C; SAKURABA, R. K; CRUZ, J. C; CHIARA, A.C.M; VERNUCIO, S. L; MENEGUSSI, G; CALDAS, L. V. E. Development and characterization tests of a PMMA ionization chamber with silver collecting electrode for use in electron beams. Apresentado no 9th International Topical Meeting on 
Industrial Radiation and Radioisotope Measurement Applications (IRRMA-9), 2014, Valência.

\section{Trabalhos completos publicados em anais de congressos}

1. NONATO, F. B. C; SILVA, J.O; VIVOLO, V; CALDAS, L.V.E. Comparison of the energy dependence of two homemade ionization chambers in relation to a standard ionization chamber in low-energy kilovoltage X-ray beams, therapy level. Proceedings of the International Conference on Radiation Protection in Medicine - Setting the Scene for the Next Decade, 2012, p. 1-4, Bonn.

2. NONATO, F. B. C; VIVOLO, V; CALDAS, L.V.E. Energy and angular dependence of radiation monitors in standard $\mathrm{X}$ radiation beams. Proceedings of the Third European IRPA Congress 2010, p. 905, Helsinki.

5. NONATO, F. B. C; VIVOLO, V; CALDAS, L.V.E. Estudo da dependência angular de detectores portáteis em campos de radiação beta e gama. Anais do XV Congresso Brasileiro de Física Médica, 2010, p. 1-4, Aracajú.

\section{Trabalhos publicados em livros de resumos de congressos}

1. NONATO, F. B. C; CINTRA, F. B; CALDAS, L. V. E. Electric field simulation of an ionization chamber of parallel plates and graphite collecting electrode. Book of Abstracts. Symposium on Radiation Measurements and Applications (SORMA XV), 2014, Michigan.

2. NONATO, F. B. C; SAKURABA, R. K; CRUZ, J. C; CHIARA, A.C.M; VERNUCIO, S. L; MENEGUSSI, G; CALDAS, L. V. E. Development and characterization tests of a PMMA ionization chamber with silver collecting electrode for use in electron beams. Book of Abstracts. 9th International Topical Meeting on Industrial Radiation and Radioisotope Measurement Applications (IRRMA-9), 2014, Valencia. 
3. NONATO, F. B. C; SILVA, J.O; VIVOLO, V; CALDAS, L.V.E. Comparison of four parallel plate ionization chambers in standard X-ray beams, therapy level. Book of Abstracts. SORMA West 2012 - IEEE Symposium on Radiation Measurements and Applications, 2012, Oakland.

4. SILVA, J.O; NONATO, F. B. C; CALDAS, L.V.E. Characterization tests of a homemade ionization chamber in mammography standard radiation beams. Book of Abstracts. ISRP 12 - 12th International Symposium on Radiation Physics, 2012, Rio de Janeiro.

6. NONATO, F. B. C; CESCON, C. T; CALDAS, L.V.E. Energy dependence study of pen dosimeters. Book of Abstracts. 18th International Conference on Medical Physics (ICMP 2011) and XVI Brazilian Congress of Medical Physics (XVI CBFM), 2011, Porto Alegre.

7. NONATO, F. B. C; VIVOLO, V; CALDAS, L.V.E. Comparing calibration factors for gamma and beta radiation of portable detectors. Book of Abstracts. International Symposium on Standards, Applications and Quality Assurance in Medical Radiation Dosimetry (IDOS), 2010, Vienna. 